\title{
Projecting Climate Effects on Birds and Reptiles of the Southwestern United States
}

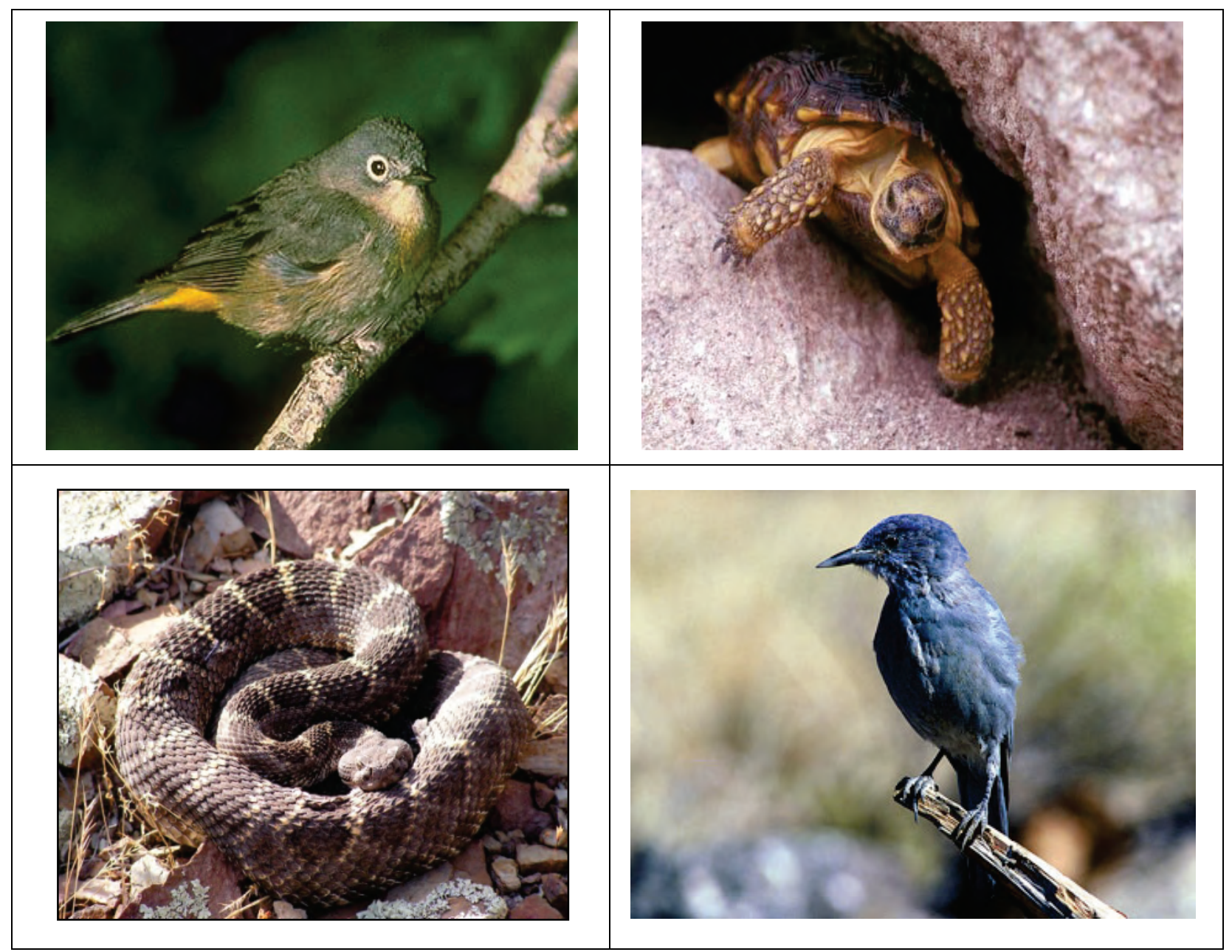

Open-File Report 2014-1050

U.S. Department of the Interior

U.S. Geological Survey 
Cover photo description clockwise from upper left: Virginia's Warbler (Vermivora virginiae) photo credit to P. Dotson/Utah Division of Wildlife Resources; Desert Tortoise (Sonoran

Population) (Gopherus agassizii) photo credit to Cecil Schwalbe/U.S. Geological Survey and University of Arizona; Pinyon Jay (Gymnorhinus cyanocephalus) photo credit to Dave Menke/U.S. Fish and Wildlife Service; and Arizona Black Rattlesnake (Crotalus cerberus) photo credit to Erika Nowak/U.S. Geological Survey and Northern Arizona University. 


\section{Projecting Climate Effects on Birds and Reptiles of the Southwestern United States}

By Charles van Riper III, James R. Hatten, J. Tom Giermakowski, David Mattson, Jennifer A. Holmes, Matthew J. Johnson, Erika M. Nowak, Kirsten Ironside, Michael Peters, Paul Heinrich, K. L. Cole, C. Truettner, and Cecil R. Schwalbe

Open-File Report 2014-1050

U.S. Department of the Interior

U.S. Geological Survey 


\section{U.S. Department of the Interior \\ SALLY JEWELL, Secretary}

\section{U.S. Geological Survey \\ Suzette M. Kimball, Acting Director}

U.S. Geological Survey, Reston, Virginia: 2014

For more information on the USGS—-the Federal source for science about the Earth,

its natural and living resources, natural hazards, and the environment-visit

http://www. usgs.gov or call 1-888-ASK-USGS

For an overview of USGS information products, including maps, imagery, and publications, visit http://www.usgs.gov/pubprod

To order this and other USGS information products, visit http://store.usgs.gov

Suggested citation:

van Riper, C., III., Hatten, J.R., Giermakowski, J.T., Matts on, D., Holmes, J.A., Johnson, M.J., Nowak, E.M., Ironside, K., Peters, M., Heinrich, P., Cole, K.L., Truettner, C., and Schwalbe, C.R., 2014, Projecting climate effects on birds and reptiles of the Southwestern United States: U.S. Geological Survey Open-File Report 2014-1050, 100 p., http://dx.doi.org/10.3133/ofr20141050.

ISSN 2331-1258 (online)

Any use of trade, firm, or product names is for descriptive purposes only and does not imply endorsement by the U.S. Government.

Although this information product, for the most part, is in the public domain, it also may contain copyrighted materials as noted in the text. Permission to reproduce copyrighted items must be secured from the copyright owner. 


\section{Contents}

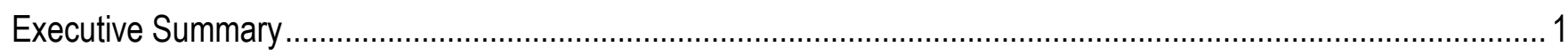

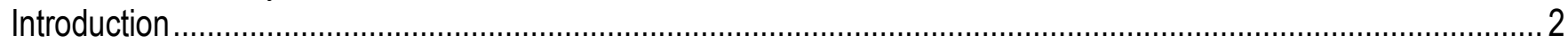

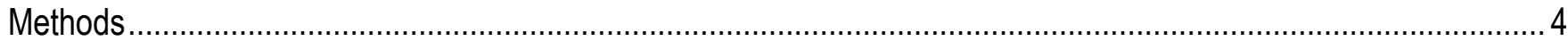

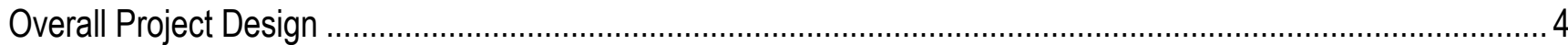

Selection of Bird and Reptile Species for Modeling...................................................................................

Registration of Location Data and Model Sample Sizes …………………………………….................

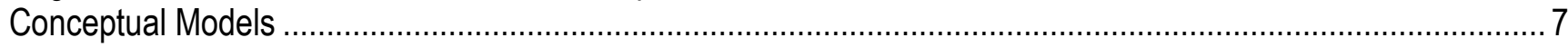

Modeling Species Distributions ......................................................................................................

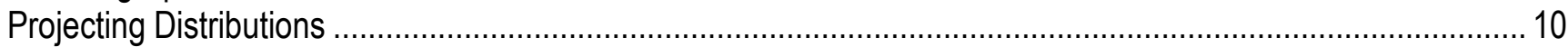

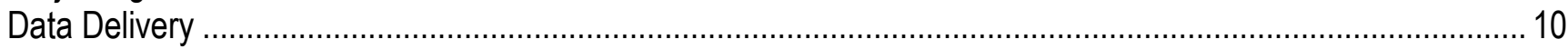

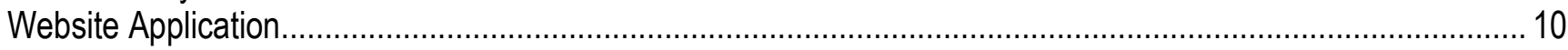



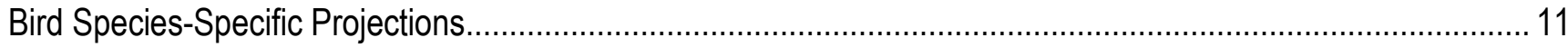

Reptile Species-Specific Projection.................................................................................................... 12

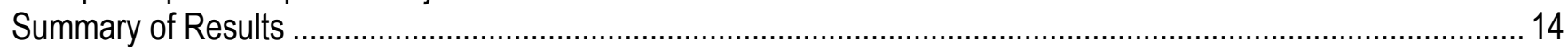

Overall General Patterns of Climate Change Influences on Birds and Reptiles ................................................. 16

Insert 1: Detailed Project Justification and Methods .................................................................................. 18

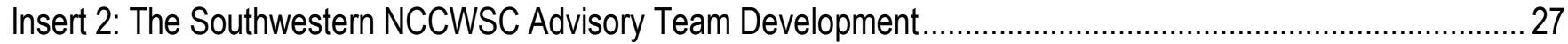

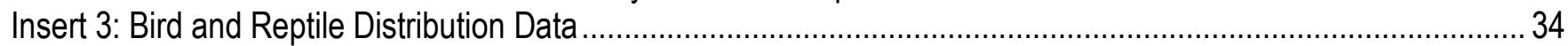

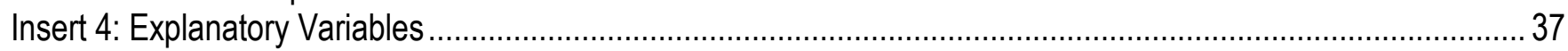

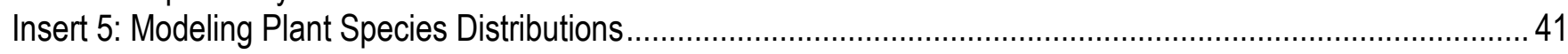

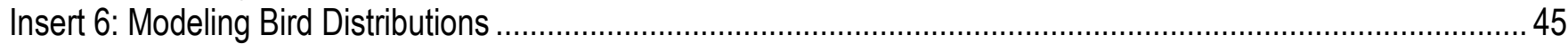

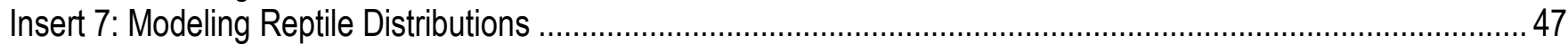

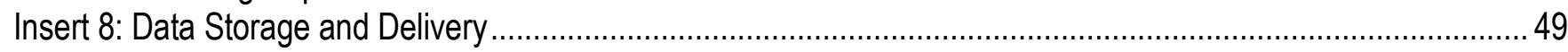

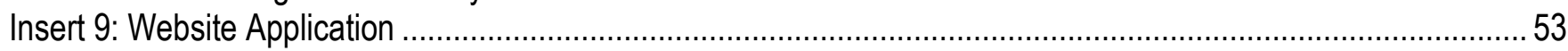

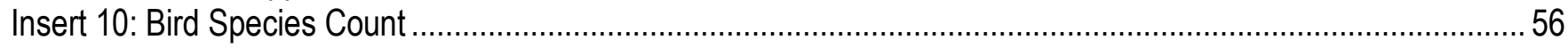

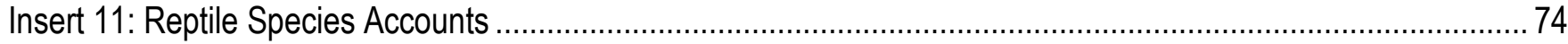

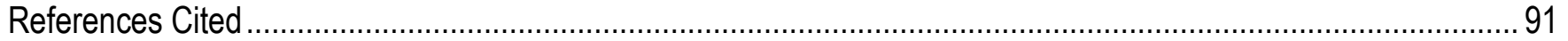




\section{Figures - Main text}

Figure 1. Conceptual model of the overall project design, including project elements and the linkage and sequencing logic that was employed.

Figure 2. Conceptual model of factors that might possibly affect sage thrasher range and population dynamics with changing environments, including explanatory variables used to model current range.

Figure 3. Graph showing percent change in projected breeding distribution of birds by 2099 in relation to total percent relative influence of static variables (TRI, insolation, soil sandiness) for a species-specific model.

Figure 4. Graph showing relation between percent projected distribution gain or loss and the median temperature of a species current distribution.

\section{Figures - Inserts}

Figure 3.1. Graph showing summary of occurrence data compiled for reptiles, expressed as unique grid cells that match the environmental data used for modeling distribution.

Figure 5.1. Conceptual model of the process used to create future plant species projections, including effects of migration rates, for plants used in modeling animal species ranges.

Figure 5.2. Model-generated example showing projected changes in a plant species distribution incorporating the effects of migration for the three periods 2010-39, 2040-69, and 2070-99.

Figure 8.1. Screen capture showing the home page of the Southwest Plant Atlas (Southwest Plant Atlas, http://www4.nau.edu/swplantatlas/endemic.htm/).

Figure 8.2. Screen capture of Southwest Plant Atlas species website page for pinyon pine (Pinus edulis) showing the layout of the model output and explanatory variable selection.

Figure 8.3. Screen capture showing species website pages of the Southwest Animal Atlas for pinyon jay (Gymnorhinus cyanocephalus) and Arizona black rattlesnake (Crotalus Cerberus) including the species description and conceptual model diagrams.

Figure 9.1. Consecutive screen captures of project website showing distribution data for

Pinus ponderosa in the western United States (darker blue-green indicates greater likelihood)

Figure 10.1. Amphispiza bilineata.

Figure 10.2. Conceptual model of factors affecting black-throated sparrow range and population dynamics, including explanatory variables used to model current range .

Figure 10.3. Predicted black-throated sparrow range in 2099, showing levels of agreement among predictions based on 5 different statistically downscaled GCMs plus a 6th representing an ensemble of 22 GCMs

Figure 10.4. Areas where $\geq 5 \mathrm{GCM}$ projections predict there will be black-throated sparrow range in 2099 compared to range in 2000, showing areas of range loss, range gain, and range persistence between 2000 and 2099

Figure 10.5. Relative influence of variables retained in the best model of current range, as measured by the chi-squared statistic ....................................................................................................... 58

Figure 10.6. Measures of range change among four decadal intervals for the period 2000 through $2099 \ldots . . .58$

Figure 10.7. Vireo vicinior....

Figure 10.8. Conceptual model of factors affecting gray vireo range and population dynamics, including explanatory variables used to model current range

Figure 10.9. Predicted gray vireo range in 2099, showing levels of agreement among predictions based on 5 different statistically downscaled GCMs plus a 6th representing an ensemble of $22 \mathrm{GCMs}$ 
Figure 10.10. Areas where $\geq 5 \mathrm{GCM}$ projections predict there will be gray vireo range in 2099 compared to range in 2000, showing areas of range loss, range gain, and range persistence between 2000 and $2099 \ldots . . .60$ Figure 10.11. Relative influence of variables retained in the best model of current range, as measured by the chi-squared statistic.

Figure 10.12. Measures of range change among four decadal intervals for the period 2000 through $2099 \ldots .61$

Figure 10.13. Vermivora virginiae

Figure 10.14. Conceptual model of factors affecting Virginia's warbler range and population dynamics, including explanatory variables used to model current range

Figure 10.15. Predicted Virginia's warbler range in 2099, showing levels of agreement among predictions based on 5 different statistically downscaled GCMs plus a 6th representing an ensemble of $22 \mathrm{GCMs}$ 63

Figure 10.16. Areas where $\geq 5 \mathrm{GCM}$ projections predict there will be Virginia's warbler range in 2099 compared to range in 2000, showing areas of range loss, range gain, and range persistence between 2000 and 2099 ......

Figure 10.17. Relative influence of variables retained in the best model of current range, as measured by the chi-squared statistic.

Figure 10.18. Measures of range change among four decadal intervals for the period 2010 through $2099 \ldots .64$

Figure 10.19. Oreoscoptes montanus.

Figure 10.20. Conceptual model of factors affecting Virginia's warbler range and population dynamics, including explanatory variables used to model current range

Figure 10.21. Predicted sage thrasher range in 2099, showing levels of agreement among predictions based on 5 different statistically downscaled GCMs plus a 6th representing an ensemble of 22 GCMs. 66

Figure 10.22. Areas where $\geq 5 \mathrm{GCM}$ projections predict there will be sage thrasher range in 2099 compared to range in 2000, showing areas of range loss, range gain, and range persistence between 2000 and $2099 . .66$ Figure 10.23. Relative influence of variables retained in the best model of current range, as measured by the chi-squared statistic.

Figure 10.24. Measures of range change among four decadal intervals for the period 2000 through $2099 \ldots .67$

Figure 10.25. Gymnorhinus cynanocephalus.

Figure 10.26. Conceptual model of factors affecting pinyon jay range and population dynamics, including explanatory variables used to model current pinyon jay range

Figure 10.27. Predicted pinyon jay range in 2099, showing levels of agreement among predictions based on 5 different statistically downscaled GCMs plus a 6th representing an ensemble of $22 \mathrm{GCMs}$

Figure 10.28. Areas where $\geq 5 \mathrm{GCM}$ projections predict there will be pinyon jay range in 2099 compared to range in 2000, showing areas of range loss, range gain, and range persistence between 2000 and 2099

Figure 10.29. Areas where $\geq 5 \mathrm{GCM}$ projections predict there will be pinyon jay range in 2099 , showing differences in modeled probabilities of range between 2000 and 2099

Figure 10.30. Relative influence of variables retained in the best model of current range, as measured by the chi-squared statistic.

Figure 10.31. Measures of range change among four decadal intervals for the period 2000 through $2099 \ldots .70$

Figure 10.32. Sitta pygmaea ..................................................................................................

Figure 10.33. Conceptual model of factors affecting pygmy nuthatch range and population dynamics, including explanatory variables used to model current range

Figure 10.34. Predicted pygmy nuthatch range in 2099, showing levels of agreement among predictions based on 5 different statistically downscaled GCMs plus a 6th representing an ensemble of $22 \mathrm{GCMs}$

Figure 10.35. Areas where $\geq 5 \mathrm{GCM}$ projections predict there will be pygmy nuthatch range in 2099 compared to range in 2000, showing areas of range loss, range gain, and range persistence between 2000 and 2099

Figure 10.36. Relative influence of variables retained in the best model of current range, as measured by the chi-squared statistic 
Figure 10.37. Measures of range change among four decadal intervals for the period 2000 through $2099 . . .73$

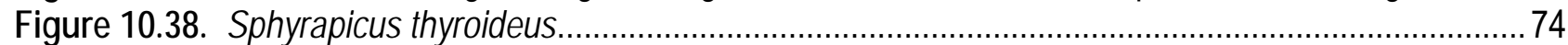

Figure 10.39. Conceptual model of factors affecting Williamson's sapsucker range and population dynamics, including explanatory variables used to model current range

Figure 10.40. Predicted Williamson's sapsucker range in 2099, showing levels of agreement among predictions based on 5 different statistically downscaled GCMs plus a 6 th representing an ensemble of 22 GCMs

Figure 10.41. Areas where $\geq 5 \mathrm{GCM}$ projections predict there will be Williamson's sapsucker range in 2099 compared to range in 2000, showing areas of range loss, range gain, and range persistence between 2000 and 2099.

Figure 10.42. Relative influence of variables retained in the best model of current range, as measured by the chi-squared statistic

Figure 10.43. Measures of range change among four decadal intervals for the period 2000 through $2099 \ldots . . .76$

Figure 11.1. Aspidoscelis velox, Arizona.

Figure 11.2. Conceptual model of factors affecting suitable habitat for plateau striped whiptail and population dynamics, including explanatory variables used to model current suitable habitat for plateau striped whiptail

Figure 11.3a. Illustration of Western United States showing projected range in 2099, showing levels of agreement among predictions based on 5 different statistically downscaled global circulation models (GCM) plus a 6th representing an ensemble of $22 \mathrm{GCMs}$

Figure 11.3b. Illustration of Western United States showing modeled areas (including vegetation variables) where projections of greater than or equal to five global circulation models project there will be suitable habitat in 2099, showing areas of habitat loss, habitat gain, and habitat persistence between 2010 and 2099

Figure 11.3c. Illustration of Western United States showing modeled areas (excluding vegetation variables) where projections of greater than or equal to five global circulation models project there will be suitable habitat in 2099, showing areas of habitat loss, habitat gain, and habitat persistence between 2010 and 2099

Figure 11.4. Graph showing percent contribution of variables retained in the best model of current range ....79 Figure 11.5. Measures of projected change in range at end of three different decades as a percent of

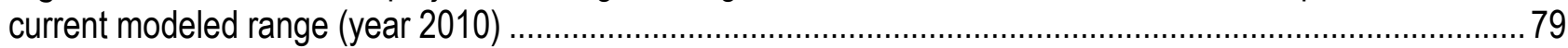

Figure 11.6. Crotalus Cerberus

Figure 11.7. Conceptual model of factors affecting suitable habitat for Arizona black rattlesnake and population dynamics, including explanatory variables used to model current suitable habitat for Arizona black rattlesnake.

Figure 11.8a. Illustration of Western United States showing predicted range in 2099, showing levels of agreement among predictions based on 5 different statistically downscaled global circulation models (GCM) plus a 6th representing an ensemble of 22 GCMs

Figure 11.8b. Illustration of Western United States showing modeled areas (including vegetation variables) where projections of greater than or equal to five global circulation models predict there will be suitable habitat in 2099, showing areas of habitat loss, habitat gain, and habitat persistence between 2010 and 2099.

Figure 11.8c. Illustration of Western United States showing modeled areas (excluding vegetation variables) where projections of greater than or equal to five global circulation models predict there will be suitable habitat in 2099, showing areas of habitat loss, habitat gain, and habitat persistence between 2010 and 2099

Figure 11.9. Graph showing percent contribution of variables retained in the best model of current range .... 82 Figure 11.10. Measures of projected change in range at end of three different decades as a percent of current modeled range (year 2010) 
Figure 11.11. Gopherus agassizii

Figure 11.12. Conceptual model of factors affecting suitable habitat for Sonoran desert (Morafka's) tortoise, and population dynamics, including explanatory variables used to model current suitable habitat for Sonoran desert tortoise

Figure 11.13a. Illustration of Western United States showing predicted range in 2099, showing levels of agreement among predictions based on 5 different statistically downscaled global circulation models (GCM) plus a 6th representing an ensemble of $22 \mathrm{GCMs}$

Figure 11.13b. Illustration of Western United States showing modeled areas (including vegetation variables) where projections of greater than or equal to five global circulation models predict there will be suitable habitat in 2099, showing areas of habitat loss, habitat gain, and habitat persistence between 2010 and 2099

Figure 11.13c . Illustration of Western United States showing modeled areas (excluding vegetation variables) where projections of greater than or equal to five global circulation models predict there will be suitable habitat in 2099, showing areas of habitat loss, habitat gain, and habitat persistence between 2010 and 2099.

Figure 11.14. Graph showing percent contribution of variables retained in the best model of current range .. 85

Figure 11.15. Measures of projected change in range at end of three different decades as a percent of current modeled range (year 2010)

Figure 11.16. Holbrookia maculate

Figure 11.17. Conceptual model of factors affecting suitable habitat for common lesser earless lizard and population dynamics, including explanatory variables used to model current suitable habitat for lesser earless lizard.

Figure 11.18a. Illustration of Western United States showing predicted range in 2099, showing levels of agreement among predictions based on 5 different statistically downscaled global circulation models (GCM) plus a 6th representing an ensemble of $22 \mathrm{GCMs}$

Figure 11.18b. Illustration of Western United States showing modeled areas (including vegetation variables) where projections of greater than or equal to five global circulation models predict there will be suitable habitat in 2099, showing areas of habitat loss, habitat gain, and habitat persistence between 2010 and 2099.

Figure 11.18c. Illustration of Western United States showing modeled areas (excluding vegetation variables) where projections of greater than or equal to five global circulation models predict there will be suitable habitat in 2099, showing areas of habitat loss, habitat gain, and habitat persistence between 2010 and 2099 .

Figure 11.19. Graph showing percent contribution of variables retained in the best model of current range... 88 Figure 11.20. Measures of projected change in range at end of three different decades as a percent of current modeled range (year 2010)

Figure 11.21. Sauromalus ater.

Figure 11.22. Conceptual model of factors affecting suitable habitat for common chuckwalla and population dynamics, including explanatory variables used to model current suitable habitat for common chuckwalla.... 89 Figure 11.23a. Illustration of Western United States showing predicted range in 2099, showing levels of agreement among predictions based on 5 different statistically downscaled global circulation models (GCM) plus a 6th representing an ensemble of $22 \mathrm{GCMs}$.

Figure 11.23b. Illustration of Western United States showing modeled areas (including vegetation variables) where projections of greater than or equal to five global circulation models predict there will be suitable habitat in 2099, showing areas of habitat loss, habitat gain, and habitat persistence between 2010 and 2099 
Figure 11.23c. Illustration of Western United States showing modeled areas (excluding vegetation variables) where projections of greater than or equal to five global circulation models predict there will be suitable habitat in 2099, showing areas of habitat loss, habitat gain, and habitat persistence between 2010 and 2099 ......

Figure 11.24. Graph showing percent contribution of variables retained in the best model of current range.. 91 Figure 11.25. Measures of projected change in range at end of three different decades as a percent of current modeled range (year 2010)

\section{Tables - Main text}

Table 1. Ranking criteria used to prioritize southwestern bird and reptile species for analysis, modeling, and projecting 6

Table 2. Bird and reptile species selected for analysis, modeling, and projecting .7

Table 3. Projected change in area of modeled distribution by 2099 as percent of baseline (1980-2009) suitable areas for birds, at an 83 percent GCM-distribution model agreement threshold, for models with and without the effects of plant distributions

Table 4. Projected change in area of modeled distribution by 2099, as percent of baseline (1940-2009) suitable areas for reptiles, at an 83 percent GCM-distribution model agreement threshold, for models with and without the effects of plant distributions

\section{Tables - Inserts}

Table 2.1. The selection process and final membership of the southwestern National Climate Change and Wildlife Science Center Advisory Team.

Table 2.2. Guidelines of the southwestern National Climate Change and Wildlife Science Center Advisory Team.

Table 2.3. April 1, 2010, AT meeting at the BLM National Training Center, Phoenix, Arizona.

Table 3.1. Breeding season of each bird species selected for National Climate Change and Wildlife Science Center projecting of climate impacts on southwest wildlife.

Table 5.1. Plants species for which current and future potential suitable climates were modeled 


\section{Conversion Factors}

SI to Inch/Pound

\begin{tabular}{lcl}
\hline \multicolumn{1}{c}{ Multiply } & By & \multicolumn{1}{c}{ To obtain } \\
\hline millimeter $(\mathrm{mm})$ & Length & \\
meter $(\mathrm{m})$ & 0.03937 & inch (in.) \\
meter $(\mathrm{m})$ & 3.281 & foot (ft) \\
kilometer $(\mathrm{km})$ & 1.094 & yard (yd) \\
kilometer $(\mathrm{km})$ & 0.6214 & mile (mi) \\
& 0.5400 & mile, nautical (nmi) \\
\hline square kilometer $\left(\mathrm{km}^{2}\right)$ & Area & \\
square kilometer $\left(\mathrm{km}^{2}\right)$ & 247.1 & acre \\
\hline
\end{tabular}

Temperature in degrees Celsius $\left({ }^{\circ} \mathrm{C}\right)$ may be converted to degrees Fahrenheit $\left({ }^{\circ} \mathrm{F}\right)$ as follows: ${ }^{\circ} \mathrm{F}=\left(1.8 x^{\circ} \mathrm{C}\right)+32$

Temperature in degrees Fahrenheit $\left({ }^{\circ} \mathrm{F}\right)$ may be converted to degrees Celsius $\left({ }^{\circ} \mathrm{C}\right)$ as follows:

${ }^{\circ} \mathrm{C}=\left({ }^{\circ} \mathrm{F}-32\right) / 1.8$ 


\section{Author Information:}

van Riper, Charles, III

ST Research Ecologist

U.S. Geological Survey

Southwest Biological Science Center

Sonoran Desert Research Station

School of Natural Resources and the Environment

University of Arizona

1110 E. South Campus Dr., Room 123

Tucson, AZ 85721-0033

Hatten, J.R.

Research Biogeographer

U.S. Geological Survey

Western Fisheries Research Center

Columbia River Research Laboratory

5501-A Cook-Underwood Rd.

Cook, WA 98605-9717

Giermakowski, J.T.

Sr. Collection Manager

Museum of Southwestern Biology

University of New Mexico

MSC03 2020, Dept. Biology

Albuquerque, NM 87131-0001

Mattson, D.

Research Wildlife Biologist

U.S. Geological Survey

Southwest Biological Science Center

Colorado Plateau Research Station

Northern Arizona University

P.O. Box 5614,

Flagstaff, AZ 86011

Holmes, J.A.

Senior Wildlife Biologist

U.S. Geological Survey

Southwest Biological Science Center

Colorado Plateau Research Station

Northern Arizona University

PO Box 5614

Flagstaff, AZ 86001

Johnson, M.J.

CPRS Director/Ecologist

U.S. Geological Survey

Southwest Biological Science Center

Colorado Plateau Research Station

Northern Arizona University

P.O. Box 5614

Flagstaff, AZ 86011
Nowak, E.M.

Herpetologist

U.S. Geological Survey

Southwest Biological Science Center

Colorado Plateau Research Station

Northern Arizona University

P.O. Box 5614,

Flagstaff, AZ 86011

Ironside, $\mathrm{K}$.

Merriam-Powell Center for Environmental Research

School of Earth Sciences and Environmental

Sustainability

Northern Arizona University

800 S. Beaver St., Room \#330

Flagstaff, AZ 86011

Peters, M.

Research Assistant Affiliate

Merriam-Powell Center for Environmental Research

School of Earth Sciences and Environmental

Sustainability

Northern Arizona University

800 S. Beaver St.,

Flagstaff, AZ 86011

Heinrich, P.

Network Administrator

Geospatial Research and Information Laboratory

Northern Arizona University

Flagstaff, AZ 86011

Cole, K.L.

U.S. Geological Survey

Southwest Biological Science Center

Colorado Plateau Research Station

Northern Arizona University

P.O. Box 5614,

Flagstaff, AZ 86011

Truettner, C.M.

Research Ecologist

Merriam-Powell Center for Environmental Research

School of Earth Sciences and Environmental

Sustainability

Northern Arizona University

800 S. Beaver St., Room \#330

Flagstaff, AZ 86011

Schwalbe, C.R.

Emeritus, U.S. Geological Survey

Southwest Biological Science Center

Sonoran Desert Research Station

School of Natural Resources and the Environment

University of Arizona

1110 E. South Campus Dr., Room 123

Tucson, AZ 85721-0033 


\section{Projecting Climate Effects on Birds and Reptiles of the Southwestern United States}

By Charles van Riper III, James R. Hatten, J. Tom Giermakowski, David Mattson, Jennifer A. Holmes, Matthew J. Johnson, Erika M. Nowak, Kirsten Ironside, Michael Peters, Paul Heinrich, K.L. Cole, C. Truettner, and Cecil R. Schwalbe

\section{Executive Summary}

- We modeled the current and future breeding ranges of seven bird and five reptile species in the Southwestern United States with sets of landscape, biotic (plant), and climatic global circulation model (GCM) variables.

- For modeling purposes, we used PRISM data to characterize the climate of the Western United States between 1980 and 2009 (baseline for birds) and between 1940 and 2009 (baseline for reptiles). In contrast, we used a pre-selected set of GCMs that are known to be good predictors of southwestern climate (five individual and one ensemble GCM), for the A1B emission scenario, to characterize future climatic conditions in three time periods (2010-39; 2040-69; and, 2070-99).

- Our modeling approach relied on conceptual models for each target species to inform selection of candidate explanatory variables and to interpret the ecological meaning of developed probabilistic distribution models. We employed logistic regression and maximum entropy modeling techniques to create a set of probabilistic models for each target species.

- We considered climatic, landscape, and plant variables when developing and testing our probabilistic models. Climatic variables included the maximum and minimum mean monthly and seasonal temperature and precipitation for three time periods. Landscape features included terrain ruggedness and insolation. We also considered plant species distributions as candidate explanatory variables where prior ecological knowledge implicated a strong association between a plant and animal species.

- $\quad$ Projected changes in range varied widely among species, from major losses to major gains.

- Breeding bird ranges exhibited greater expansions and contractions than did reptile species.

- We project range losses for Williamson's sapsucker and pygmy nuthatch of a magnitude that could move these two species close to extinction within the next century. Although both species currently have a relatively limited distribution, they can be locally common, and neither are presently considered candidates for prospective endangerment.

- We project range losses of over 40 percent, from its current extent of occurrence, for the plateau striped whiptail, Arizona black rattlesnake, and common lesser earless lizard. Currently, these reptile species are thought to be common or at least locally abundant throughout their ranges.

- The total contribution of plants in each distribution model was very small, but models that contained at least one plant always outperformed models with only physical variables (climatic or landscape). The magnitude of change in projected range increased further into the future, especially when a plant was in the model. 
- Among bird species, those that had the strongest association with a landscape feature during the breeding season, such as terrain ruggedness and insolation, exhibited the smallest contractions in projected breeding range in the future. In contrast, bird species that had weak associations with landscape features, but strong climatic associations, suffered the greatest breeding range contractions. Thus, landscape effects appeared to buffer some of the negative effects of climate change for some species.

- Among bird species, magnitude of change in projected breeding range was positively related to the annual average temperature of their baseline distribution, thus species with the warmest breeding ranges exhibited the greatest changes in future breeding ranges. This pattern was not evident for reptiles, but might exist if additional species were included in the model.

- Our results provide managers with a series of projected range maps that will enable scientists, concerned citizens, and wildlife managers to identify what the potential effects of climate change will be on bird and reptile distributions in the Western United States. We hope that our results can be used in proactive ways to mitigate some of the potential effects of climate change on selected species.

\section{Introduction}

Global circulation models (GCM) of future climates predict extreme change for the Southwestern United States (Solomon and others, 2007; Diffenbaugh and others, 2008). Temperatures are projected to increase $3.5-4^{\circ} \mathrm{C}$ within the next $60-90$ years while precipitation is projected to decline by 5-20 percent (Seager and others, 2007). The coalescing effect of these changes in temperature and precipitation in this already arid region will profoundly affect the distributions and viability of plant and animal populations. Region-wide ecosystem processes and system dynamics will be especially sensitive to relatively small shifts in climate in the arid and semi-arid environments (Millennium Ecosystem Assessment, 2005).

Managers of public lands and associated wildlife resources in the Southwestern United States need information about climate change consequences so they can better adapt management strategies to help conserve and sustain habitats of wildlife species. Prediction of coarse-scale changes, such as shifts in the distribution of dominant plant species, are needed to identify those habitats most vulnerable to climate change and to aid in prioritizing conservation efforts (U.S. Fish and Wildlife Service, 2010; Rowland and others, 2011). Dominant vegetation structure is a major determinant of the distribution of many animal species. Probabilistic predictions of future wildlife species distributions, directly linked to climate change, are needed to provide managers with empirical assessments of the future prospects for all species and especially those of special interest.

We report here on a project that utilized downscaled climate projections for the A1B emission scenario (a balanced emphasis on all energy sources in the next century) to project potential changes in birds and reptile ranges throughout the Southwestern United States. We used species distribution models (also referred to as ecological niche, bioclimatic, or habitat distribution models) to estimate losses and gains in projected ranges of select upland species in response to projected climate change. Following the admonitions and advice of previous researchers (for example, Luoto and Heikkinen, 2008; Thuiller and others, 2008; Virkkala and others, 2010; McMahon and others, 2011), we included the cascading effects of static landscape features and changing plant species distributions to assess the potential dynamics of habitat change, including thresholds and tipping points. 
Our study area focused on the Sonoran Desert and Colorado Plateau ecosystems within Arizona, western New Mexico, Utah, southwestern Colorado, and southeastern California, but also included the rest of the Western United States. Focal wildlife species included resident and migratory birds and reptiles, which compose the majority of vertebrate biodiversity in this region (Boykin and others, 2007). Focal species were selected based on several sources of information, including input from a Resource Managers Advisory Group as well as wildlife and conservation partners. To assure relevance and responsiveness to real world management needs, we established an advisory team to provide guidance and feedback on all aspects of the project including planning, species prioritization, data acquisition and management, and product delivery tools.

This interdisciplinary project was undertaken by a diverse team of U.S. Geological Survey (USGS) and university-based scientists. Our research built on previous efforts of USGS researchers and collaborators supported by the U.S. Department of Energy National Institute for Climate Change Research (NICCR) and the USGS/National Park Service Natural Resource Protection Program (NRPP). These earlier efforts included development of downscaled databases of the most recent GCM results from the Fourth Assessment Report (AR4) dataset (Solomon and others, 2007), and evaluation of all 22 GCMs for their ability to hindcast 20th century precipitation seasonality in the arid southwest. The best of these were statistically downscaled to a 4-km grid for the entire Western United States (Garfin and others, 2010). This foundational work was essential to the research reported herein because, although all GCMs project increases in temperatures, annually and in all seasons, they differ greatly in their estimations of future precipitation seasonality. Thus, we concentrated on a range of GCMs that were successful at depicting historical shifts among seasonal precipitation peaks that dictate the current biogeographic limits for many plant and animal species of the Southwestern United States. Based on these results we selected five of the best-fitting models for projecting plant and animal species distributions. These five models encompassed the spectrum of plausible future climates or produced results that closely matched recent 20th century climates. Additionally, we averaged the results of the 22 models to create an ensemble future scenario for projections. Recognizing that Mauer and others (2007) and Mearns and others (2009) provide easy-to-access statistically downscaled data sets, we chose to follow Garfin and others (2010); their paper provides details on how we downscaled and evaluated GCMs for this project.

We benefitted not only from our expertise in applying downscaled models of future climate change to project ongoing and future changes in plant and habitat distributions (Cole and others, 2008), but also from previous work with inventory and monitoring (I\&M) efforts in National Parks of the Southern Colorado Plateau and Sonoran Desert Networks; strong relationships with resource and wildlife management agencies and interest groups; and multi-disciplinary expertise in reptiles and birds. Our experience confirmed that successful modeling efforts are dependent upon expert input regarding the ecology of each focal species.

Our multidisciplinary project focused on meeting four objectives:

1. Identify and prioritize plant and animal species of interest to land managers in relation to prospective climate change;

2. Develop spatially explicit models to project and explain changes in distributions of selected bird and reptile species;

3. Incorporate the effects of current and projected future ecological dependencies of animal distributions on plant species distributions; and

4. Develop web-based tools for land managers that include: access to and application of downscaled climate models; identification of potential changes in ranges of target species; and prioritized species and geographic locations most vulnerable to global climate change. 
In an effort to keep this initial National Climate Change and Wildlife Science Center (NCCWSC) project summary document to a manageable size, we have opted to provide detailed conceptual and methodological information into 11 Inserts attached to the main document. In these documents, Insert 1 details project conceptual design and justifications associated with our southwestern NCCWSC project. It explains why the focus of our effort was on documenting changes in species distribution patterns, why we chose to do a few species in detail rather than examining many species at a coarse level, and how and why we chose the focal bird and reptile species. Insert 1 also details how we examined distributional data, the probabilities and thresholds of each species occurrence, what limiters and drivers were responsible for distributional patterns, and what information we decided to include and what to exclude from our modeling process. Insert 1 ends with a discussion on hypotheses associated with our conceptual models and a large section outlining uncertainties recognized within the modeling process. In Insert 2, we outline specifics about the advisory team of managers and interested stakeholders that assisted us with this global climate change project. Inserts 3 and 4 detail explanatory variables and how we utilized bird and reptile distribution data, whereas Insert 5 does the same for plants. Insert 6 provides details on how we modeled and tested bird distributional changes associated with changing climate, and Insert 7 does the same for reptiles. Insert 8 explains in detail how we managed and stored data from this project, and Insert 9 details our website development and the tools that were developed for land manager use. The final two inserts (10 and 11) provide specifics on the individual bird and reptile species accounts, giving a general background, the conceptual models that we utilized, the maps of expected distributional changes, and a summary of the importance of each variable to the final model.

\section{Methods}

\section{Overall Project Design}

Our project consisted of nine distinct elements or activities (rounded boxes in figure 1). We first selected bird and reptile species to model based on a number of criteria that attended to representativeness and our ability to model a species distribution. Second, we thoroughly reviewed the literature to synopsize our current understanding of each species ecology, as the basis for developing conceptual models of ecological relations. These models helped us to identify candidate explanatory variables. Third, we then conducted data development by assembling a Geographic Information System (GIS) that contained layers of data corresponding to our candidate explanatory and response variables for the entire extent of the Western United States. Parallel to our data-centric activities, we also developed, fourth, our ecological scenarios and, fifth, our climate scenarios. The ecological scenarios consisted of models with and without inclusions of plant species distributions as explanatory variables, considering the effects of static features as a distinct model component. Our climate scenarios consisted of carefully selected global circulation models (GCMs) that we used to project climate at three set future time intervals. Sixth, at the heart of our project, we developed statistical models to explain current species distributions; and, seventh, evaluated the performance of each model. Eighth, we projected future distributions of each of our selected species. Finally, we evaluated changes in projected animal species ranges as well as overall uncertainty in our projections. We provide detailed explanations of each of these elements in Insert 1. 


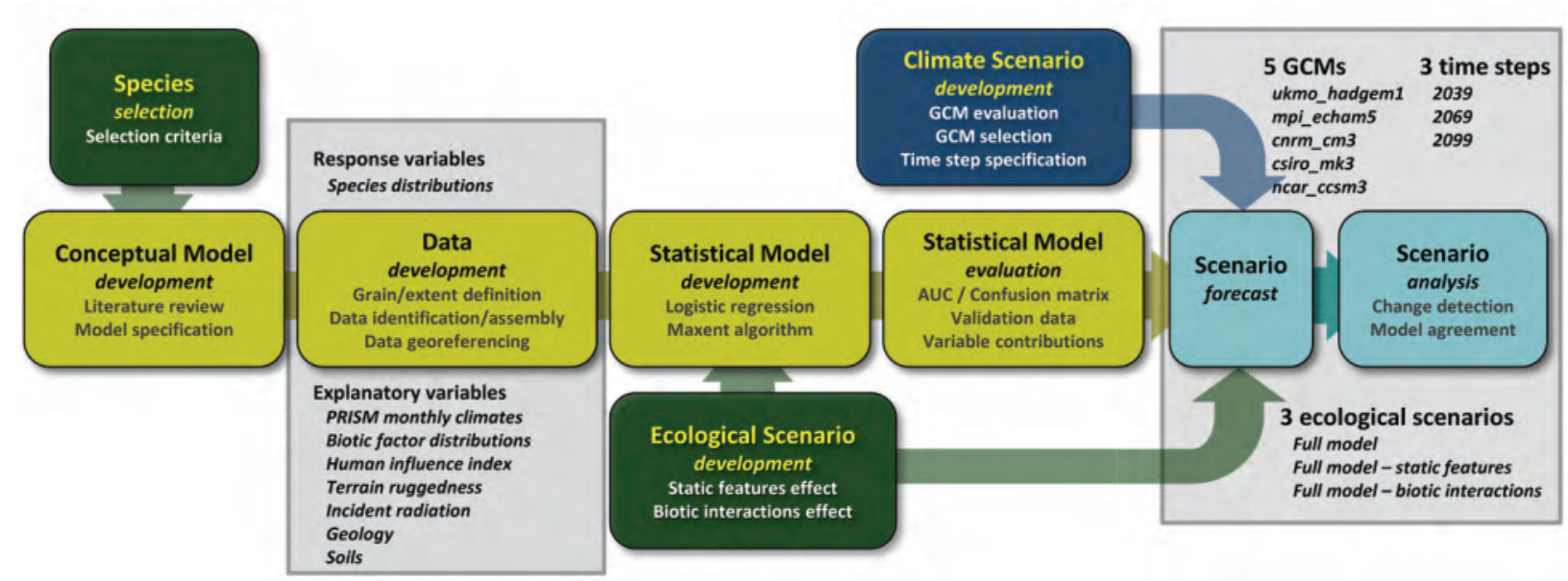

Figure 1. Conceptual model of our overall project design, including project elements and the linkage and sequencing logic that was employed.

\section{Selection of Bird and Reptile Species for Modeling}

We developed a list of candidate species for modeling based on input from our NCCWSC Advisory Team (for details on the Advisory Team and species selection, see Insert 2). The species list was based on recommendations of the managers, who were selected at a formational meeting during October 2009. We also incorporated results of a survey that was sent to southwestern land managers and conservation community members. We then reviewed these lists and removed some species and added others according to the following:

- The bulk of a species range is within the interior western U.S.

- The species are present within a substantial portion of our study area (for example, this excludes rare species with limited ranges).

- There is sufficient information available about the ecology of candidate species.

- The species has not been extirpated over a substantial portion of its range, or we have good historic range maps on the historic distribution.

- There is adequate present distribution information; the extent of distribution is represented well by available samples.

- There is access to sufficient candidate explanatory variables in spatial GIS form to warrant modeling.

- Different functional groups (for example, long- and short-lived species, predators versus herbivores) are represented for both birds and reptiles.

- Species that are currently common, but with a likelihood of being sensitive to climate change are represented. 
Table 1. Ranking criteria used to prioritize southwestern bird and reptile species for analysis, modeling, and projecting.

\begin{tabular}{|c|c|c|c|}
\hline Ranking criteria & Score $=3$ & Score $=2$ & Score $=1$ \\
\hline Data Availability ${ }^{1}$ & easily available & difficult to obtain & $\begin{array}{l}\text { very difficult/non- } \\
\text { existent }\end{array}$ \\
\hline Ancillary Data Availability ${ }^{2}$ & easily available & difficult to obtain & very difficult / complex \\
\hline $\begin{array}{l}\text { Sample Size } \\
\text { (\# presence records) }^{3}\end{array}$ & high & moderate & low \\
\hline Data Type & presence/absence & presence only & unknown \\
\hline Species Detectability & high & moderate & low \\
\hline Species Current Range & $\begin{array}{l}\text { entirely within } \\
\text { western US }\end{array}$ & $\begin{array}{l}\text { western US and } \\
\text { Mexico and/or Canada }\end{array}$ & $\begin{array}{l}\text { west, mid-west and east } \\
\text { US, or mostly Mexico }\end{array}$ \\
\hline Data Distribution $^{4}$ & across range & moderate & limited/unknown \\
\hline Association with plant species & high/strong & moderate & low \\
\hline Association with plant community & high/strong & moderate & low \\
\hline Species of Conservation Concern ${ }^{5}$ & high & moderate & low/commonly found \\
\hline $\begin{array}{l}\text { Perceived vulnerability to Climate } \\
\text { Warming }^{6}\end{array}$ & high & medium & low \\
\hline
\end{tabular}

${ }^{1}$ Scoring for Data Availability of Birds: 3=sufficient data available from-Avian Knowledge Network (AKN)/EBird; $2=$ significant proportion of records in sources other than AKN/EBird (for example, endangered species), $1=$ insufficient data in AKN/EBird and no known additional data sources. For reptiles, we relied on our knowledge of databases.

${ }^{2}$ Ancillary Data includes all data other than reptile or bird presence/absence data; that is, data for other variables (plant species distribution data, soil texture data); to be included in the modeling, as identified in the conceptual models.

${ }^{3}$ Scoring for Sample Size (number of presence records): $1=$ less than 1,000 presence records, 2=1,000-5,000 presence records, 3=greater than 5,000 records from EBird. For reptiles, we estimated the expected relative sample sizes.

${ }^{4}$ Data Distribution refers to the availability of presence data in relation to the species range and whether there are data from across the entire range, or from only a limited portion of the range.

${ }^{5}$ The following scoring applied to bird Species of Conservation Concern: If a species was listed as of continental concern, a regional stewardship species, of regional concern, or as a continental stewardship species for any western Bird Conservation Region by Partners in Flight (PIF) score = 1. If the species is listed on the 2007 Audubon WatchList, the species WatchList score $=1$. If a species is on the U.S. Fish and Wildlife Service (USFWS) Birds of Conservation Concern List (2008), its USFWS score $=1$. If a species is a Candidate for listing, listed as Threatened, or listed as Endangered under the Federal Endangered Species Act (ESA) list, its ESA score $=1$. Then we added

PIF+WatchList+USFW+ESA and values of 3 or 4 were scored as Species of Conservation Concern = 3, 2 = 2, and 1=1. A similar process was used for reptiles, based on a compilation developed by Southwest Partners in Amphibian and Reptile Conservation. While the list compilation is not comprehensive, it serves as an objective, relative measure indicating species of concern for regional federal and state agencies. We counted the number of times a species was listed as a conservation priority by U.S. Forest Service and Bureau of Land Management regions, the Navajo Nation, and the USFWS (for example, ESA). A high score of 3 indicated 14-7 occurrences of the species on federal lists; a moderate score of 2 indicated 6-1 list occurrences, and a score of 1indicated the species was not on any list.

${ }^{6}$ Perceived Vulnerability to Climate Warming for birds was taken from the State of the Birds Report 2010 which lists Climate Change Vulnerability Scores as high, medium, or low. No similar document exists for reptiles, so Nowak, Schwalbe, and Giermakowski used their expert opinion. 
We then ranked the species by, first, assigning a score of 1 to 3 to each criterion for each species (table 1). Then, individual criteria scores were summed to give an overall score for each species. Then the species overall scores were used to produce ranked lists for birds and reptiles, with the species with the highest score having the highest rank. We used the ranked lists to select six upland reptile and seven bird species (table 2) that we felt represented a broad range of natural and life histories.

Table 2. Bird and reptile species selected for analysis, modeling, and projecting.

\begin{tabular}{ll}
\hline \multicolumn{1}{c}{ Bird species } & \multicolumn{1}{c}{ Reptile species } \\
\hline Black-throated sparrow & Striped plateau whiptail \\
Gray vireo & Arizona black rattlesnake \\
Pinyon jay & Sonoran desert tortoise \\
Pygmy nuthatch & Lesser earless lizard \\
Sage thrasher & Common chuckwalla \\
Virginia's warbler & \\
Williamson's sapsucker & \\
\hline
\end{tabular}

Because of constraints and the complexity of robustly modeling the potential changes in hydrology, no riparian species (riparian birds, amphibians, and gartersnakes) were included in this project. For additional details about bird and reptile distributions and datasets, refer to Insert 3.

\section{Registration of Location Data and Sample Sizes}

We modified the number of bird and reptile location records to one per grid cell (approximately $16 \mathrm{~km}^{2}$ ) to minimize sampling bias, which is especially important for correlative modeling (Phillips and others, 2009). We registered all georeferenced point range data for birds and reptiles by cells that we used for our spatial modeling. Once registered, each grid cell containing presence locations constituted one record of occurrence for an individual species. This registration of locational data to a uniform spatial grid allowed us to directly and systematically relate locations to explanatory environmental variables registered within the same grid, and guarded against finescale spatial and temporal autocorrelation, while accommodating detailed spatial uncertainty in recorded locations. This process substantially reduced the number of presence observations used for spatial modeling. In the case of reptiles, the original 23,954 georeferenced records were reduced to 5,087 grid cells representing the presence of five different taxa (see Insert 3, fig. A-1). The number of cells where presence was documented varied from about 200 to about 3,000 for individual species, which is sufficient for reliably modeling species distributions using logistic regression and Maxent (Guisan and Zimmermann, 2000; Kadmon and others, 2003; Wicz and others, 2008).

\section{Conceptual Models}

We developed conceptual models for each species; figure 2 is an example for the sage thrasher. 


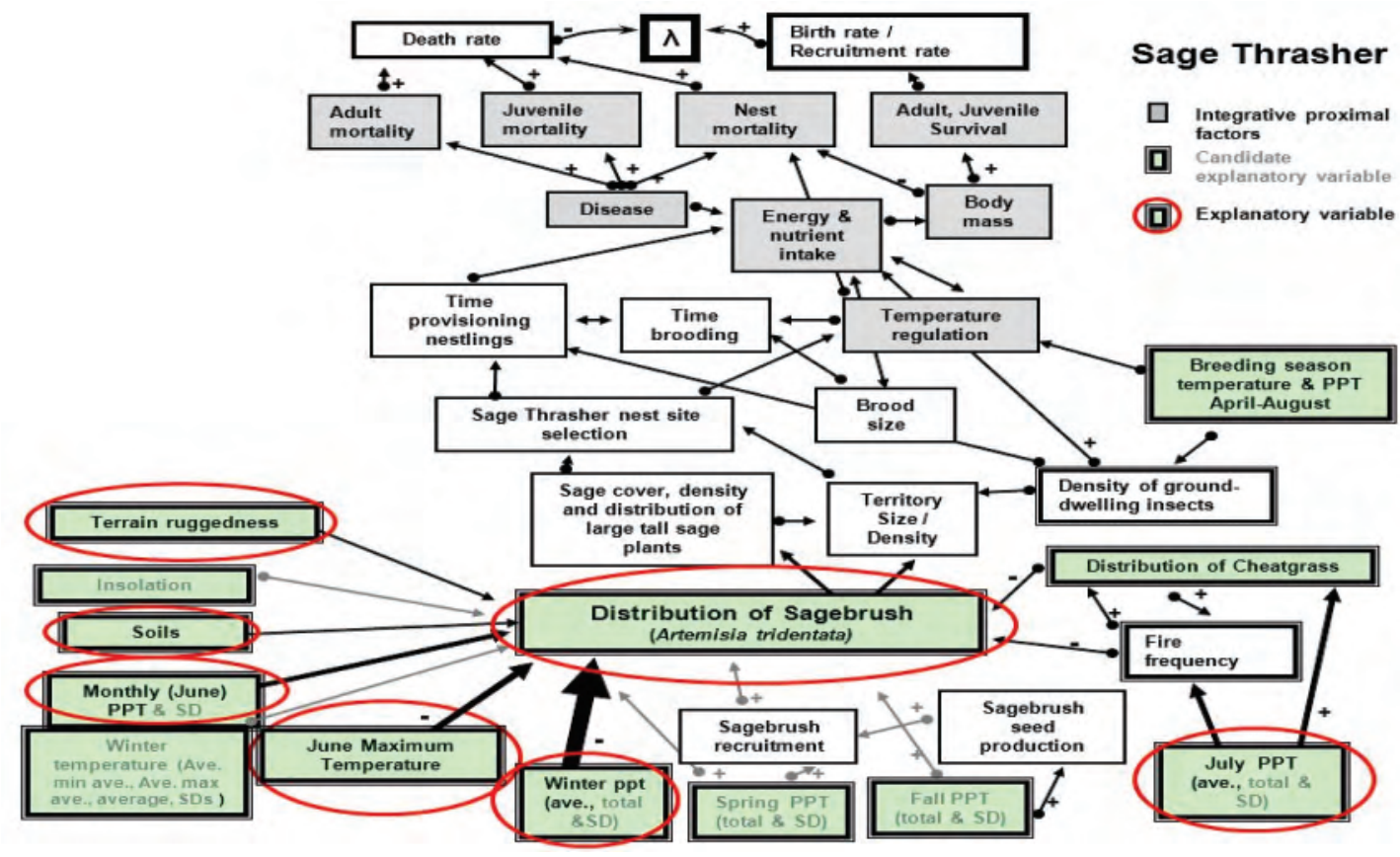

Figure 2. Conceptual model of factors that affect sage thrasher range and population dynamics with changing environments, including explanatory variables used to model current range (in green and circled red). The relative strength of different effects is denoted by the width of connecting arrows.

The sage thrasher conceptual model (fig. 2) is an example of an initial conceptual model that comprised our a priori hypotheses regarding determinants of range, and a concluding conceptual model that shows the relative importance of each of those effects. To develop our initial conceptual models, we first conducted a thorough literature review and/or used our own data to identify suites of factors likely to determine survival and reproduction of a given species. Our conceptual models illustrate causally how a species population demography (that is, survival and reproduction) is linked through proximal physiological and metabolic drivers to spatial and temporal variables that are available to use in statistical modeling. As part of this exercise, we identified the nature of prospective relations (fig. 2, positive or negative symbols), as well as the likelihood of any interactions. We differentiated four categories of factors within each conceptual model: (1) proximal physiological and metabolic drivers affecting a species survival and reproduction, (2) conceptually intermediate ecological phenomena affecting (1), (3) distal environmental measures which were candidate explanatory variables in statistical models, and (4) key ecological phenomena for which we had no measured surrogate that could be modeled. Taken together, these factors provided a well-informed logic for selecting candidate explanatory variables, a sound basis for interpreting any effects that emerged from our statistical modeling, and a means of identifying key factors that were not accounted for in any quantitative analysis.

Our concluding conceptual model incorporated the results of our statistical analyses (fig. 2, boxes circled in red and with larger arrows). Effects that were either not supported or weakly supported by our quantitative results were dropped from the conceptual models (fig. 2, green boxes not circled in red). Effects that were moderately or strongly supported were given amplified importance through the graphic form of enlarging the arrows denoting effects (fig. 2). 
For a detailed summary of the explanatory variables in our animal modeling, see Insert 4. For more details on how we went about modeling and incorporating the distributions of plant species, see Insert 5.

\section{Modeling Species Distributions}

We used an eight-step process to model current and future ranges of selected species: (1) we developed a conceptual model of each species life history; (2) we assembled a spatial database that characterized baseline (1980-2009 for birds; 1940-2009 for reptiles) and future (2010-99) climates throughout the western U.S., plus topographic and vegetation features; (3) we used logistic regression for birds and the Maxent algorithm for reptiles to identify significant associations between species locations and biophysical variables, and to construct cell-based probabilistic models of species occurrence; (4) we evaluated each model in terms of error rates and projective efficiency, given the supporting data; (5) we created distribution maps for each focal species in the Western United States; (6) for birds, we challenged each map with an independent breedinglocation dataset; (7) we modeled distribution for each species using future projections of climate and plant distributions for three time intervals (2010-39, 2040-69, 2070-99) with six GCMs (that is, 18 simulations); and, (8) we created maps of projected future distributions for each focal species, and quantified change between baseline and future projected range. For each GCM simulation, we created species distribution models with and without plant distributions, which allowed us to clearly distinguish the modifying effects of plant distributions in our models.

We modeled current and future distributions of reptiles using the Maxent algorithm (Maxent, version 3.3.3k, available at http://www.cs.princeton.edu/ schapire/maxent/; Phillips and others, 2006; Phillips and Dudík, 2008). Maxent uses a maximum entropy probability distribution to contrast occurrence data with background environmental data and estimates a probability distribution that has the maximum entropy (that is, most dispersed, or uniform) given certain constraints. The constraints are that the expected values of each feature (for example, a climate variable) must equal the empirical average (the average value at known occurrence points; Phillips and others, 2006). Maxent is one of the best algorithms to calculate the likely suitability of landscape for a species when presence or absence data are not available (Elith and others, 2006; Elith and Leathwick, 2009; Elith and others, 2011). Unlike birds, absence from specific areas for many species of reptiles is difficult to confirm because of their cryptic habits and low detectability. In addition, for many reptile species, available data only document their presence. Models built with presence-only data do not incorporate information on the frequency of occurrence of a species in a region, and therefore cannot accurately predict probability of presence (MacKenzie and others, 2002; Guisan and Thuiller, 2005). However, such models can be used to estimate a relative index of the suitability of landscape for a species (Elith and others, 2006). For additional details about bird model development, fit, and verification, see Insert 6; for more details on reptiles, see Insert 7. 


\section{Projecting Distributions}

Once we finalized models depicting current distribution, we projected two distribution models (one with and one without vegetation) obtained from baseline climatic conditions according to 18 different future climatic scenarios (three different time periods and six different GCMs). In the case of Maxent, we applied the option to "fade by clamping" because we applied the models to future climates with unknown variable ranges. This option reduced projections at each point by the difference between clamped and non-clamped output (Phillips and Dudík, 2008). We provided results as the logistic model output. This allowed us to represent landscape suitability for each cell as a scaled index (Phillips and Dudik, 2008) and, from that, calculate changes in projected ranges based on predefined output thresholds above which projections were considered to be suitable for the given species (Pearson and others, 2007). Although there are many ways to calculate these thresholds (Liu and others, 2005), the choice depends on the purpose of the model (Lobo and others, 2008). We calculated thresholds by equalizing sensitivity and specificity for training samples, assuming that such an approach equalized the risks of over- and under-specifying (Freeman and Moisen, 2008). We then calculated the percentage of range "gained" or "lost" based on where five out of six GCM-habitat models concurred on the delineation of potential range (83 percent agreement threshold). We calculated range change considering scenarios with and without the effects of unlimited dispersal, either by the focal animal species alone or by plant species in models as independent variables. Calculated range losses would have been less if we had adopted less stringent thresholds (for example, agreement among 3 or 50 percent of projections) for delineating future range.

\section{Data Delivery}

Data delivery for this project can be divided into two overlapping frameworks: (1) data delivery and archiving for project scientists and (2) data delivery and archiving of final products for all stakeholders. For final archiving and data delivery to the public, we used Federal Geographic Data Committee (FGDC) metadata and national metadata clearinghouses for documentation and discovery of data and websites, and a web mapping application for final delivery. For details on data storage and delivery, see Insert 8.

\section{Website Application}

This aspect of the project was an effort to provide managers and other stakeholders with a useful tool that will present a simple way for understanding how the ranges of a select group of animal and plant species will be affected by global climate change. To accomplish this, a website was developed that will serve as the primary interface between groups of users and the spatial data assembled by project scientists. The primary goal of our website design is to display projected timeseries data according to various models. For additional details about the website design and development, refer to Insert 9. 


\section{Results}

For purposes of this report we have chosen to present our modeling results for each species in the form of a standardized 3-page species account (Inserts 10 and 11). Here, we summarize our species-specific results and provide a brief synoptic summary of our projections for each species group-birds and reptiles. Each species account contains three basic informational themes. The first page contains information about the species natural history with a conceptual model that encapsulates our prior understanding of key ecological and environmental relations, modified to incorporate the results of our statistical models. The second page presents habitat maps showing projected distributions for the 2070-2099 time period and areas of range loss, gain, and range persistence between 2000 and the 2070-2099 time period. The third and final page presents information in non-spatial form about model performance, model content, and summary statistics for distributional gains and losses in habitat by future time interval. More complete results for each species can be accessed at our project web portal (ftp://grail1.bio.nau.edu/) and interested persons can obtain the password from Paul Henrich (Paul.Henrich@nau.edu). The complete results include projected geospatial changes in habitat distribution for each species permuted by time interval and GCM, along with options for overlaying reference information such as state boundaries, land ownership, and major highways.

\section{Bird Species-Specific Projections}

Climate changes for the Western and Southwestern United States will affect bird species in unique ways, based largely on the natural history and habitat needs of each species. Specifics of how these changes will differentially affect each of the bird species we included in the modeling are detailed in Insert 10.

Black-throated sparrow-Explanatory variables in the best-fit model for the black-throated sparrow included, in decreasing rank order, terrain ruggedness, mean spring precipitation, the range of creosote bush (Larrea tridentata), mean winter temperatures, and minimum June temperature. This sparrow's breeding range is projected to increase by 34-47 percent between 2010 and 2099 when an 83 percent agreement threshold was applied (see Insert 10, p. 59).

Gray vireo-Explanatory variables in the best-fit model for the gray vireo (which inhabits some of the hottest, most arid regions of the Southwestern United States) are, in decreasing rank order, maximum breeding season temperature, terrain ruggedness, the range of Utah juniper (Juniperus osteosperma), insolation (incident solar radiation), and mean breeding season precipitation. The gray vireo's breeding range is projected to increase from $58-71$ percent between 2010 and 2099 when an 83 percent agreement threshold was applied (see Insert 10, p. 62).

Virginia's warbler - The Virginia's warbler presently has a relatively restricted breeding range, inhabiting scrubby habitats below the pine belt in the northern part, and scrubby habitats within surrounding conifers in the southern part of its range (Olson and Martin, 1999). Explanatory variables in the best-fit model for the Virginia's warbler included, in decreasing rank order, terrain ruggedness, the range of Gambel oak (Quercus gambelii), mean winter precipitation, mean summer temperature, mean summer precipitation, and insolation. The Virginia's warbler's breeding range is projected to decrease slightly, by 1.5-7 percent, between 2010 and 2099 when an 83 percent agreement threshold was applied (see Insert 10, p. 65). 
Sage thrasher-Considered a sage obligate, this bird species is generally dependent on large patches and expanses of sagebrush steppe for successful breeding. The distribution of sage thrasher had one of the strongest associations with the distribution of a plant species. Explanatory variables in the best-fit model for the sage thrasher were, in rank decreasing order, mean winter precipitation, maximum June temperature, mean July precipitation, the range of big sagebrush (Artemisia tridentata), percent sand in the soil, and terrain ruggedness. We were unable to project the distribution of big sagebrush as we lacked an adequate distribution model for this plant species, and therefore we projected the sage thrasher distributions using only the model without plant distributions. The thrasher breeding range is projected to decrease by 78 percent between 2010 and 2099 when an 83 percent agreement threshold was applied (see Insert 10, p. 68).

Pinyon jay-This jay species coevolved as a non-migratory mutualist with pinyon pines. Not surprisingly, the distribution of the pinyon jay has strong associations with the distributions of pinyon pines which provide the bird's main food resources (Marzulff and Balda, 1992). Explanatory variables in the best-fit model for the pinyon jay are, in decreasing rank order, mean winter precipitation, maximum summer temperatures, the range of pinyon pine (Pinus edulis), single-leaf pinyon (Pinus monophylla), and Jeffrey pine (Pinus jeffreyi), terrain ruggedness, and insolation. The pinyon jay's breeding range is projected to decrease by 25-31 percent between 2010 and 2099 when an 83 percent agreement threshold was applied (see Insert 10, p. 71).

Pygmy nuthatch - Another pine-associated bird species in the southwest is the pygmy nuthatch. Explanatory variables in the best-fit model for the pygmy nuthatch included, in decreasing rank order, mean fall precipitation, mean winter temperatures, mean winter precipitation, the range of ponderosa pine (Pinus ponderosa), minimum summer temperature, and terrain ruggedness. The pygmy nuthatch's breeding range is projected to decrease by $75-81$ percent between 2010 and 2099 when an 83 percent agreement threshold was applied (see Insert 10, p. 74).

Williamson's sapsucker-This species inhabits open coniferous and mixed coniferousdeciduous forests of western United States. Explanatory variables in the best-fit model for the sapsucker are, in decreasing rank order, the range of Jeffrey pine (Pinus jeffreyi), mean breeding season temperatures, the range of Douglas fir (Pseudotsuga menziesii), the range of ponderosa pine, winter precipitation, mean breeding season precipitation, and terrain ruggedness. The Williamson's sapsucker breeding range is projected to decrease by 73-78 percent between 2010 and 2099 when an 83 percent agreement threshold was applied (see Insert 10, p. 77).

\section{Reptile Species-Specific Projection}

Our modeling results suggest that future climate change will negatively affect the distributions of reptiles in the Western and Southwestern United States. The following is a synopsis of projections for each of the five reptiles that we included in the modeling during this project.

Plateau striped whiptail - This medium-sized (to $90 \mathrm{~mm}$ ) lizard inhabits a variety of grassland, and shrub habitats of the Colorado Plateau and central New Mexico. The whiptail is found ranging to elevations as high as $2440 \mathrm{~m}$. Because of its strong association with grasslands, the distribution of black grama (Bouteloua eriopoda) has the strongest effect of all explanatory variables in the best-fit model of distribution for this lizard. Other variables include, in decreasing rank order of effect, winter average temperatures, insolation, total summer (July-September) precipitation, and terrain ruggedness. The range was projected to decrease by 42 percent, assuming no dispersal, or by 17 percent with unlimited dispersal when an 83 percent agreement threshold was applied (see Insert 11, p. 80). 
Arizona black rattlesnake-This montane rattlesnake is found exclusively in Arizona and western New Mexico. It typically inhabits pine-oak woodlands or chaparral habitats. At higher elevations, individuals rely on volcanic outcrops and talus slopes for cover and hibernation whereas at lower elevations they are restricted to cool, moist drainages. Explanatory variables in the best-fit model for the Arizona black rattlesnake, in decreasing rank order of effect, were minimum winter (October-April) temperature, terrain ruggedness, total summer precipitation, rock type, insolation, geology and distribution of Gambel oak (which was strongly correlated with distributions of other oaks). Regardless of dispersal assumptions, range of this snake was projected to decrease between 32 and 46 percent when an 83 percent agreement threshold was applied (see Insert 11, p. 83).

Desert tortoise - The Sonoran population of the desert tortoise (Morafka's Desert Tortoise), recently recognized as a separate species, is found throughout the Arizona Upland subdivision of the Sonoran desert, specifically in Sonoran uplands with rocky outcrops and alluvial fans. Explanatory variables for this tortoise that are most important in the best-fit models, in decreasing rank order, were the extent of brittlebush (Encelia farinosa), average winter temperatures, total summer precipitation, and winter minimum temperatures. Although brittlebush is not directly associated with tortoises, it is likely that its importance in the model is because of how the extent of the plant's distribution relates to the extents of semidesert and desert grasslands as well as desert scrub habitats. Desert tortoise is the only species of reptile for which projections do not include a decrease in suitable habitat by 2099 but only when unlimited dispersal is assumed. However, assuming no dispersal, models indicate a slight decrease (-1 percent) in the extent of suitable areas (see Insert 11, p. 86).

Common lesser earless lizard - This species is a locally common and widespread lizard found across short-grass prairie and open habitats between the Southern Colorado Plateau and western edge of the Great Plains. Explanatory variables in the best-fit models for the common earless lizard were, in decreasing rank order, range of black grama, total monsoonal (July-September) precipitation, winter average temperatures, summer average temperatures, winter precipitation, early summer (May-June) precipitation, and soil depth. Depending on dispersal assumptions, the range of this lizard is projected to decrease by 22-49 percent from 2010 to 2099 when an 83 percent agreement threshold was applied (see Insert 11, p. 89).

Common chuckwalla - This a large lizard found across the Mojave and Sonoran deserts of the Southwestern United States. Best-fit models of its range included three main explanatory variables which were, in rank order of importance, the range of creosote bush, the range of brittlebush, and May-June precipitation. Regardless of dispersal assumptions, projected ranges are likely to decrease by between 13 and 23 percent from 2010 to 2099 when an 83 percent agreement threshold was applied (see Insert 11, p. 92). 


\section{Summary of Results}

Projected changes for birds - Projected breeding distributions for each bird species varied widely within and among the three time periods (and six GCMs) that we examined (Insert 10). We determined that the magnitude of change was largely dependent upon the GCM-distribution model agreement threshold. At an 83 percent agreement threshold, black-throated sparrow and gray vireo are projected to experience major gains in breeding habitat (table 3). By contrast, pygmy nuthatch, sage thrasher, and Williamson’s sapsucker are projected to experience large losses in breeding habitat. Thus, these last three species might be expected in the future to experience large population declines (table 3).

Table 3. Projected change in area of modeled distribution by 2099 as percent of baseline (1980-2009) suitable areas for birds, at an 83 percent GCM-distribution model agreement threshold, for models with and without the effects of plant distributions.

\begin{tabular}{lcc}
\hline \multicolumn{1}{c}{ Species } & Models with plant distributions & Models without plant distributions \\
\hline Black-throated sparrow & $+34 \%$ & $+47 \%$ \\
Gray vireo & $+58 \%$ & $+71 \%$ \\
Pinyon jay & $-31 \%$ & $-25 \%$ \\
Pygmy nuthatch & $-81 \%$ & $-75 \%$ \\
Sage thrasher & N/A & $-78 \%$ \\
Virginia's warbler & $-7 \%$ & $-2 \%$ \\
Williamson's sapsucker & $-78 \%$ & $-73 \%$ \\
\hline
\end{tabular}

In all of our bird models, inclusion of plant distribution effects led to more negative projections - either less gains or greater losses in breeding range. All bird models also contained a quadratic term that introduced an effect of coarse-grain terrain ruggedness (TRI). An additional three models (gray vireo, Virginia's warbler, pinyon jay) included an effect of insolation. The combined effects of static features (TRI, insolation, and, in one model, soil sandiness; calculated as the sum of $\chi^{2}$ s for all static feature effects) in each bird model was positively related to the magnitude of change in breeding habitat by 2099 (fig. 3). Overall, we determined that the greater the aggregate effect of static features, the greater the increase in projected bird breeding range, or the less the projected loss in numbers of individuals. 


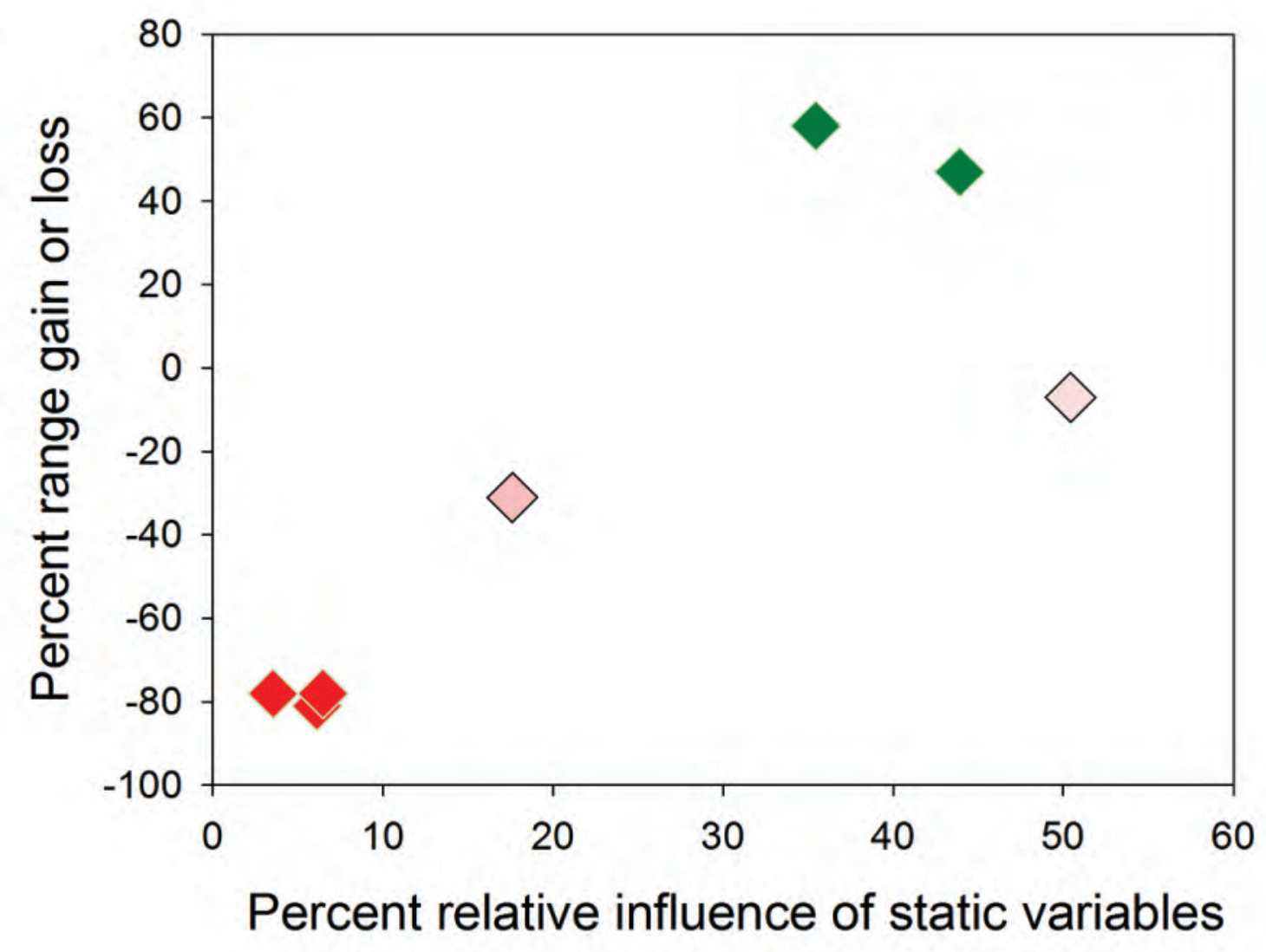

Figure 3. Graph showing percent change in projected breeding distribution of birds by 2099 in relation to total percent relative influence of static variables (TRI, insolation, soil sandiness) for a species-specific model. Green diamonds denote species projected to experience major distributional gains in habitat (black-throated sparrow and gray vireo); red diamonds denote major distributional losses in habitat (pygmy nuthatch, sage thrasher, Williamson's sapsucker); and pink diamonds denote little projected change (pinyon jay and Virginia's warbler).

Projected changes for reptiles-We quantified the effect of dispersal on projected distributions of reptiles at two extremes: (1) we assumed no dispersal into newly suitable habitats, and (2) we calculated the maximum nearest neighbor between all known records of a species and used that as a buffer distance representing the potential of unlimited dispersal. Differences in modeled suitable areas with and without dispersal are given in table 4 . 
Table 4. Projected change in area of modeled distribution by 2099, as percent of baseline (1940-2009) suitable areas for reptiles, at an 83 percent GCM-distribution model agreement threshold, for models with and without the effects of plant distributions.

\begin{tabular}{lcccc}
\hline & \multicolumn{2}{c}{ Models with plant distributions } & \multicolumn{2}{c}{ Models without plant distributions } \\
\cline { 2 - 5 } \multicolumn{1}{c}{ Species } & Unlimited dispersal & No dispersal & Unlimited dispersal & No dispersal \\
\hline $\begin{array}{l}\text { Striped Plateau } \\
\begin{array}{l}\text { Whiptail } \\
\text { Arizona Black }\end{array}\end{array}$ & $-17 \%$ & $-42 \%$ & $-22 \%$ & $-42 \%$ \\
$\begin{array}{l}\text { Rattlesnake } \\
\text { Sonoran Desert }\end{array}$ & $-32 \%$ & $-36 \%$ & $-44 \%$ & $-46 \%$ \\
$\begin{array}{l}\text { Tortoise } \\
\begin{array}{l}\text { Lesser Earless Lizard } \\
\text { Common Chuckwalla }\end{array}\end{array}$ & $-21 \%$ & $-1 \%$ & $+25 \%$ & $0 \%$ \\
\hline
\end{tabular}

Most reptiles were projected to experience one-third range distributional losses by 2099, regardless of dispersal potential or inclusion of plant species distributions (Insert 11). The sole exception to this pattern was the Sonoran desert tortoise, for which we projected increase in suitable area but only when assuming unlimited dispersal. Unlike the bird models, only one reptile model included an effect of terrain ruggedness; and only three of the five models included any effect of a static variable. Measures of insolation, soil composition, and geologic features each were important in two models. Inclusion of plant species distributions had an inconsistent and generally lesser effect on future projections compared to the more uniform effects of these variables in bird distribution models (see more specifics in Insert 11).

\section{Overall General Patterns of Climate Change Influences on Birds and Reptiles}

Considering all of the species that we modeled, there appeared to be a positive relation between projected distributional gains or losses and the average annual temperature of the species current distribution (fig. 4). 


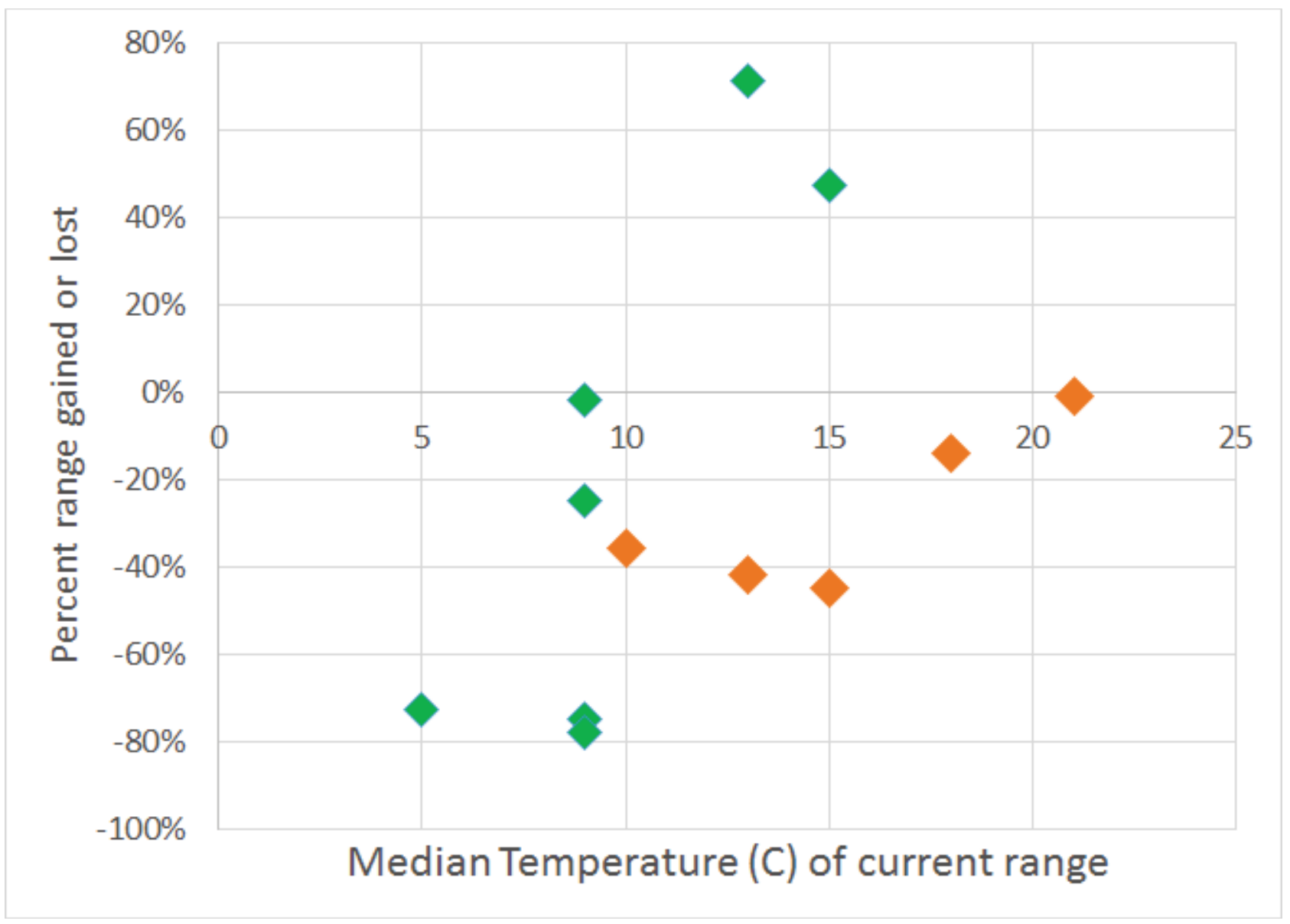

Figure 4. Graph showing relation between percent projected distribution gain or loss and the median temperature of a species current distribution. Green diamonds denote bird species and orange diamonds denote reptile species.

The warmer the current range, the greater the projected distributional gain or the less the projected loss. This pattern was more evident for birds than reptiles. Coarse-grain terrain ruggedness index (TRI) also was a variable that frequently contributed significantly to bird models but had less of an influence on the reptile species. Insolation, on the other hand, was an important variable in all animal models (see Inserts 10 and 11). In summary, we found that changing climates will not uniformly affect all species and that some bird species will be affected differently than some reptile species. Overall, some species will gain in suitable areas and thus possibly experience increases in population numbers, while other species will experience distribution contractions and likely shrinking populations. Land managers should be aware of these potential changes so that they can adjust their management practices accordingly. 


\section{Insert 1: Detailed Project Justification and Methods}

\section{Distributions: Our Focus of Attention}

The goal of our project was to project the future breeding ranges of birds and reptiles, based upon spatially explicit environmental models obtained under baseline climatic conditions (19802009 for birds and 1940-2009 for reptiles), and for three future time period intervals (2010-39; 2040-69; 2070-99). The scale of our modeling was both coarse and broad because species distributions are hundreds of thousands to millions of square kilometers, and projected changes in distributions could be larger than our focal study area. Consequently, although our focal area was the Southwest, our larger study area had to encompass regions where species might expand, which included the entire western United States.

The resolution, or grain, of our analysis was correspondingly coarse. Our minimum mapping unit was $16 \mathrm{~km}^{2}$ ( $4 \times 4 \mathrm{~km}$ squares, or grid cells), which is of a size comparable to very large project areas in most land management agencies, and the minimum useful grain of most climate projections. Because our minimum resolution transcended the scale of most management actions, this project was not designed to inform matters such as short-term rangeland and forest management practices on individual management units. Rather, we offered information that will help managers to better anticipate the nature and magnitude of climate-driven changes in wildlife habitats and potential distributions, with implications for planning at regional and continental scales.

We offer explanations for projected changes that are rooted in a thorough understanding of the natural history of each species, with the potential for extrapolation to ecologically similar species. Our attention to selecting representative species and to grounding our work in ecological knowledge was the basis for a relatively broad scope of inference, despite focusing on comparatively few species. Inference was based on an understanding of context, contingency, and connection, which is what we offer in our results.

\section{A Few Well, Versus Many Poorly}

We assumed that our results would be of greater value, and provide a broader scope of inference, if we modeled a few key representative species well, rather than many species poorly. Projecting is a chancy business (Berteaux and others, 2006; Jackson and others, 2009). Projections that ignore or make little use of prior ecological knowledge in both the design and interpretation of models are likely to produce nonsensical results at best, or misleading results at worst (Austin, 2002; Barry and Elith, 2006; Berteaux and others, 2006; Elith and Leathwick, 2009). Several prior research efforts have run tens to hundreds of species through automated modeling procedures, attentive only to climate envelopes, and automatically processing scores of climate variables, in an attempt to produce comprehensive results for large groups of species (for example, Huntley and others, 2004; Elith and others, 2006; Lawler and others, 2009; Kissling and others, 2010). It is important to understand that animal species respond to more than just climate events, thus we choose to model fewer species and with non-climatic variables. 


\section{Our Focal Species, and Why}

We modeled the ranges of bird and reptile species for which we had sufficient data and ecological knowledge - enough data with enough coverage to support our quantitative work, and enough information on ecological relations to support the development of conceptual models (see Thuiller and others, 2004; Elith and Leathwick, 2009; Babet-Massin and others, 2010). We focused on birds and reptiles because they covered the majority of terrestrial vertebrate diversity in the Southwest, including species with a wide range of life histories (Boykin and others, 2007). In the broadest sense, these species represent, on the one hand, highly mobile endotherms that would presumably be able to respond to changes in range conditions (birds), versus, on the other hand, ectotherms with limited dispersal potential that would presumably be quite sensitive to climate (reptiles). This diversity matched our goal of learning how species with different dispersal capacities and life histories might respond to changing climate patterns. We also required the ranges to either be mainly contained within, or encompass a significant portion of the interior Southwestern United States, and for occurrence data to coincide roughly with the species known historic distribution (Kadmon and others, 2003; Thuiller and others, 2004; Sinclair and others, 2010; Veloz and others, 2012). This last condition pertained to our focus on climate-related effects on distributions, rather than distribution as an artifact of direct human effects-which is the typical reason why most current distributions differ dramatically from those of the past.

Given these criteria, certain categories of species were excluded from consideration, including some that were originally of interest to managers. The distributions of intrinsically rare species were not modeled for two reasons. First, a limited distribution does not support the reliable detection of climate-related or other broad-scale effects, because of intrinsically limited sample sizes (at a grain of $16 \mathrm{~km}^{2}$ ) and intrinsically limited span of variation in potential environmental drivers (Elith and Leathwick, 2009). Second, many intrinsically rare species are so because of historical and evolutionary artifacts (for example, migration followed by isolation), or because of association with highly anomalous environments. As a consequence, we did not model endangered, threatened, or otherwise at-risk species with restricted distributions. Historically wide-ranging but more recently widely-extirpated species, such as the yellow-billed cuckoo (Coccyzus americanus), also were not considered good candidates, especially if we lacked reliable data for historic distributions. Virtually all recent extirpations have been the result of direct human causes, including over-harvest and the destruction of critical habitats such as native riparian corridors (Collar and others, 1997; Czech and Krausman, 1997). Given our interest in climate change, we needed distribution data that was more likely to reflect climate limiters rather than recent historical human activities (Sinclair and others, 2010).

\section{Data on Distributions}

The scale of our modeling and projections matched the scale of regional or continental occurrence data for most bird and reptile species. Broad-scale occurrence data can typically be obtained at the resolution of watersheds or areas as large as $64 \mathrm{~km}^{2}$. Occurrence also is reckoned at a coarse temporal scale, typically decades. For purposes of our analysis, a species was considered present if there was a single record within an approximately $16 \mathrm{~km}^{2}$ cell within the last several decades. Our temporal window for determining presence differed between birds and reptiles because of differences in the distribution of observations in time between these two groups. The vast majority of bird observations in AKN/EBird have been recorded since the 1970s, whereas observations of reptiles are much more evenly distributed going back to the 1940s. Our objective was to match the temporal reckonings of past climate with past species distributions for both birds and reptiles, which led us to truncate bird observations at 1990 and reptile observations at 1940 . 
Our estimates of past climate correspondingly varied between birds and reptiles, with climate averages for our bird models encompassing 1980-2009 and climate averages for our reptile models encompassing 1940-2009.

Ascertaining species presence (or absence) at the grain of $16 \mathrm{~km}^{2}$ over several decades is at about the coarsest demographic resolution possible where we could still retain meaningful information with which to work. Working at this scale we lost information about most demographic processes, including birth, death, immigration, and emigration rates, as well as ultimate metrics such as density. Nonetheless, we expected coarse-grained presence to be significantly correlated with all of these processes at broader scales. Therefore, we expected to detect a species where densities where higher, and where birth and immigration rates were correspondingly higher and death rates lower. Even so, our model results are not likely to be sensitive to finer-scale demographic phenomena such as density, and do not support or inform management at that finer scale.

\section{The Nature of Distributions: Probabilities and Thresholds}

Distributions are intrinsically difficult to quantify. Some might be deceived into thinking otherwise by the typical black and white, binary ranges that are shown in most maps. But whether a species is "present" or not necessarily varies with the spatial and temporal grain of record-keeping, and with the intensity of survey efforts. In other words, a species is more likely to be "present" if this determination is made for larger grid cells, based on data collected over longer spans of time, and involving more intensive survey efforts. As survey effort and the spatial and temporal span increase, so do the sample unit-specific probabilities that a species will be documented as present. But much of this fuzzy information gets lost in either polygonal range maps or presence-absence or presence-only data. Even so, the underlying probabilistic sampling processes are real and important, and a necessary part of interpreting present and future projected ranges (Austin, 2002; Legendre and others, 2002; Barry and Elith, 2006; Elith and Leathwick, 2009).

The probabilistic or fuzzy nature of distributions was captured in the output of modeling methods that we used for this project: logistic regression and Maxent. Both methods produced probabilities, which in the case of logistic regression was obtained by back-transforming the modeled log odds. These spatially-explicit probabilities more fully capture the information contained in models than do binary surfaces that are more commonly recognized as range maps. Yet some analyses and some visual applications required that we translate a predicted surface of occurrence probabilities into a binary (present versus absent) map for a given species.

The production of binary maps required setting a threshold in terms of modeled probabilities. Wherever a value was above the specified threshold, the associated cell was considered to be range for this species. Wherever values were below this threshold, the cell was not deemed to be part of the animal's range. But what constitutes "true" presence reckoned in terms of modeled probabilities? There probably is no knowable answer, given that we could not estimate all of the underlying sampling processes that went into producing the presence-only or presenceabsence data used for our modeling (Guisan and Zimmermann, 2000; Barry and Elith, 2006; Elith and Leathwick, 2009). Nor is there uniform agreement in concept regarding what does or does not constitute "presence." As a result, we set thresholds as values that equalize training sensitivity and specificity on a premise that such an approach equalized the risks of over- and under-specifying (Freeman and Moisen, 2008). 


\section{Limiters and Drivers of Distributions}

Our focus on distributions and the large extent and coarse resolution of our analysis had implications for the nature and scale of ecological drivers. Most managers operate at the spatial extent of hectares or small watersheds, and focus on fine- or mesoscale manipulations of the structure and composition of vegetation or animal populations. Interest is typically in densities and vital rates of species. But the scale of our analysis and the scale of ecological processes that determine species distributions did not match this traditional focus.

The determinants and drivers of species ranges typically operate largely (but not wholly) at the limits of species tolerances (Guisan and Zimmermann, 2000; Elith and Leathwick, 2009). For vertebrate animals, these factors include broad-scale coarse-grain phenomena such as climate, insolation (incident solar radiation), regional soil characteristics, regional geomorphology, regional land use patterns, and, in cases where there is direct dependence, the distribution of plant species (for example, Schweiger and others, 2008; Austin and Van Neil, 2011; Stanton and others, 2012). As a bottom line, our results were not intended to-nor should they-inform finer-scale management of resources, both as a consequence of the grain of our analysis and the scale and delimiting nature of underlying ecological processes.

\section{Explanatory Variables}

Logistical criteria-Our goals imposed some stringent demands upon the variables that we used in our explanatory predictive models. Any candidate variable had to be represented by digital spatial data that encompassed the entire extent of not only our focal area, but also the area into which species might expand. In many of the bird cases this comprised the entire western United States. The variable also had to have uniform meaning relative to its referent classes and other indices throughout this extent (Longley and others, 2005). More important, we had to be able to project future spatial configurations of our explanatory variables (Berteaux and others, 2006; Elith and Leathwick, 2009; Jackson and others, 2009).

These considerations debarred using many databases related to vegetation structure and composition, such as products of GAP analysis or remote-sensing based estimates of vegetation cover and productivity. We did use the distributions of select plant species as explanatory variables, but only because our modeling of animal species distributions were attached to the results of another major undertaking of our larger southwestern NCCWSC project that was devoted to modeling and projecting only plant species distributions (Cole and others, 2008; Garfin and others, 2010). Features that we assumed would be static, at least for 99 years, were not constrained to the need of being projected. These variables included measures of geology, geomorphology, soils, and solar insolation.

What we did NOT include - We included most factors - as explanatory variables - that we thought were important to determining distributions of the species that we modeled. Most prominently, these included climate, soils, geomorphology, geology, hydrology, land use, and plant species distributions, all at a coarse scale. However, there were other factors that we did not include, which were nonetheless likely to influence current and future animal distributions. These factors included disease, vectors, predation, inter-specific competition, and major transformations of vegetation structure and composition owing to changes in land use, fire regimes, and the invasion of non-native species (Austin, 2002; Ibáñez and others, 2006). 
The future effects of diseases and insects are imponderables. Most major disease or vector effects on species distributions have been driven by the outbreak of particularly virulent non-native diseases and vectors (van Riper and others, 1986) or mutant species or strains (De Leo and others, 2002). Although important, such phenomena are so complex as to be unpredictable. We had no way to introduce or project such effects. Nonetheless, the recent histories of white-nose syndrome and bats, of West Nile virus and birds, and of chytridiomycosis and amphibians are instructive (Friend and others, 2001; Daszak and others, 2003; Foley and others, 2010).

Invasions by non-native species and large-scale changes in fire regimes are better suited to projecting, but well beyond the scope of our project. If researchers at some future time were to reliably predict spatially-explicit patterns of fire regimes or invasions by non-native species, while explicitly accounting for climate change, such results would present a great opportunity to integrate the effects of fire and invasive species into projections of animal distributions.

Finally, predation and competition were conceivably within the purview of this project, but not accounted for because of time constraints and other priorities. We know that predation and competition can be powerful forces, even to the extent of configuring species distributions (Austin, 2002; Guisan and Thuiller, 2005; McMahon and others, 2011). Human predation on a number of vertebrates has led to extirpations over large areas (Collar and others, 1997; Czech and Krausman, 1997). Spotted owls (Strix occidentalis) are probably declining in distribution in the Northwestern U.S. because of competition with (and other effects of) the barred owl (Strix varia; Kelley and others, 2003; Gutiérrez and others, 2007). Native leopard frogs (Lithobates sp.) are being similarly affected by introduced bullfrogs (Lithobates catesbeiana) and crayfish in the Southwestern United States (Hayes and Jennings, 1986; Kats and Ferrer, 2003). These kinds of effects could be modeled by introducing other species distributions as explanatory variables in instances where the predator or competitor was known. We see this as a logical next step for the work started under the auspices of this project.

Plant species - We included plant distributions as explanatory variables in instances where we had reason to believe an animal was in some way directly dependent on food or other conditions provided by the plant. The widespread dependence of pinyon jays (Gymnorhinus cyanocephalus) on the seeds of pinyon pines (Pinus sp.) is a classic case (Marzluff and Balda, 1992). Given that in our larger project we also modeled current and future distributions of plants (Cole and others, 2008; Garfin and others, 2010), we were in a position to project the future distributions of plants in instances where the plant species efficiently predicted an animal's distribution-in a way that we could readily explain. Plants potentially had a substantial effect on future projections of animal distributions because of the intrinsically limited mobility of many plant species (Araújo and others, 2006; Schweiger and others, 2008). Even though climate envelopes may expand rapidly, colonization by plants may occur at a much slower pace, and where an animal is dependent on the plant, expansion of the animal's distribution would be correspondingly curbed. We dealt with this phenomenon by introducing a "mask" around current plant distributions that represented the distance we expected the plant to migrate within a projected time increment, which in turn affected expansion of an animal's distribution, mediated through the overall structure of the projective model. 
The use of plant distributions as explanatory variables in models of animal distributions is conceptually demanding. There are many instances where a plant species may act strictly as an environmental surrogate, or proxy, without any direct link to the life history of the focal animal. In these cases, the plant species distribution will receive considerable statistical support-as a statistically efficient variable. One plant-related variable could capture the current concatenation of several climate and other variables. This circumstance may work well if the sole aim is to efficiently represent current patterns statistically. But one could be misled and left searching for a post hoc explanation if the aim is to explain and project ranges. Certain configurations of climate associated with a plant species distribution today may uncouple and reconfigure in novel ways in the future, with implications for a given animal's distribution. Using a plant surrogate would not allow us to track these kinds of novel configurations. And if climate rather than a plant were truly determining where an animal could live, our introduction of a migratory mask for the plant, with an effect on the animal, would be spurious. We relied heavily on our review of the literature, and related conceptual models to navigate through these difficulties. We also produced models with and without plant species variables for each animal that we considered, so as to consistently provide at least one statistical explanation that did not depend on plant predictors.

Hydrology and riparian vegetation - Riparian bird and reptile species are of considerable interest to managers in the Southwestern United States-including the southwestern willow flycatcher (Empidonax traillii extimus), yellow-billed cuckoo, leopard frogs, and narrow-headed garter snakes (Thamnophis rufipunctatus). Water is limited and quite influential in this semi-arid to arid region, and riparian areas, rivers, and streams have been dramatically altered to serve human purposes other than the conservation of biodiversity (Reisner, 1986; Barnett and others, 2008). But hydrology is another difficult-to-work-with explanatory variable, especially if one is interested in projecting its future configurations. Hydrology is a function of climate inputs, watershed characteristics, and local stream reach features. Riparian vegetation, which is often more directly relevant to terrestrial vertebrates, is denoted by structure and composition, which is a function not only of local hydrology, but also streamside geomorphology and history (Shafroth and others, 2002; Webb and Leake, 2006).

Rapid advances are occurring in our collective ability to model current and future hydrology, primarily because water and riparian areas are such important resources. The NHDPlus database (NHDPlus Version 2, http://www.horizon-systems.com/nhdplus/) provides a comprehensive spatial representation of current hydrology for our study area at the resolution of individual stream reaches, based on models of historic hydrologic data. This is an important asset in modeling the distributions of riparian animal species; however, predicting hydrology using GCM projections is ongoing and far from comprehensive for our larger study area (for example, Christensen and Lettenmaier, 2007). We were in a position to model the current distributions of riparian animal species, but chose not to predict where they would be in the future.

\section{Conceptual Models}

Hypotheses-We relied upon conceptual models to synthesize, represent, and relate relevant life history information about our focal animal species, as a basis for designing and interpreting our statistical species distribution models. We selected focal species partly on the basis of whether existing information was sufficient to identify factors that conceivably determined its distribution. We were particularly wary of dredging data, which is typified by exploring dozens of effects without any prior basis for plausibility or functional interpretation. 
Statistical fit alone is a not a good criterion for making future projections, primarily because some variables may correlate well with current range, but mask some important effects that are functionally uncorrelated, and prone to "go in different directions" under future climates (Guisan and Zimmermann, 2000). This kind of risk would be amplified if some statistically-buried effects were "pinned" to the landscape, as would be the case with geomorphology or solar radiation, while others were highly mobile, as in the case of climate. Moreover, lack of attention to prior knowledge increases the odds that some factors critical for explanation and prediction may be overlooked entirely.

Conceptual models were not only a key means of disciplining our thinking, but also an efficient way to articulate hypotheses about how the world worked in ways relevant to explaining why species occurred where they did. We carefully reviewed the literature to identify a suite of factors likely to determine where a species lived, died, or reproduced, along with any functional explanation. We then interrelated these factors to form a logical picture of the determinants and contingencies of the species distribution. We also identified the nature of prospective relations (positive or negative), and the likelihood of any interactions that required an interaction term in a statistical model. These conceptual maps were then carefully followed in constructing candidate statistical models for explaining and projecting species distributions.

In addition to bounding the range of the plausible — and the interpretable-we also viewed our conceptual models as hypotheses to be tested statistically by our quantitative models, realizing that all of our tests were "weak" rather than "strong," at least in conventional scientific terms (Barry and Elith, 2006; Berteaux and others, 2006; Elith and Leathwick, 2009; Jackson and others, 2009). Variables that had major effects and were retained in our best statistical models supported the effect hypothesized in our conceptual models. The effects embodied by variables that were not retained in any model were not necessarily rejected, but rather provisionally relegated to the category of minor, at least at the scale of delineating and determining distributions.

Logic and explanation - None of the variables that we used in our statistical models directly measured ecological processes or states that, in turn, directly affected vital demographic processes. In a proximal sense, species live or die on the basis of physiological function, including thermoregulation, metabolism, and essential chemical and other reactions. These functions are sustained in turn by ingestion of essential nutrients and the metabolism of those nutrients to form adipose or other reserves. Physiological homeostasis also is sustained by avoiding physical damage, whether by predators or any other injurious agent. But we had no means of measuring any of these individual-specific phenomena in a spatially-explicit manner at the scales we were using, and in a way that could be projected into the future.

Put another way, all of the variables that we used in our statistical models were surrogates for effects operating conceptually nearer to the vital processes that, in reality, determined whether a species occupied or otherwise survived in a given $16-\mathrm{km}^{2}$ piece of ground. We carefully identified proximal vital processes, and back-tracked to measures that we could adequately explain within our models (fig. 1 on p. 5; fig. 2 on p. 8). Importantly, these conceptually more distant measures were thus related in an interpretable way to a proximal vital process. Our conceptual models allowed us to explicitly track how each variable that entered into a statistical model related to ultimate vital rates through intervening distinguishable ecological processes. This provided a basis for identifying plausible candidate explanatory variables and interpreting statistical models at all stages of development. 
We produced two conceptual models for each species-an initial model that informed selection of candidate variables for statistical models and a concluding conceptual model that integrated the results of our statistical analyses. This concluding conceptual model resulted from parsing, pruning, and otherwise refining our original conceptual model. Effects that were not supported by our quantitative results were removed from the conceptual models. Effects that were strongly supported were given amplified importance through the graphic form of enlarging the arrows denoting effects (see "Winter ppt" in figs. 1-2). These revisions of our original models represented an essential aspect of scientific practice that entails the modification of original hypotheses — or informed speculations about how the world might work — in light of new evidence (Hilborn and Mangel, 1997; Burnham and Anderson, 2002). Our models constituted new evidence, and our final conceptual models represented our revised understanding of how a given species distribution was determined based on the results of this project.

\section{Uncertainty}

Uncertainty entered into our analyses in many ways, and at virtually all steps of the process. Without being exhaustive, there was uncertainty about the match between our species observation data and the "true" current distribution (and, throughout, we will tacitly insert quotations around "true" given the conceptual and philosophical ambiguity of this concept). Likewise, there was uncertainty in the match between our explanatory measures and the true underlying environment. There was uncertainty in the behavioral, genetic, and (related) taxonomic homogeneity of each species, with implications for the homogeneity of its response to the environment, including climate change (Parmesan, 2006). There was uncertainty in the effects of using different modeling methods, and choices of approach within modeling methods (Araújo and others, 2005; Elith and others, 2006; Pearson and others, 2006)_for one, the difference between results from Maxent and logistic regression and how spatial autocorrelation was or was not dealt with in each model. There also was uncertainty regarding the sufficiency of our candidate explanatory variables, and the resulting specification of models based simply on which variables were or were not considered (Burnham and Anderson, 2002). There was uncertainty in how the modeled explanatory variables related in concept to underlying ecologic and demographic phenomena. There was also uncertainty in the projected future climate based on a wide range of variation and uncertainty in each statisticallydownscaled global circulation model (GCM).

This litany of uncertainty could be construed as cause for undue caution. However, all exercises in explanation and projection are affected by a similar suite. We conscientiously dealt with these uncertainties as we were able. Our first task was to simply recognize each uncertainty, its nature, and its source. We were then in a position to determine how best to deal with uncertainty in the GCM models. Some uncertainties were beset by imponderables. For example, we were never in a position to determine whether we had identified the "true" set of candidate variables for explaining a species distribution (Burnham and Anderson, 2002). This was in the category of not knowing what we did not know. On the other hand, there were numerous opportunities for us to either reduce or clarify uncertainty, either in concept or by explicit quantitative means. 
Perhaps the most straight-forward means we used to clarify uncertainty was in the match of our data to our models. There are numerous metrics for assessing model adequacy, including "confusion" matrices (that is, calculated percentages of false negatives, false positives, true negatives, and true positives generated by a given model), and assessments of predictive signal, including area under the Receiver Operating Characteristic (ROC) curve (Fielding and Bell, 1997; Guisan and Zimmermann, 2000). We used both of these measures. We also used a subset of the data withheld from developing any given model to test it - the difference between "training" data and "test" data (Muñoz and Felicisimo, 2004). None of the methods constituted a strong test of our models, but they nonetheless were a relatively unambiguous means of assessing how well our different models described and projected existing animal distribution data.

We relied primarily on sensitivity analysis to quantify the consequences of different choices regarding method or approach. Sensitivity analysis simply asks the question: What would have been the results doing something one way versus another (Saltelli and others, 2008)? In each case we had decided on a particular path to take, with consequences for all that followed. But sensitivity analysis allowed us to document the consequences at any given juncture. A sampling of choices includes whether to use logistic regression or Maxent, or what threshold to apply to projected distribution probabilities to best develop a binary range map. Sensitivity analysis does not support definitive conclusions regarding the "best" course of action, but it did allow us to track the consequences of choices that we did make.

We dealt with uncertainty in climate projections, first, by selecting GCMs that performed well in our region and, second, by identifying spatial areas of agreement and disagreement between specific GCM projections. We relied on a previous analysis of GCM performance (Garfin and others, 2010) to identify 14 out of 22 GCMs that showed the best agreement in terms of precipitation seasonality of the western United States, with particular attention to the summer-fall monsoon. We then selected 5 of those top 14 models that were either statistically the best performers, or captured the range of variation in projected climates, in terms of wet-dry and coolerhotter extremes. We projected future species ranges by running our models of current range on each of the six climate projections (one each for the 5 models, plus a sixth representing an aggregate of all 22 GCMs - our "ensemble" projection). Once that was done, we then looked for areas of agreement among the six projections, calculated spatially in terms of the number of GCMs that were in agreement. The best case occurred where all six models agreed about whether a species would be present or not. Although we will never know the true future until it happens, we think this reckoning of uncertainty among GCMs provides a robust basis for reaching conclusions about future animal distribution patterns.

Finally, we relied heavily on conceptual models and our understanding of prior ecological research to reduce uncertainty in both model specification and interpretation. This approach using conceptual models allowed us to identify candidate variables that were highly plausible and linked in logical and known ways to vital underlying ecological and demographic processes. The conceptual models also allowed us to identify factors that we hypothesized were important, but for which we could not identify any operational surrogates for entry into statistical models. Some of these factors included specific predators or diseases. Even though we were not able to quantify the effects of these factors, we at least knew what was not included, which, when used for interpretation, reduced the overall uncertainty of our models and their projections. 


\section{Insert 2: The Southwestern NCCWSC Advisory Team Development}

\section{Pre-Advisory Team Efforts}

Prior to constituting the NCCWSC project advisory team (AT), input on project design was solicited from a wide range of southwestern managers and stakeholders who elected to participate in a workshop held on October 5, 2009. A brief description of the stakeholder engagement process follows, featuring workshops and meetings specifically designed to elicit input.

October 5, 2009, Inaugural stakeholder workshop, High Country Conference Center, Flagstaff, Arizona - This workshop was convened as part of the 10th Biennial Conference of Research on the Colorado Plateau, and designed to capitalize on the presence of a large number of people potentially interested in this project and its products. Participation was solicited, and an invitation extended to all who were interested. Workshop topics included: (1) a NCCWSC project overview; (2) developing criteria for selecting species to model; (3) candidate species; (4) considerations and constraints affecting species distribution modeling; and (5) sources of species distribution data.

October 2009-March 2010_Following the October 2009 workshop, input was solicited by e-mail from workshop participants regarding: (1) Advisory Team (AT) nominations; (2) criteria for species selection; (3) prioritization of prospective focal species identified during the 2009 workshop; and (4) additional suggested species. Five AT respondents prioritized the distributed species list, and four AT respondents offered comments regarding additional candidates. We initially considered modeling mammal species distributions, but decided during these early deliberations not to model this taxonomic group. We considered data availability and reliability to be problematic, and some of the recommended species (for example, pronghorn [Antilocapra americana] and Arizona gray squirrel [Sciurus arizonensis]) exhibited distributions that were either too restricted to be reliably modeled, or were artifacts of historic anthropogenic influences. We excluded most imperiled or critically imperiled wildlife species for similar reasons, despite the continued advocacy of some stakeholders that such species be included.

\section{Advisory Team Efforts}

The southwestern NCCWSC project AT was formally constituted on 1 April 2010, after a 6 month nomination and solicitation process. An additional three members were added on September 7, 2010. The full AT consisted of nine members representing federal and state bureaus as well as non-governmental organizations. The U.S. Fish and Wildlife Service (FWS), National Park Service (NPS), U.S. Forest Service (FS), Bureau of Land Management (BLM), Arizona Game and Fish Department, The Nature Conservancy, Sky Island Alliance, and Center for Biological Diversity were organizations represented by the AT (table 2.1). 
Table 2.1. The selection process and final membership of the southwestern National Climate Change and Wildlife Science Center Advisory Team.

- Over 20 nominations received from a wide range of interests with the goal of establishing a team composed of:

o Three representatives from federal resource management agencies or tribal governments

0 One to two representatives from state wildlife agencies

o Two representatives from academic or science institutions

o Two representatives from non-governmental organizations (NGOs)

- Upon review of nominations, interviews and reference checks, the research team selected the Advisory Team member as follows:

o Federal:

- Lisa Thomas, National Park Service, Southern Colorado Plateau I\&M Ecologist and Network Manager

- Karl Ford PhD., BLM National Operations Center, Project Leader for Rapid Ecoregional Assessments of the Colorado Plateau and Sonoran Desert; climate change science information

- Bill Noble, U.S. Forest Service, Wildlife Biologist, Four Forests Restoration Initiative

- Brenda Smith, U.S. Fish and Wildlife Service, Northern Arizona Field Office Director

o State:

- Brian Wakeling, Arizona Game and Fish, Assistant Director for Game Species Management

o Academic (also State):

- Laura Huenneke PhD., Vice President for Research, Northern Arizona University

o NGOs:

- Marcos Robles PhD., Ecologist for Climate Change, The Nature Conservancy

- Taylor McKinnon PhD., Conservation Biologist, Center for Biological Diversity

- Louise Misztal, GIS specialist and Ecologist, Sky Islands Alliance

Operations of the AT were governed by a set of guidelines outlining roles and responsibilities that were adopted at the first AT meeting (table 2.2). 
Table 2.2. U.S. Geological Survey Southwest Biological Science Center NCCWSC Project - Projecting Climate Impacts on Southwestern Wildlife - Advisory Team Guidelines

\section{U.S. Geological Survey Southwest Biological Science Center NCCWSC Project - Projecting Climate Impacts on Southwestern Wildlife Advisory Team Guidelines}

PURPOSE: The purpose of this document is to define the roles, responsibilities, operating principles, and operations for the Advisory Team associated with the U.S. Geological Survey National Climate Change and Wildlife Science Center (NCCWSC) project entitled "Projecting climate impacts on wildlife of the arid Southwest at regional and local scales using downscaled climate models," Lead P.I. Dr. Charles van Riper (now referenced as "Projecting Climate Impacts on Southwestern Wildlife"). These guidelines are intended to provide clarity in order to facilitate effective and efficient activities and communications among the Advisory Team (AT) and the Research Team (RT).

\section{OBJECTIVES OF TEAM:}

- To foster communication and collaboration between stakeholders and the U.S. Geological Survey (USGS) staff and research collaborators involved with this project.

- Through two-way communication, support the NCCWS Center and project goal of providing scientific and technical information to help natural resource managers cope with a changing climate.

- To assure that the project is focused on key manager and stakeholder priorities.

- To deliver results and information that is understandable and useful for managers and stakeholders.

- To promote opportunities for related collaborations in management and research through a variety of means such as information exchange, data sharing, leveraging activities and complementary research and monitoring.

- To build common goals and organizational "buy-in" for this project as a cornerstone for climate change research and adaptive resource management in the southwest.

\section{MEMBER ROLES AND RESPONSIBILITIES}

- Promote ongoing dialog and two-way communication by 1) representing and communicating their organization's perspectives and 2) keeping their organization informed about and engaged in the project.

- Inform the project team about manager and stakeholder needs and priorities.

- Advise the project team about focal species selection and prioritization.

- Identify data sources and facilitate data sharing and access in support of the project.

- Advise the project team about how to develop and deliver project results to maximize their utility for managers and stakeholders (e.g. technology transfer and decision support tools).

- Provide overall feedback to the RT and USGS on the project and other climate change research needs and priorities.

- Identify and promote opportunities for collaborations relevant to this project and climate change research and adaptive resource management in the southwest. 
III. OPERATING PRINCIPLES

A. USGS Leadership and Liaison: The primary USGS liaison for the AT is Kate Kitchell, Module II leader and SBSC Acting Center Director. The liaison is responsible for coordinating, facilitating, and assuring support for the AT; assuring follow-through on AT input; and responsiveness from the RT to the AT. Individual interactions between AT and RT members are welcome at any time throughout the project process.

B. Advisory Team Leadership: The Advisory Team may choose to select a team leader who may serve as the primary coordinator and spokesperson for the group. This leader could also take on facilitation roles carried out by the USGS Liaison and subsequently incorporated into these guidelines.

C. Decision-making: The AT will make decisions or recommendations to the USGS by consensus. They may choose to establish further decision-making procedures through a consensus process.

D. Record keeping and reporting: USGS will be responsible for keeping and distributing notes from all meetings and conference calls. Within one week of meetings/calls, notes will be circulated in draft to Advisory and RT members for review and revision prior to final distribution. Notes will be posted on the USGS SBSC website and USGS NCCWSC website.

E. Confidentiality of unpublished/preliminary data and results: Unpublished and preliminary information about the project will be shared with AT members in order to facilitate project goals. However, in accordance with USGS policy, such information is not available for public release until it has undergone full quality control, peer review, and publication. Therefore, AT members are expected to maintain confidentiality of this information. Release or distribution of selected information may be allowed on a case-bycase basis upon request to and approval by the USGS Liaison and Project Lead PI (van Riper).

F. Frequency of meetings and conference calls: The AT will meet no more than 3 times per calendar year. Each meeting will be no more than 2 days total (including travel) unless requested by a consensus of AT members. Conference calls may be scheduled between meetings in order to accomplish AT objectives. Meetings will be scheduled with a minimum of 6 weeks' notice in order to maximize participation.

G. Outreach and communication: Outreach products will be developed and distributed initially by USGS and further distributed with the assistance of AT members.

Recommendations from the AT for outreach and communication actions and products are welcome and encouraged.

\section{COMPOSITION MEMBERSHIP}

The AT membership is composed of a minimum of 8 members representing federal, state, academic/research, and non-governmental organizations who bring technical expertise, diverse perspectives, geographic representation of the study region, and demonstrated abilities to work in a collaborative context. Up to 3 additional members may be added to facilitate project goals. Recommendations for additional members and rationale may be provided to the USGS Liaison at any time during the course of the project. These will be evaluated and vetted with the AT and RT to meet project goals. 


\section{FUNDING FOR ADVISORY TEAM ACTIVITIES}

All costs and expenses associated with the AT will be covered by the USGS, subject to the approval of the USGS liaison. USGS will reimburse AT members for said expenses (contact Serena Mankiller smankiller@usgs.gov).

\section{TERM}

This Advisory Team will remain in effect through the duration of this project and the public release of project primary results and products. Expected sunset date is June 2012.

\section{REVIEW AND REVISION OF GUIDELINES}

These guidelines may be reviewed in response to substantive issues or needs raised by AT members or USGS. Revisions would be developed and vetted with the AT and RT, and implemented upon consensus among AT members.

The AT met on five different occasions to review the southwestern NCCWSC project and to offer feedback.

April 1, 2010, AT meeting, BLM National Training Center, Phoenix, Arizona-This meeting inaugurated the AT and established its guidelines. Agenda topics included: (1) introduction of the AT members; (2) consensus on and clarification of AT guidelines; (3) project overview and design; and (4) solicitation of input from the AT on project focus and objectives; selection of focal species; data sources and data access; products and information transfer; and communications and potential collaborations (table 2.3).

Table 2.3. April 1, 2010, AT meeting at the BLM National Training Center, Phoenix, Arizona.

\section{USGS - Advisory Team Meeting \\ NCCWSC Project - Projecting Climate Impacts on Southwestern Wildlife Location - BLM National Training Center in Phoenix April 1, 2010; Time: 9:30-4:00 - (working lunch)}

Facilitator - Kate Kitchell and Charles van Riper III; Note taker - Serena Mankiller

Meeting Objectives:

1. Become acquainted with the Advisory Team Members and their respective activities and interests related to this project.

2. Clarify roles, responsibilities, and operating principles for Advisory Team - (hand out)

3. Learn about purpose, objectives, methods, data, progress, and outcomes of the project

4. Initiate process to seek input from the Advisory Team on the following (including, but not limited to):

- Project focus and objectives

- Focal species

- Available data sources and access to the data

- Project outputs and science transfer

- Opportunities for collaborations and communications 
Meeting Agenda:

9:30 - 9:45 Welcome, introductions, agenda review - Kate

9:45 - 10:00 Update on USGS activities related to NCCWSC (LCCs, CSCs) - Kate \& Charles

10:00 - 11:15 Advisory Team member introductions - summary reports of relevant activities (10 Minutes each max.)

11:15 - 11:45 Discussion of Advisory Team guidelines (see advance material)

11:45 - 12:15 Lunch Break (continue with working lunch)

12:15 - 1:45 Comprehensive project report

(Purpose, objectives, methods, data, progress, outcomes)

- Overview \& Introduction (10 min.)

- Module I: climate-plant modeling (30 min.)

- Module III: habitat \& wildlife modeling (30 min.)

- Module IV: data and web-based products (20 min.)

1:45 - 2:00 Break

2:00 - 3:30 Discussion and input from the advisory team about:

- Overall project direction, objectives, and relevance (20 min.)

o What are the priority issues, concerns and questions for stakeholders related to climate change and wildlife?

o How can this project be developed and implemented to respond to these needs?

- Methods (Modules I \& III) (10 min.)

- Focal species - criteria, additions, deletions, adjustments? (15 min.)

- Data availability and sharing (15 min.)

o What information and data do you know of that would benefit this project?

o How can it be accessed and shared?

o What limitations or constraints need to be considered?

- Products \& outputs: making research results useful and relevant for managers and partners (20 min.)

o What do managers need to assist them?

o What formats (e.g. web, fact sheets, reports, decision trees) are most useful?

o Do the types of outputs we envision seem useful? If not, how should we adjust?

- Recommendations on outreach and communications materials (e.g. fact sheet) (5 min.)

- Other (5 min.)

3:30 - 4:00 Action items, next steps \& feedback on meeting - Kate

- Summarize

- Reimbursement reminder

- Next meeting/call

- Notes 
September 7-8, 2010, $2^{\text {nd }}$ AT meeting, USFS Rocky Mountain Research Station, Flagstaff, Arizona - The agenda of this meeting included: (1) introduction of the final AT members; (2) project overview provided by scientists; (3) update on project progress, including the results of prototype models for pinyon jay, Virginia’s warbler, and Arizona black rattlesnake; and (4) solicitation of AT input on methods for representing and displaying uncertainty; modeling methods for plant and animal distributions; a finalized list of focal species; and the form of products and the methods for presenting them. Of note, the AT clarified at this meeting that we would prefer if the southwestern NCCWSC model fewer species well rather than do many species poorly. We also discussed the possibility of modeling vegetation structure, which we decided was too problematic, especially when tasked with projecting changes in vegetation structure under future climates.

June 20-21, 2011, $3^{\text {rd }}$ AT meeting, USGS Flagstaff Science Center, Flagstaff, ArizonaThe agenda of the third AT meeting included: (1) a review of the project design and related considerations; (2) an update on progress; (3) final agreement on species to be modeled (see below); (4) data and product delivery; and (5) design and performance of the project website. This meeting offered the AT its first opportunity to interact with the project website and offer explicit feedback on the basis of hands-on use. All participants concluded at this meeting that there was a need to add a bird species associated with higher-elevation mixed conifer forests, which led to the addition and inclusion of Williamson's sapsucker.

March6-7, 2011, Final AT meeting, Northern Arizona University, Applied Research \& Development Building, Flagstaff, Arizona-At this final meeting we presented near-final results of the project to the AT. The AT provided feedback on models, overall results, form of project outputs, potential uses by managers, website features, and website navigation. 


\section{Insert 3: Bird and Reptile Distribution Data}

\section{Bird Distribution Data}

We acquired and processed three types of bird location data: (1) presence only; (2) presence and absence; and, (3) polygonal range maps. Species presence and absence were acquired from the Avian Knowledge Network (AKN) website (Avian Knowledge Network, http://www.avianknowledge.net). The AKN is an organization that assembles locational observations of birds from a wide range of sources. The assembled data come from bird monitoring, bird banding, and broad-scale citizen based bird surveillance programs.

We acquired presence data by species for the period 1990-July 2009, for the entire United States. We first imported these data into Microsoft Access ${ }^{\circledR}$ databases from downloaded ASCII text files. Once imported, these data were manipulated in Access ${ }^{\circledR}$ to remove unwanted attributes and records identified on the basis of project specifics. We then converted the presence databases into Environmental Systems Research Institute (ESRI) ArcGIS ${ }^{\circledR}$ layers. We then analyzed the GIS layers to remove records such as those that were outside project study area, from unwanted collections, and outside the species breeding dates. Birds of North America accounts (Dobbs and others, 1997; Barlow and others, 1999; Olson and Martin, 1999; Reynolds and others, 1999; Kingery and Ghalambor, 2001; Balda, 2002; Johnson and others, 2002) were used to estimate breeding season for each bird species (table 3.1).

Table 3.1 Breeding season of each bird species selected for National Climate Change and Wildlife Science Center projecting of climate impacts on southwest wildlife.

\begin{tabular}{ll}
\hline \multicolumn{1}{c}{ Bird species } & \multicolumn{1}{c}{ Breeding season } \\
\hline Black-throated sparrow & March 15 - August 31 \\
Gray vireo & April 15 - August 15 \\
Pinyon jay & February 1 - July 15 \\
Pygmy nuthatch & March 15 - August 15 \\
Sage thrasher & April 1 - August 15 \\
Virginia’s warbler & May 1 - July 31 \\
Williamson's sapsucker & April 15 - July 31 \\
\hline
\end{tabular}

We acquired and processed absence observation data similarly to the presence observations, although the presence-absence data had to be acquired as sample events. The sample event data included records for all species in the United States from 1990 to July 2009. Sample event data were all analyzed within ArcGIS ${ }^{\circledR}$ to produce absence observation events for each species.

Nature Serve collects, manages, and disseminates detailed local information on plants, animals, and ecosystems. We acquired species range maps from the Nature Serve website (Nature Serve, $h t t p: / / w w w . n a t u r e s e r v e . o r g / e x p l o r e r /)$. Range maps were gathered by taxonomic family and extracted as ESRI shapefiles for each desired species. We analyzed the shapefiles within ArcGIS ${ }^{\circledR}$ to remove all but each species breeding range. We further used ArcGIS ${ }^{\circledR}$ to generate 1 degree buffers around breeding range polygon(s), and then used these buffered ranges to clip out all observations of the corresponding species that fell outside our study area. All three data types (presence and absence observation events, and range maps) were delivered for analysis in shapefile format with a standard spatial reference of Geographic Coordinate System, World Geodetic System (1972). 


\section{Reptile Distribution Data}

Reptile distribution data are generally less readily available than are data about birds. Nevertheless, we compiled 31,788 occurrence records of five selected taxa of reptiles from a variety of sources, including natural history museums, inventory and monitoring programs, and other research databases. We obtained the majority of records from the HerpNET data portal (HerpNET, http://www.herpnet.org) and Global Biodiversity Information Facility (GBIF; Accessed through GBIF Data Portal, http://data.gbif.org), as well as National Park Service Inventory and Monitoring Network databases (Northern Colorado Plateau, Southern Colorado Plateau, Sonoran, Chihuahuan, and Mojave; Persons and Nowak, 2006a, 2006b; Persons and others, 2006; Persons and Nowak, 2007). Other sources of data included Natural Heritage programs, studies conducted under scientific collecting permits obtained from state wildlife agencies, and individual research programs or books in preparation, for which we directly contacted authors and investigators.

Records of occurrence for our selected taxa in the Western United States included data collected between 1852 and 2010, although the majority of records (58 percent) were obtained after 1980. We were not able to confirm the taxonomic determination of each specimen or observation but we did scrutinize individual data points that we deemed suspect because of their geographic position and excluded such uncertain data from analyses. Because much of the location information associated with obtained data was only descriptive (that is, not geo-referenced), we assigned geographic coordinates either automatically through specialized programs (GEOLocate ver. 3.21; Rios and Bart, 2010) or manually by finding the location using Google Earth ${ }^{\mathrm{TM}}$ (Google Inc., Mountain View, California) and other resources within a geographical information system (ArcGIS ${ }^{\circledR}$ ver. 10, ESRI Inc., Redlands, California). In cases where coordinates were generated by software (unsupervised), we reviewed the correspondence of individual sets of coordinates to the locality description.

We reduced the number of records to one per grid cell (approximately $16 \mathrm{~km}^{2}$ ) to minimize sampling bias, which is especially important for correlative modeling (Phillips and others, 2009). We registered all georeferenced point range data for reptiles by cells that were used for our spatial modeling. Once registered, each grid cell containing one or more presence locations constituted our record of presences for individual species. This process substantially reduced the number of presence observations used for spatial modeling. In the case of reptiles, the original 23,954 georeferenced records were reduced to 5,087 grid cells, or points, representing the presence of five different taxa (fig. 3.1). 


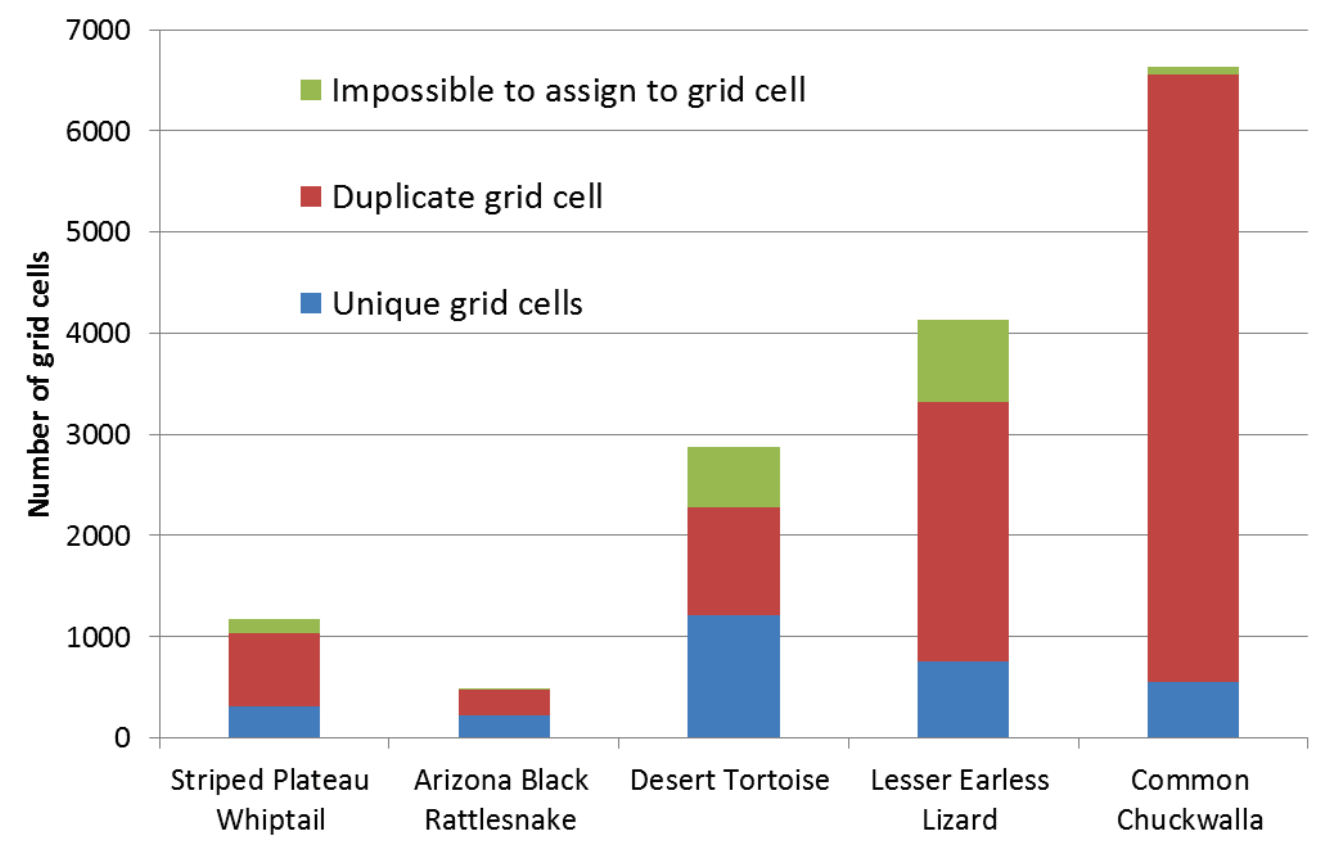

Figure 3.1 Graph showing summary of occurrence data compiled for reptiles, expressed as unique grid cells that match the environmental data used for modeling distribution.

The number of cells where presence was documented varied from about 200 to about 3,000 for individual species, which is considered sufficient for reliably modeling species distributions using logistic regression and Maxent (Guisan and Zimmermann, 2000; Kadmon and others, 2003; Wicz and others, 2008). 


\section{Insert 4: Explanatory Variables}

We identified candidate explanatory variables on the basis of several key criteria. These variables needed to be represented by digital spatial data that encompassed the entire extent of not only the Southwestern United States focal area, but also the area into which species might expand, in most cases comprising the entire Western United Sates. The variables also had to have uniform meaning relative to its referent classes throughout this extent. More important, we had to be able to project future spatial configurations of our explanatory variables.

These considerations debarred using many databases related to vegetation structure and composition, such as GAP or remote-sensing based estimates of vegetation cover and density. We did use the distributions of select plant species as explanatory variables, but only because our modeling of animal species ranges were incorporated into the results of another major undertaking of our larger project that was devoted to modeling and projecting plant species ranges (Cole and others, 2008; Garfin and others, 2010). Features that we assumed would be static, at least for 99 years, were not constrained to the need of being projected. These variables included measures of geology, geomorphology, soils, and solar insolation.

Climate variables (temperature and precipitation)_Climate was the key factor and foundation of our models, and we obtained climate data from the PRISM (Parameter-elevation Regressions on Independent Slopes Model) climate dataset (PRISM Climate Group, Oregon State University, http://prism.oregonstate.edu, accessed September 26, 2013). PRISM's average maximum and minimum monthly temperatures were averaged together to calculate monthly means that corresponded with the mean monthly temperatures provided in the Intergovernmental Panel on Climate Change (IPCC) AR4 GCM simulation results. We obtained IPCC AR4 GCM results from the World Climate Research Programme's (WCRP) Coupled Model Intercomparison Project phase 3 (CMIP3) multi-model dataset (Meehl and others, 2007; Solomon and others, 2007). Details on the models and their configurations are available at http://www-pcmdi.llnl.gov (Lawrence Livermore National Laboratory, Program for Climate Model Diagnosis and Intercomparison, accessed September 11, 2013, at http://www-pcmdi.llnl.gov).

We analyzed the 22 IPCC models (48 simulations) incorporating the effects of estimated greenhouse gas and aerosol changes from the late 19th century through 1999, and then incorporated the IPCC Special Report on Emissions Scenarios (SRES) A1B scenario to 2100 (Intergovernmental Panel on Climate Change, 2000). Results for each GCM simulation were statistically downscaled to a 2.5-minute grid (approximately 4-km grid), as described by Garfin and others (2010). Each downscaled model was evaluated based on its ability to simulate precipitation seasonality in the western United States and on its accurate representation of a range of projected future climates for the southwest region (Garfin and others, 2010). Our focus was to examine the proximate climate response only in our region, and we did not examine GCM abilities to reproduce models such as tropical ocean circulation, Asian monsoon, or Arctic winds. We selected five different GCMs from the top 14 best performing models as a basis for climate projections, including the two that were top ranked (ukmo_hadgem1 and mpi_echam5) and three others that represented a spectrum of projected climates in terms of warmth and aridity (cnrm_cm3, csiro_mk3, and ncar_ccsm3). 
The following climate variables were specified as a candidate in at least one of our statistical models:

- Breeding season average temperature - The average of each bird species breeding season monthly average temperature, 1980-2009.

- Breeding season average maximum average temperatures \& average minimum average temperatures-The average of the maximum average breeding season monthly temperature, 1980-2009, and the average of the minimum average breeding season monthly temperature, 1980-2009.

- Breeding season total precipitation (PPT)_-The mean annual total precipitation for breeding season months, 1980-2009.

- Spring, summer, fall, and winter average maximum average temperatures \& average minimum average temperatures - The average of the maximum average monthly spring (March through May), summer (June through August), fall (September through November), and winter (December through February) temperatures, 1980-2009, and the average of the minimum average monthly spring, summer, fall, and winter temperatures, 1940 or 1980-2009.

- Spring, summer, fall, and winter total PPT-The mean of the yearly total spring (March through May), summer (June through August), fall (September through November), and winter (December through February) precipitation, 1940 or 1980-2009.

- Southwest winter total PPT-The mean of the yearly total November through March precipitation, 1940 or 1980-2009.

- Southwest spring total PPT-The mean of the yearly total May through June precipitation, 1940 or $1980-2009$.

- Southwest monsoon total PPT-The mean of the yearly total July through September precipitation, 1940 or 1980-2009.

- Monthly PPT - The average of monthly precipitation, 1940 or 1980-2009.

Insolation-Incoming solar radiation (insolation) is the primary energy that drives many of the Earth's physical and biological processes. On a global scale, variation in insolation results from the Earth's tilt and rotation on its axis and its revolution around the Sun. On a landscape scale, slope, aspect, elevation, and shadows create highly variable spatial and temporal insolation patterns (Dubayah and Rich, 1995). Insolation increases with steeper slope, more southerly aspect, and higher elevation (Barry and Chorley, 1976; Brady and Weil, 2002). This variability contributes to microclimate differences, including factors such as air and soil temperature regimes, evapotranspiration, snow melt patterns, soil moisture, and light available for photosynthesis. In the northern hemisphere, during the winter, insolation decreases with increasing latitude. During the summer this relationship reverses and insolation increases with latitude (Barry and Chorley, 1976). Topographic effects on insolation are most pronounced in the northern hemisphere during winter solstice, when the sun is at its nadir (Stiling, 1996).

We used ArcGIS ${ }^{\circledR}$ 9.3 Spatial Analyst Area solar radiation tool to develop two layers that quantified the amounts of solar radiation received on January 1 and May 1. Because the tool only allows one latitudinal input, a 90-meter digital elevation model (DEM) was clipped in slightly overlapping quarter decimal degree latitudinal bands. We ran the solar analyst tool for each band, and then mosaiced each together using the "blend" function. 
Geology and landform - Abiotic habitat variables are important habitat components for birds and reptiles, particularly during the overwinter (reptile denning) period, during the hot summer months, and during nesting and development of juveniles (Van Devender, 2002; Schofer, 2007; Ernst and Lovich, 2009; Nowak and Arundel, unpub. data, 2009). Volcanic formations and talus fields, boulders, caliche soils, and other outcrops provide important overwinter denning and summer sheltering habitat for reptiles, especially in high elevation habitats. We used the following variables to denote these potential effects:

- Terrain ruggedness index (TRI)_A statistical measure of how "rough" the landscape is (Riley and Malecki, 2001). An area with many mountains or canyons has high terrain ruggedness, whereas a flat plain has low terrain ruggedness. TRI was calculated at two spatial scales, 90-m and 4-km grid cells.

- Lithology -A dataset on surficial lithology classes for the conterminous United States was obtained from the U.S. Geological Survey Ecosystem Mapping Project (U.S. Geological Survey, GEOSS, http://rmgsc.cr.usgs.gov/ecosystems/usa.shtml\#SL). The layer classes were derived from the U.S. Geological Survey map "Surficial Materials in the conterminous United States", which was based on texture, internal structure, thickness, and environment of deposition or formation of materials. This original map was produced from a compilation of regional surficial and bedrock geology source maps using broadly defined common map units for the purpose of providing an overview of the existing data and knowledge. The dataset includes 18 lithology classes that typically control or influence the distribution of vegetation types.

- Rocktype-From: Schruben and others (Geology of the Conterminous United States at 1:2,500,000 Scale A Digital Representation of the 1974 P.B. King and H. M. Beikman Map). The Geologic Map of the United States is primarily a bedrock map, which depicts geologic materials present beneath the soil or relatively thin mantles of surficial deposits, not necessarily the surficial materials themselves. For example, the map does not depict the glacial deposits in the northern States, the widespread eolian deposits in the high plains, and the high-level gravels that mantle older Tertiary and pre-Tertiary units in much of the Atlantic and Gulf Coastal Plains.

- Landform-From: Manis and others (2001). Preclassification: An Ecologically Predictive Landform Model. Gap Analysis Program Bulletin No. 10, December 2001. USGS GAP Analysis Program. Moscow, Idaho. (U.S. Geological Survey, 1999, http://earth.gis.usu.edu/swgap/data/metadata/landform_albers.htm). We created this layer from 30-m DEMs that were resampled into a 90-m DEM and then partitioned into 115 slightly overlapping latitudinal strips. We ran the aml script developed by Manis and others (2001) for each strip, after which we merged and analyzed the output for artifacts. Once artifacts were removed, we extracted and added a water body class from resampled 30-m USGS Landfiredata.

Soils type and structure-Soil composition and texture play an important part in the nesting ecology of reptiles, particularly gravelly soils and sandy or friable soils. Soil moisture is particularly important in determining hatching success of egg-laying reptiles, as well as overwinter survival of juveniles. We used the following data to denote the effects of soils:

- Depth to lithic layer-From the Natural Resources Conservation Service (NRCS) U.S. general soils map (Soil Survey Staff, Natural Resources Conservation Service, United States Department of Agriculture, U.S. General Soil Map [STATSGO2]). 
- Drain index-We joined a drainage index table developed by the USDA Forest Service and Michigan State University (USDA, http://foresthealth.fs.usda.gov/portal [accessed 9/11/2013]) with the map unit key field of the U.S. General Soil Map (STATSGO2 http://websoilsurvey.nrcs.usda.gov [accessed 9/30/2013]).) to form a measure of the long-term wetness of a soil. The Drainage Index (DI) indicates the amount of water that a soil contains and is not meant to mimic the concept of "plant available water," which is mostly dependent upon soil texture. The DI only loosely (secondarily) takes soil texture into consideration. The main factors affecting DI are the depth to the water table, soil moisture regime and volume, and (lastly) texture. The DI is calculated from the soil taxonomic subgroup classification in the U.S. system of soil taxonomy, along with its textural family and slope class.

- Percent of sand, silt, and clay-We generated three soil texture layers, in the form of percentages of soil particle size classes (sand, silt, or clay) for the study area using the NRCS U.S. General Soils Map (U.S.D.A. http://websoilsurvey.nrcs.usda.gov [accessed 09/30/2013]). We used default settings of the NRCS Soil Data Viewer 5.2 tool in ArcGIS 9.2 to attribute the soil data map for percent sand, silt and clay. We used the majority function in $\operatorname{ArcGIS}^{\circledR} 9.3$ to convert the resulting polygon map to a 4-km grid.

Distribution of plant species - We utilized two different methods to develop presenceabsence maps of current distributions for plant species that were potentially important to birds and reptiles. Our use of methods depended on the spatial distribution of occurrence records. For plant species with sparse or patchily distributed occurrence data we used heads-up digitizing that used information on elevational distribution, occurrence by plant community types, and expert opinion. For species that had been systematically and intensely sampled, as in the Forest Inventory and Analysis (FIA) databases, we used ArcGIS ${ }^{\circledR} 9.3$ Geostatistical Analyst to interpolate presenceabsence range maps. We registered ranges to a $4-\mathrm{km}$ resolution grid using radial splines that encompassed an 8-12 cell neighborhood and a threshold of 0.10 .

In addition to FIA, data sources of plant presence and absences included the LANDFIRE Reference Database (2007), the Central Mojave field data (Thomas and others, 2002), the southwest ReGAP project (http://earth.gis.usu.edu/swgap/trainingsites.html [accessed 9/12/2013]), the participants of the Consortium of California Herbaria (http://ucjeps.berkeley.edu/consortium/, [accessed 9/12/2013]), the Global Biodiversity Information Facility (http://www.gbif.org, [accessed 9/12/2013]/), and the Southwest Environmental Information Network (SEINet http://swbiodiversity.org/seinet/projects/index.php, [accessed 9/12/2013]).

We used methods described in Cole and others (2011) to project the future distributions of plant species that were found to have explanatory power in the bird and reptile distribution models. Future distributions were based on models of current range, projected changes in climate, and the estimated migration rate of the affected plant species, for more information see Insert 5.

Densities of humans (Human Influence Index)—We obtained an index of human influence from the Wildlife Conservation Society (WCS) and the Center for International Earth Science Information Network (CIESIN) at Columbia University (Sanderson and others, 2002). The Human Influence Index was produced by overlaying data layers that represent the various factors presumed to exert an influence on ecosystems, such as human population distribution, urban areas, roads, navigable rivers, and agricultural land uses. The human "footprint" has been identified as an important covariate in the presence and persistence of several species of reptiles, with reductions in the extent and quality of habitat by human land use or other activities having caused significant declines in populations of desert tortoises (Berry and others, 2002; Tracy and others, 2004) and Arizona black rattlesnakes. 


\section{Insert 5: Modeling Plant Species Distributions}

We modeled plant species distributions after Cole and others (2008), based on the concept of climate limits (fig. 5.1).

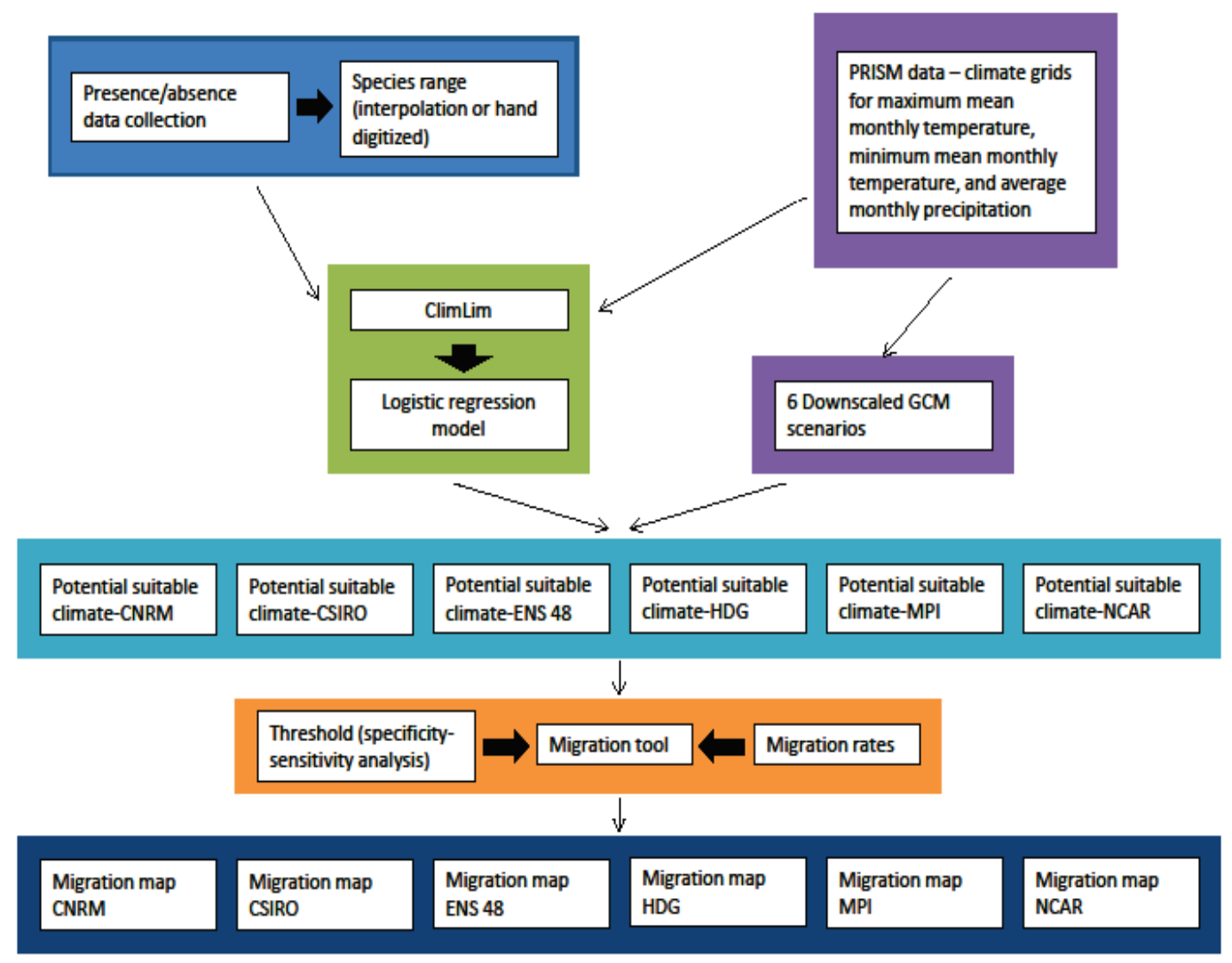

Figure 5.1. Conceptual model of the process used to create future plant species projections, including effects of migration rates, for plants used in modeling animal species ranges. 
Climatic limiters provide important insights into the ability of species to adapt to future climates. We used a method called ClimLim to infer climatic limits for a given species based on its documented current distribution. This method is similar to the approach described by Arundel (2005). We gathered presence and absence data for individual plants from various published sources, such as the Forest Inventory Analysis, and created ranges for each species either by interpolation or hand digitizing. The ClimLim program associates the 36 climate variables available from PRISM with species presence and absence points, calculates which variables are associated with the edges of the species current distributions, and ranks their importance. We used the climate variables identified as limiters by ClimLim as candidate explanatory variables in logistic regression models, and then applied the resulting logistic regression equations to the various GCM grids to project potential suitable climates, which corresponded with probabilities of species occurrences. We also applied the logistic regression models to the original PRISM climate data to project current potential distribution. In total, we estimated the current and future potential suitable climate for 50 dominant plant species (table 5.1) for the periods 2010-39, 2040-69, and 2070-99.

Plant migration rates were integrated into future projections for 17 of the 50 plant species included in the model, utilizing a migration rate of $50 \mathrm{~m} /$ year for long-lived "climax" species, and a rate of $500 \mathrm{~m} /$ year for early successional species (table 5.1). 
Table 5.1. Plants species for which current and future potential suitable climates were modeled. Migration estimates were made for a subset of the indicated species.

\begin{tabular}{|c|c|c|}
\hline Species & Common name & Migration preformed \\
\hline Juniperus deppeana & alligator juniper & $\mathrm{X}$ \\
\hline Juniperus monosperma & One-seed juniper & $\mathrm{X}$ \\
\hline Juniperus osteosperma & Utah juniper & $\mathrm{X}$ \\
\hline Juniperus scopulorum & Rocky Mountain juniper & $\mathrm{X}$ \\
\hline Abies concolor & white fir & $\mathrm{X}$ \\
\hline Abies lasiocarpa & subalpine for & $\mathrm{X}$ \\
\hline Abies lasiocarpa var. arizonica & corkbark fir & $\mathrm{X}$ \\
\hline Picea engelmannii & Engelmann spruce & $\mathrm{X}$ \\
\hline Picea pungens & blue spruce & $\mathrm{X}$ \\
\hline Pinus aristata & bristlecone pine & $\mathrm{X}$ \\
\hline Pinus edulis & pinyon pine & $\mathrm{X}$ \\
\hline Pinus flexilis & limber pine & $\mathrm{X}$ \\
\hline Pinus jeffreyi & Jeffrey pine & \\
\hline Pinus monophylla var. fallax & singleleaf pinyon & $\mathrm{X}$ \\
\hline Pinus monophylla var. monophylla & singleleaf pinyon & \\
\hline Pinus ponderosa & ponderosa pine & $\mathrm{X}$ \\
\hline Pinus strobiformis & southwestern white pine & $\mathrm{X}$ \\
\hline Pseudotsuga menziesii & Douglas spruce & $\mathrm{X}$ \\
\hline Rhus ovate & sugar sumac & \\
\hline Rhus trilobata & skunkbush & \\
\hline Baccharis pteronioides & yerba de pasmo & \\
\hline Encelia farinosa & brittlebush & \\
\hline Gutierrezia sarothrae & broom snakeweed & \\
\hline Tetradymia canescens & gray horsebrush & \\
\hline Carnegiea gigantea & saguaro & \\
\hline Salsola tragus & tumbleweed & \\
\hline Arctostaphylos pungens & pointleaf manzanita & \\
\hline Acacia greggii & Catclaw acacia & \\
\hline Robinia neomexicana & New Mexico locust & \\
\hline Quercus arizonica & Arizona white oak & \\
\hline Quercus emoryi & Emory oak & \\
\hline Quercus gambelii & Gambel oak & $\mathrm{X}$ \\
\hline Quercus turbinella & scrub oak & \\
\hline Garrya wrightii & wright silktassel & \\
\hline Ceanothus greggii & desert ceanothus & \\
\hline Cercocarpus ledifolius & curl-leaf mountain mahogany & \\
\hline Cercocarpus montanus & alderleaf mountain mahogany & \\
\hline Coleogyne ramosissima & blackbrush & \\
\hline Populus tremuloides & quaking aspen & \\
\hline Nolina microcarpa & beargrass & \\
\hline Achnatherum hymenoides & Indian ricegrass & \\
\hline Bouteloua eriopoda & black grama & \\
\hline Bouteloua gracilis & blue grama & \\
\hline Bromus rubens & foxtail brome & \\
\hline Bromus tectorum & cheatgrass & \\
\hline Centaurea diffusa & diffuse knapweed & \\
\hline Elymus elymoides & bottlebrush squirreltail & \\
\hline Muhlenbergia montana & mountain muhly & \\
\hline Pleuraphis jamesii & galleta & \\
\hline Poa fendleriana & muttongrass & \\
\hline
\end{tabular}


These estimates were used to create "buffers" around current ranges of a size determined by the migration rate and the duration of each time interval. We then intersected the buffer and the current range with the potential suitable climate for each time interval. The output represented the projected distribution for the next time interval. This process provided a coarse estimate of where the given species could no longer live (unsuitable); where the climate conditions were suitable but natural migration rates were not sufficient to keep pace with change (assisted migration); and where unsuitable habitat at a previous time interval became suitable again (recolonize). These estimates did not incorporate anomalous biotic as well as some abiotic factors that determine species migration. Potential adaptive strategies also were not accounted for by these models. Figure 5.2 shows a sample of the pinyon pine maps generated as the results of this project.
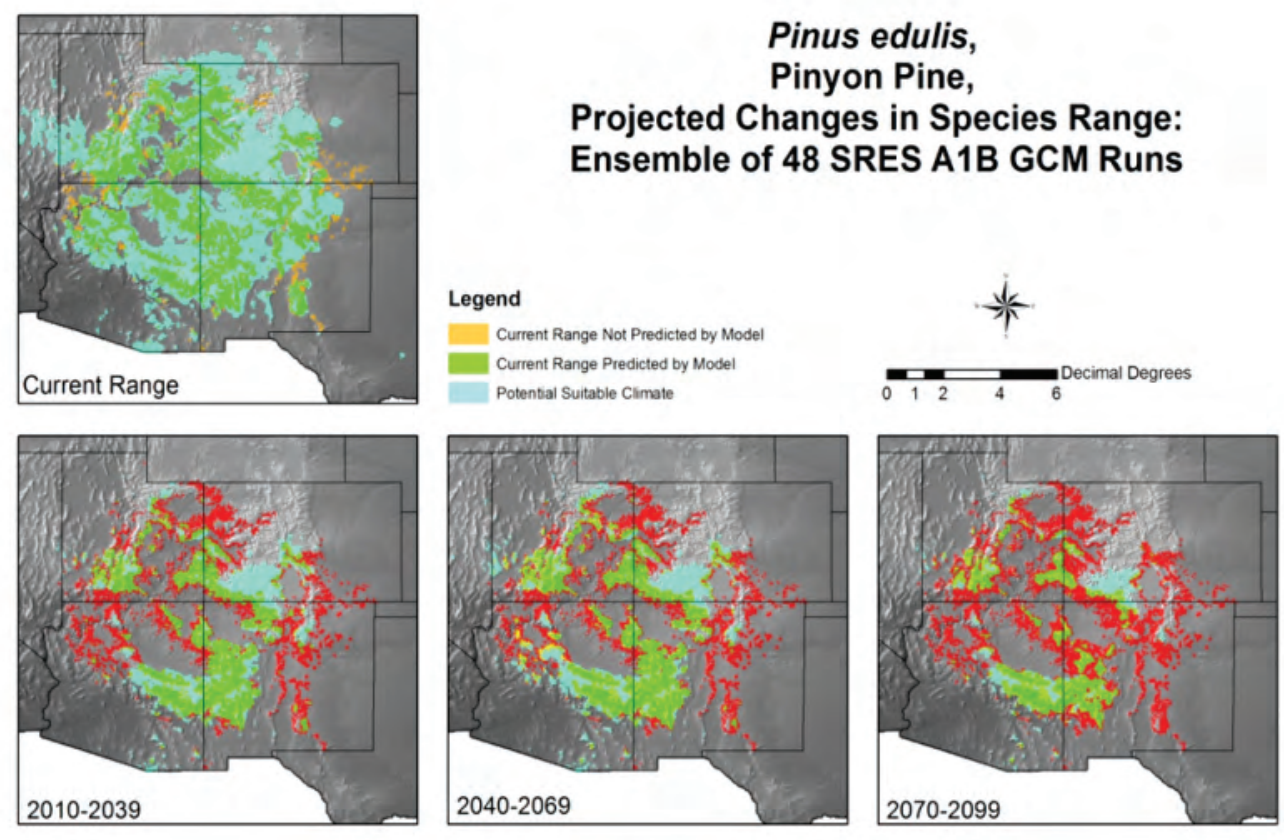

\section{Ensemble of 48 SRES A1B GCM Runs}

Pinus edulis,

Pinyon Pine,

Unsubable

$\square$ Sutable $\square$ Mgration $\square$ Recolonize

$\square$ Assisted Migration

Figure 5.2. Model-generated example showing projected changes in a plant species distribution incorporating the effects of migration for the three periods 2010-39, 2040-69, and 2070-99. The featured species is pinyon pine (Pinus edulis), which we used as part of the model to project future distributions of pinyon jay. Projections are based on the ensemble future warming scenario, which is the average of the results of the 22 global climate models developed by the Intergovernmental Panel on Climate Change Fourth Assessment Report (Solomon and others, 2007). 


\section{Insert 6: Modeling Bird Distributions}

Statistical design-We developed an environmental dataset for spatial modeling bird distributions by using a case-control sampling design (Keating and Cherry, 2004). Specifically, we compared a set of randomly selected presence locations with a set of absence locations, using 80 percent of presence-absence locations for model construction and 20 percent for model testing. Absence data were selected randomly from areas that had been searched between 1990 and 2009 and found to not contain a given bird species. Whenever a cell contained both presence and absence data, given that one year may contain the focal species and the next year not, we prioritized presence over absence. Thus, any cell between 1990 and 2009 that contained a presence record of a focal species was assigned a presence rating. Presence-absence observations were assigned to the center of the cell (centroid), thus all detections were at least $4 \mathrm{~km}$ apart from one another. For robust estimation of each parameter, we ensured that there were at least 10 presence observations per parameter in every candidate model (Peduzzi and others, 1996).

We initially conducted an intensive analysis of two bird species (pinyon jay and Virginia's warbler) to discern how spatial auto-correlation (Legendre, 1993) affects model parameters, and to ascertain how Maxent and logistic regression differ in predictive capabilities. Specifically, we hoped to find how birds and habitat correlate at multiple scales of analyses, and to build a crosswalk between model results obtained from Maxent and logistic regression. Although we could not conduct intensive modeling for every bird species, we hoped to gain greater understanding of our overall results through our seven intensively modeled subsets of bird species.

Spatially explicit modeling —We used binary logistic regression, considering both univariate and multivariate models, to identify environmental associations and to develop equations useful for spatially explicit (GIS-based) distribution models. Logistic regression is ideal for evaluating relationships between predictor variables and a species range because presence-absence data are binary (Keating and Cherry, 2004). We used Arc/Info ${ }^{\circledR}$ GRID (Environmental Systems Research Institute, 1992) to calculate and map the probability that a species would be present within $16-\mathrm{km}^{2}(4 \mathrm{~km} \times 4 \mathrm{~km})$ cells. We calculated the relative probability $(P)$ with the following equation:

$$
P=e^{g(x)} / 1+e^{g(x)}
$$

where :

$g(x) \quad$ is the linear combination of parameter estimates obtained from the logistic regression (Hosmer and Lemeshow, 1989). In equation 1, the relative suitability of an area is linked to the probability of breeding season occupancy based on the logistic regression under consideration. Each model assigned cells a probability between 0 and 99 percent.

$e \quad$ an exponential function, approximately equal to 2.718281828 . 
Multivariate model selection and fit-We only considered variables derived from our conceptual models for model development and verification, as opposed to using large datasets tied to automated forward or backward stepping routines and Akaike's Information Criterion (AIC) selection. We screened variables for collinearity by examining pairwise Pearson's correlation coefficients among all pairs of variables, then evaluated the significance of each covariate in our models with the G-statistic, which is analogous to the $\chi^{2}$ statistic, produced from backwards stepping and a log-likelihood ratio test (Hosmer and Lemeshow, 1989). We checked for linearity between the logit and continuous variables through the incorporation of quadratic and cubic higherorder terms). Given the importance of habitat suitability in our analyses, we relied upon area-underthe-curve (AUC; Egan, 1975) and a classification table (Story and Congalton, 1986) to determine the performance of each candidate model. We did not rely solely on AIC (Burnham and Anderson, 2002) in our selection process because it consistently supported very large and cumbersome models that were difficult to interpret and performed little or no better than far simpler models. For brevity sake, we only present models that achieved the highest classification accuracies and were ecologically interpretable.

Evaluation of included variables - We evaluated the relative contribution of variables included in each logistic regression model by the Wald $\chi^{2}$ statistic, which is proportional to the contribution of a variable to explaining variation in the response, and is conditional on the model. Model verification-Spatial accuracies of our logistic-regression models were assessed with an independent dataset (that is, withheld bird species presence locations not used in model development). Model accuracies depended upon a movable probability cutpoint used to delineate (extract) suitable versus unsuitable breeding locations (cells) from the probability grid. For our analyses, we selected probability cutpoints (thresholds) that roughly balanced commission and omission errors. Model accuracies were calculated as model sensitivity (1-omission error), specificity (1-commission), and overall accuracy (sensitivity + specificity/2). Presence locations that fell outside of a projected distribution were counted as an omission error (Story and Congalton, 1986), whereas cells that were predicted to be occupied but found to be empty were counted as a commission error. 


\section{Insert 7: Modeling Reptile Distributions}

Statistical design and spatially explicit modeling-All reptile models were fitted in Maxent by taking advantage of built-in functions for random seeds, background selection, cross-validation, and model averaging (Phillips and Dudík, 2008). Although choice of background data can have important effects on projections (VanDerWal and others, 2009), we used a random background set of data from the entire set of possible locations throughout western United States to serve as pseudo-absences. A large number of locations $(10,000)$ from a broad range of conditions was used to ensure good representation of all possible environments, which is important when models are to be projected into very different conditions, as would be the case with future climates (Elith and others, 2010). We debiased background samples by weighing samples according to variations in cell area because all covariate data for this study were unprojected. We then fitted models using five-fold cross-validation to estimate errors around fitted functions and to determine predictive performance using withheld data (Elith and others, 2010). In practice this meant that the algorithm randomly selected and withheld 20 percent of the cells containing presences for use in model testing for each "fold.” The remaining 80 percent of reptile species presences were used for model training.

Multivariable model selection-All variables that we identified as important in the conceptual models for each reptile taxon were initially included in a model, although we did not include any variables that would account for spatial patterns in the distributional data. For the most part we used default settings in Maxent for model development, but restricted variable specification to hinged, quadratic, and categorical features (in machine learning language, features are transformations of variables into functions). These features produce model projections similar to those based on generalized linear or additive models (Phillips and Dudík, 2008; Elith and others, 2010), which made the models produced by Maxent comparable to those developed for birds using logistic regression. We did not select for automatic examination of interacting variables because of the complexity of interpreting ad hoc interactions, nor did we select linear or threshold features because these tend to be redundant with hinge features (Elith and others, 2010). Default regularization parameters were selected for all models because we did not have data on the relative or absolute detectability of the different reptile species.

We examined correlations among all continuous variables by calculating the Pearson pairwise correlation coefficients using “ENM Tools” (Ecological Niche Modeling Tools software by Warren and others, 2010). However, we did not exclude correlated variables because the strength of correlations varied spatially and because analyses also have shown that Maxent is more stable to the effects of correlated variables compared to stepwise regression (Hastie and others, 2009). To choose whether models should include the effects of plant species distributions, we first calculated raw outputs from Maxent models to select the most parsimonious model based on AIC, $\mathrm{AIC}_{\mathrm{c}}$, and BIC (Burnham and Anderson, 2002; Warren and Seifert, 2011). Then, using the most parsimonious model, we calculated both models that included and excluded the effect of distribution of different plant species. 
Model and variable evaluation -We evaluated in several ways variables that were included in the final models, using the built-in jackknife test that quantifies the contribution of each variable to the model (expressed as percent and based on increase in gain; Phillips and others, 2006) as well as permutation importance (Phillips and Dudik, 2008). We then ran models excluding variables with less than a 5 percent contribution and examined differences in area under the curve (AUC) for training and test data. We used AUC of the receiver operating characteristic (ROC) as a thresholdindependent measure of model performance (Elith and others, 2006). We plotted ROC for all possible thresholds, with sensitivity (true positive rate) on the y-axis and 1-specificity (false positive rate) on the x-axis (Fawcett, 2003). We characterized the AUC performance of each model at all possible thresholds, summarized by a number ranging from 0 to 1 , where 1 indicates perfect model performance, 0.5 indicates the equivalent of a random process (presence and background not different), and less than 0.5 indicates performance worse than random (Phillips and others, 2006).

Projecting changes in ranges - Once adopted, we projected the final model of current conditions according to 15 different future scenarios (three different time periods and five different GCMs). In the case of Maxent, we applied the option to "fade by clamping" because we applied the models to future climates with unknown variable ranges. This option reduced predictions at each point by the difference between clamped and non-clamped output (Phillips and Dudík, 2008). Our model results are provided as the logistic model output. This allowed us to represent potential habitat in each cell as a scaled index (Phillips and Dudik, 2008) and, from that, calculate changes in projected habitats based on predefined output thresholds above which projections were considered to be suitable for the given species (Pearson and others, 2007). Although there are many ways to calculate these thresholds (Liu and others, 2005), the choice depends on the purpose of the model (Lobo and others, 2008). We calculated thresholds by equalizing sensitivity and specificity for training samples, assuming that such an approach equalized the risks of over- and under-specifying (Freeman and Moisen, 2008). We then calculated the percentage of habitats "gained" or "lost" by using model ensembles of five out of six models being concordant (>83 percent concordance) and compared statistics generated on area assuming either no dispersal or unlimited dispersal. 


\section{Insert 8: Data Storage and Delivery}

It was decided that the most reasonable repository for all of the data from this NCCWSC project would be at the Geospatial Research and Information Laboratory (GRAIL) site at Northern Arizona University (NAU). There were already a number of large data sets being managed by GRAIL, and the NCCWSC data would complement existing Colorado Plateau information. Moreover, we felt that access to data would be easier at a public state institution rather than through a federal agency. To this end, a computer server was purchased and dedicated solely at GRAIL for Southwest NCCWSC data storage.

Data delivery for this project was divided into two overlapping frameworks: (1) data delivery and archiving for NCCWSC project scientists; and, (2) data delivery and archiving of final products to all stakeholders, including DOI agency personnel, state and tribal agencies, and the public. In order to provide rapid and secure access to preliminary data and working datasets to project scientists, we used several tools, including ftp, ssh, and ESRI geodatabases. For final archiving and data delivery to stakeholders, we will use FGDC metadata and national metadata clearinghouses for documentation and discovery of data and websites, and a web mapping application for final delivery.

Our project ftp site is: ftp://grail1.bio.nau.edu/. This ftp site is being used to house both input data and preliminary model output. As of June 2012 there were 95 gigabytes (GB) of NCCWSC data stored on the ftp server. This ftp server now requires a login because of new security vulnerabilities within the ftp protocol. Final data products will be made available through public access websites.

Our metadata clearinghouse is: http://mprlsrvr1.bio.nau.edu/metadataexplorer/ We have now uploaded metadata for more than 50 datasets to the Geodata.gov (http://catalog.data.gov/dataset). We will continue to upload additional metadata as datasets are documented.

Much of the working data for the southwest NCCWSC project is stored in an ArcSDE ${ }^{\circledR}$ geodatabase and processed using ArcGIS ${ }^{\circledR}$ and customized scripts. The geodatabase for this project, housed within GRAIL at NAU, is approximately 30 GB and comprises 30 raster catalogs, each of which includes a few dozen raster datasets.

Several feature classes and custom tool boxes also are included in this NCCWSC geodatabase. In addition, there are multiple free-standing SQL databases and stored procedures which were used by the project programmer and GIS Analysts to format, select, and analyze various climate datasets (figs. 8.1, 8.2, 8.3). 


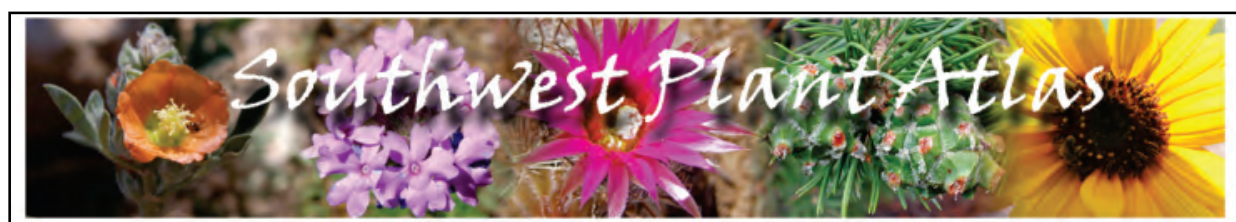

$A|B-| C|D| D|F| G|H| I|J| K|L| M|N| O|P-| Q-|R| S|T| U|V| W|x| Y \mid Z$



Figure 8.1. Screen capture showing home page of the Southwest Plant Atlas (Southwest Plant Atlas, http://www4.nau.edu/swplantatlas/endemic.html). This website contains the model output and explanatory material for the plant species distribution modeling effort. 


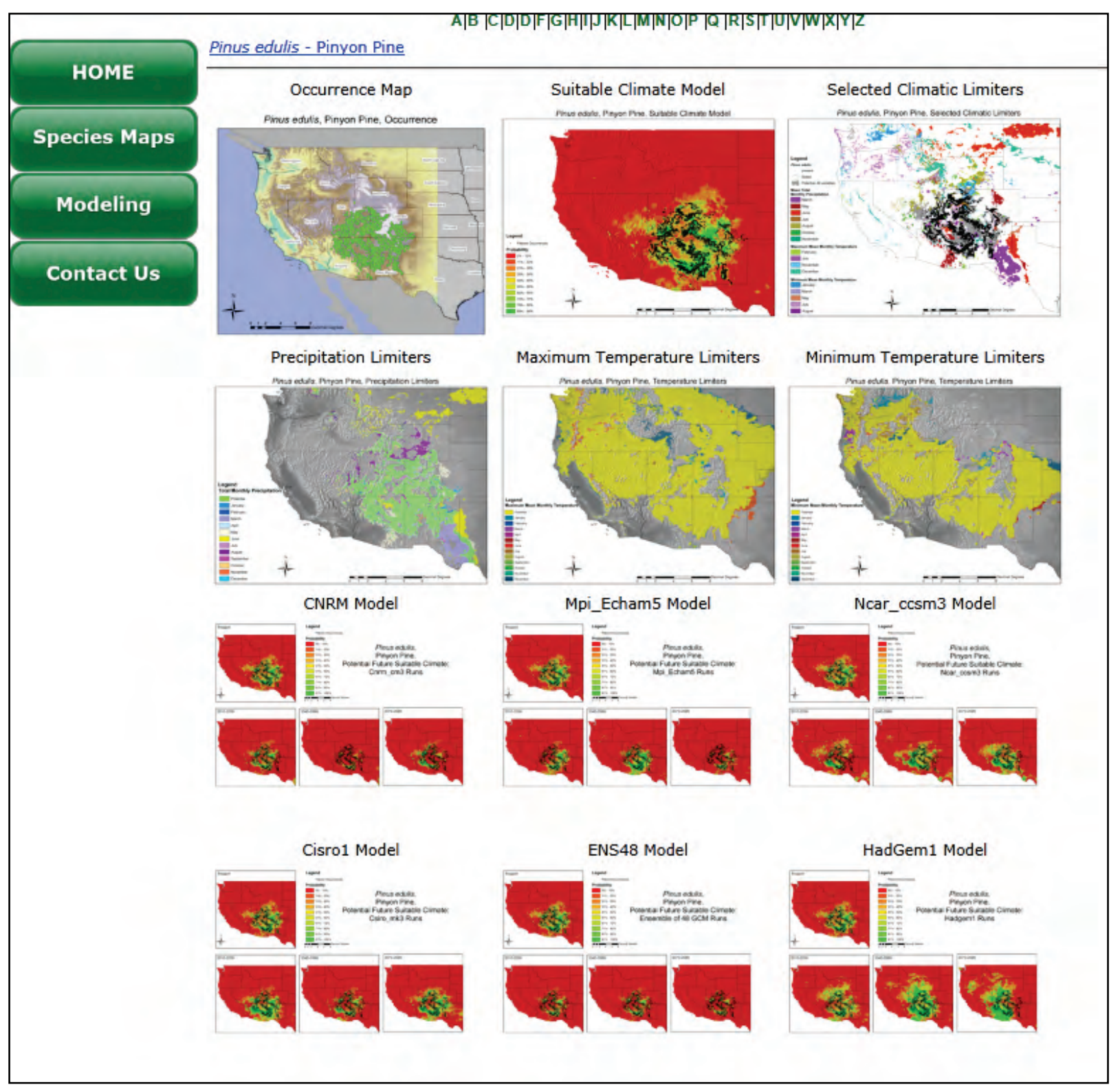

Figure 8.2. Screen capture of Southwest Plant Atlas (Southwest Plant Atlas, http://www4.nau.edu/swplantatlas/endemic.html) species website page for pinyon pine (Pinus edulis) showing the layout of the model output and explanatory variable selection. 


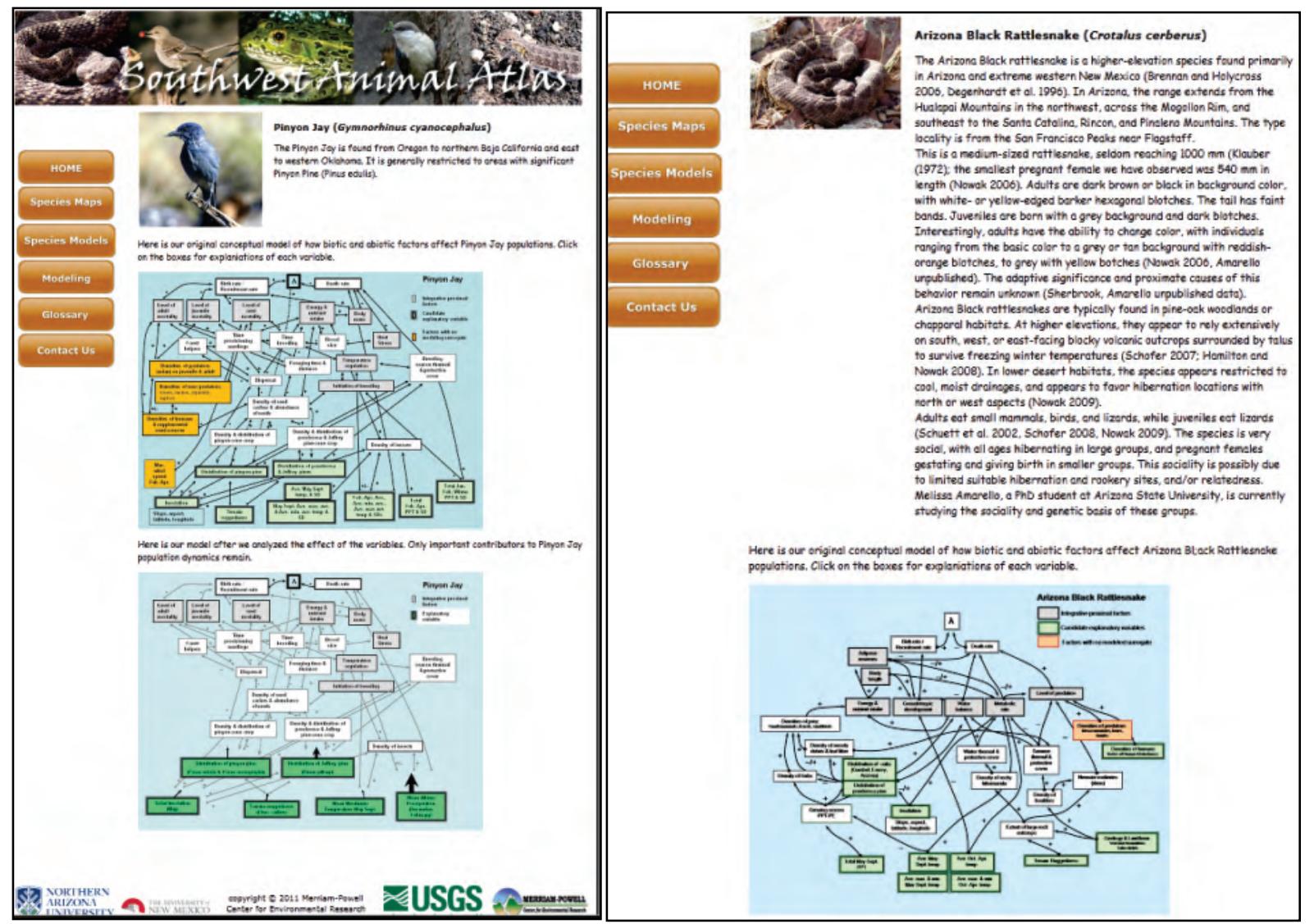

Figure 8.3. Screen capture showing species website pages of the Southwest Animal Atlas (Southwest Plant Atlas, http://www4.nau.edu/swplantatlas/endemic.html) for pinyon jay (Gymnorhinus cyanocephalus) and Arizona black rattlesnake (Crotalus Cerberus) including the species description and conceptual model diagrams. The first pane (pinyon jay) shows the a priori version of conceptual model and the resulting final model after incorporating results from the statistical models. Both the original conceptual model and resulting final model are shown for every bird and reptile species that was modeled in the southwestern NCCWSC project. Additionally, by clicking on boxes in the conceptual models, one is directed to a link that explains each variable or process.

All southwest NCCWSC datasets are made available to the mapping application (and directly to any ArcGIS ${ }^{\circledR}$ user) through REST (Representative State Transfer) services hosted on cpbc.bio.nau.edu. A catalog of these REST services can be seen at:

http://cpbc.bio.nau.edu/CPBC_ArcGIS/rest/services. End users may directly connect to any of these services using ArcMap or other REST enabled mapping tools.

Finally, we have populated http://www4.nau.edu/swplantatlas/maps.html with data and background information on modeling techniques and rational. These websites were designed using a standard html and css framework with virtual directories pointing to large file servers to hold the large number of map images for each species. As of June 2012, all plant and animal species included in our models have been added to the websites. 


\section{Insert 9: Website Application}

This southwest NCCWSC project is an ambitious effort to provide managers and other stakeholders with an understanding of how the ranges of a select group of animal and plant species in Southwestern United States will be affected by global climate change. To accomplish this goal, a website has been developed that will serve as the primary interface between the stakeholder group of users and the spatial data assembled by project scientists.

We considered various approaches to presenting our southwest NCCWSC data in a manageable and maximally informative way. Typically, most web-based approaches collapse a time-series of spatial data into a single spatial extent and place the burden of contextualizing the data on the end-user.

Another approach, exemplified by the Point Reyes Bird Observatory California Avian Data Center website (California Avian Data Center, http://data.prbo.org/cadc2/index.php?page=climate-change-distribution), is to present a current species range juxtaposed by a single, projected future range. This was adopted by the southwestern NCCWSC as a model for our first website design, but has a number of usability issues, the most critical being the inability to compare selected time-periods and models at a glance. Nonetheless, this design imposes fewer demands on the end-user: no downloading or sequential loading of data required. It is a reasonable, if incomplete, solution for displaying a time-series at varying spatial scales.

Our final design is unlike any currently extant websites. We relied heavily on the work of Edward Tufte (Tufte, 2013), who advocates presenting "slices of information” in "parallels of time and space," enabling users to see trends and make comparisons. Our website not only incorporates these ideas, but also extends them. Static displays are now dynamic-users may select from a menu of time-periods and models to produce custom displays of data. Additionally, a "tethered" zoom feature allows a selected area of interest within a single window to be presented in all windows; this allows an end-user to immediately see variation across time and among models at different spatial scales (see fig. 9.1). 


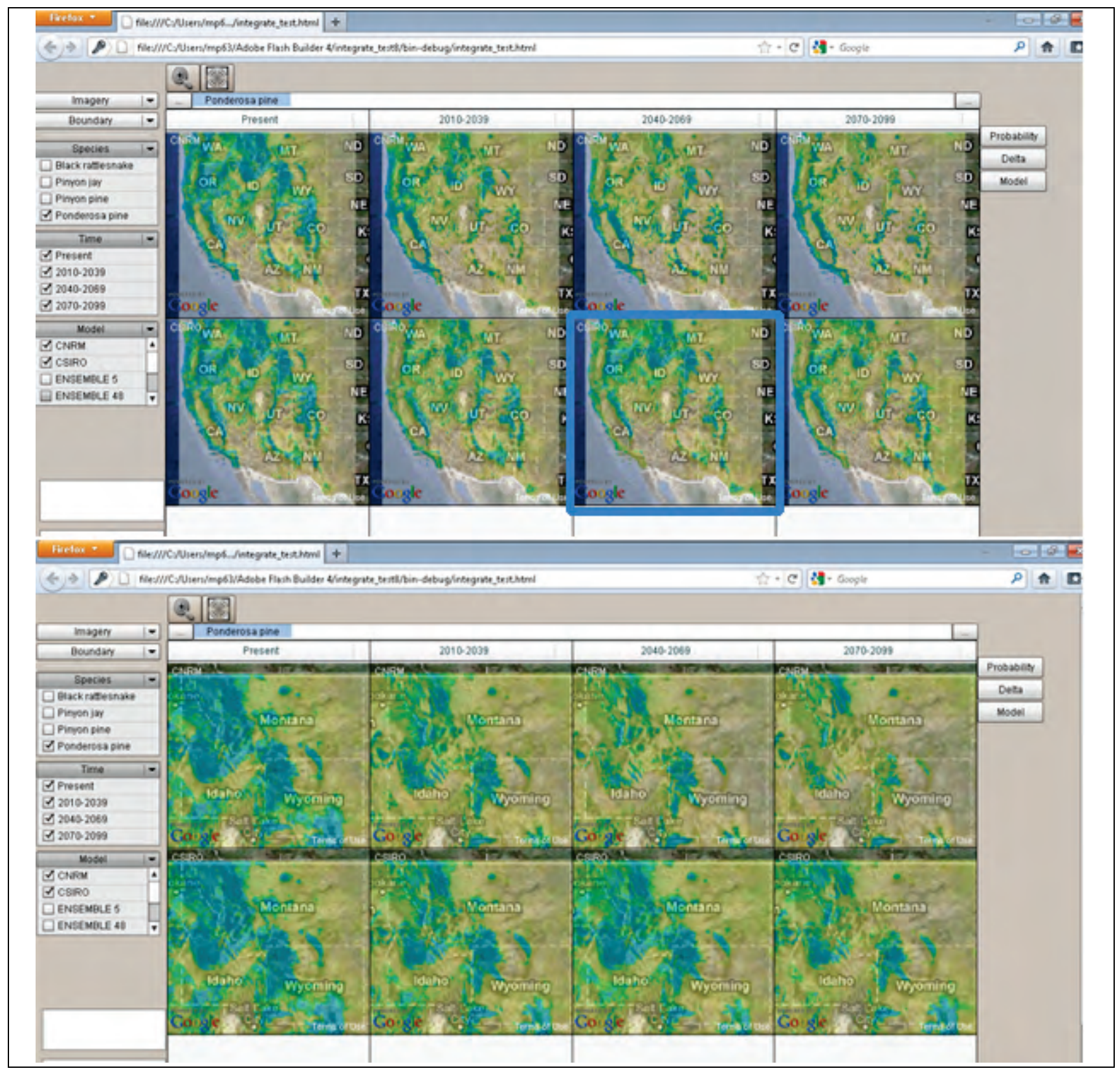

Figure 9.1. Consecutive screen captures of the project website showing distribution data for Pinus ponderosa in the western United States (darker blue-green indicates greater likelihood). The columns represent time, and the rows represent the individual models used for projection (in this case, Centre National de Recherches Meteorologiques (CNRM) (http://www-

pcmdi.Ilnl.gov/ipcc/model_documentation/CNRM-CM3.htm [accessed 9/12/2013] and Commonwealth Scientific and Industrial Research Organization (CSIRO) (http://www.csiro.au/[accessed 9/12/2013]). The bright-blue bounding box in the upper image reflects the user chosen window for zooming and the bottom shows the change-Montana, Idaho, and Wyoming are now the only visible state names. Notice that not only do all cells maintain the same spatial extents at any given scale, they also allow end-users to identify trends and make immediate comparisons/contrasts. 
This southwestern NCCWSC website design is a major advance in building displays that allow users to fully explore multi-dimensional datasets. However, the website is still in a development stage and a number of features have been suggested by the Advisory Team to complete its functionality. This includes a suite of analytic tools that allow users to quantify various properties of the displayed imagery; for example, calculating the area where a retraction in range has occurred. Additionally, under consideration is a blink comparator-this would be the software analog of the mechanical device used by astronomers to track foreground changes against a static background of stars. In this case, the static image is one of the distribution images from a particular time period and model, over which another image is quickly inserted and removed.

\section{Web Site Development Methods}

The primary goal of our website design is to display projected time-series data according to various model outputs. This immediately suggests a dynamic matrix or grid as the key design element. Unfortunately, there are no easily accessible extant technologies for addressing this approach. The mapping application uses data housed in an ESRI geodatabase and served as ESRI mapping services through ArcGIS ${ }^{\circledR}$ Server 10 at http://cpbc.bio.nau.edu/CPBC_ArcGIS/rest/services (ArcGIS ${ }^{\circledR}$ Server 10 at http://cpbc.bio.nau.edu/CPBC_ArcGIS/rest/services. [accessed 9/12/2013]). Both raster (bitmap) and vector graphics are served in this manner.

Outside of the key design consideration noted above, a number of usability principles have been incorporated into our web interface. A small sampling includes having no menu item more than two levels deep, frequently used tools having a larger design footprint than is found in a typical mapping application, storage of user selections so that a return visit brings the user back to the previous state, and last (but not least), a minimalist interface for advanced users. Future work will center on testing website usability with the AT members.

For those technically inclined, a brief summary of the tools used to build this website and a rationale follows. The core technology behind the website is Actionscript ${ }^{\circledR}$. Language features like composite user interface components, advanced datagrids, and item renderers have allowed us to construct a website that is simple to use and yet offers a powerful way of accessing large collections of multi-dimensional data-without the output being unsightly. Additionally, Actionscript ${ }^{\circledR}$ has the ability to use $\mathrm{C}$ code to do processor-intensive tasks. In our case, we are using a C-based shapefile parsing library to display vector data inside of our web application. This functionality, currently being integrated, should provide a measurable boost to performance.

We have scoured various forums for any hint that ESRI considers multiple maps in a single web-based application as a design goal but could find no extant working examples. Flex-based Bing ${ }^{\circledR}$ maps rely on ESRI's technology and were excluded from consideration. Google Maps ${ }^{\mathrm{TM}}$ does provide software tools that allow user-generated bitmap data to be overlaid on its imagery layers. This allows end-users to see orienting features like state boundaries or highways as they navigate the map. Other sources, including Openscales and Openlayers for instance, have similar features but lack the technical aspects required by the southwestern NCCWSC stakeholder end users. 


\section{Insert 10: Bird Species Count}

\section{BLACK-THROATED SPARROW}

\section{Amphispiza bilineata}

The black-throated sparrow inhabits arid upland habitats of the southwestern United States and Mexico, and breeds as far north as Washington. Throughout its range it prefers semi-open habitat with evenly spaced shrubs and trees 1-3 m high. Habitat and vegetation density may influence habitat selection more than specific shrub species, although it is closely associated with creosote bush (Larrea tridentata) throughout the southern part of its range. During the breeding season it is a groundforaging omnivore, eating a variety of insects and seeds. Their food resources in arid environments depend on climatic conditions. Wet years yield more arthropods and seeds than do drier years. Initiation of nest building by the sparrow is variable depending on rainfall, elevation, and food availability. In desert areas, nesting is initiated by midsummer rains, but nesting may also start in early spring in years of adequate winter rainfall. In southern New Mexico and central Arizona, their nests tend to be oriented in northerly and easterly directions, which is thought to provide early-morning sun, maximum shade, and shelter from afternoon sun and southwesterly winds.

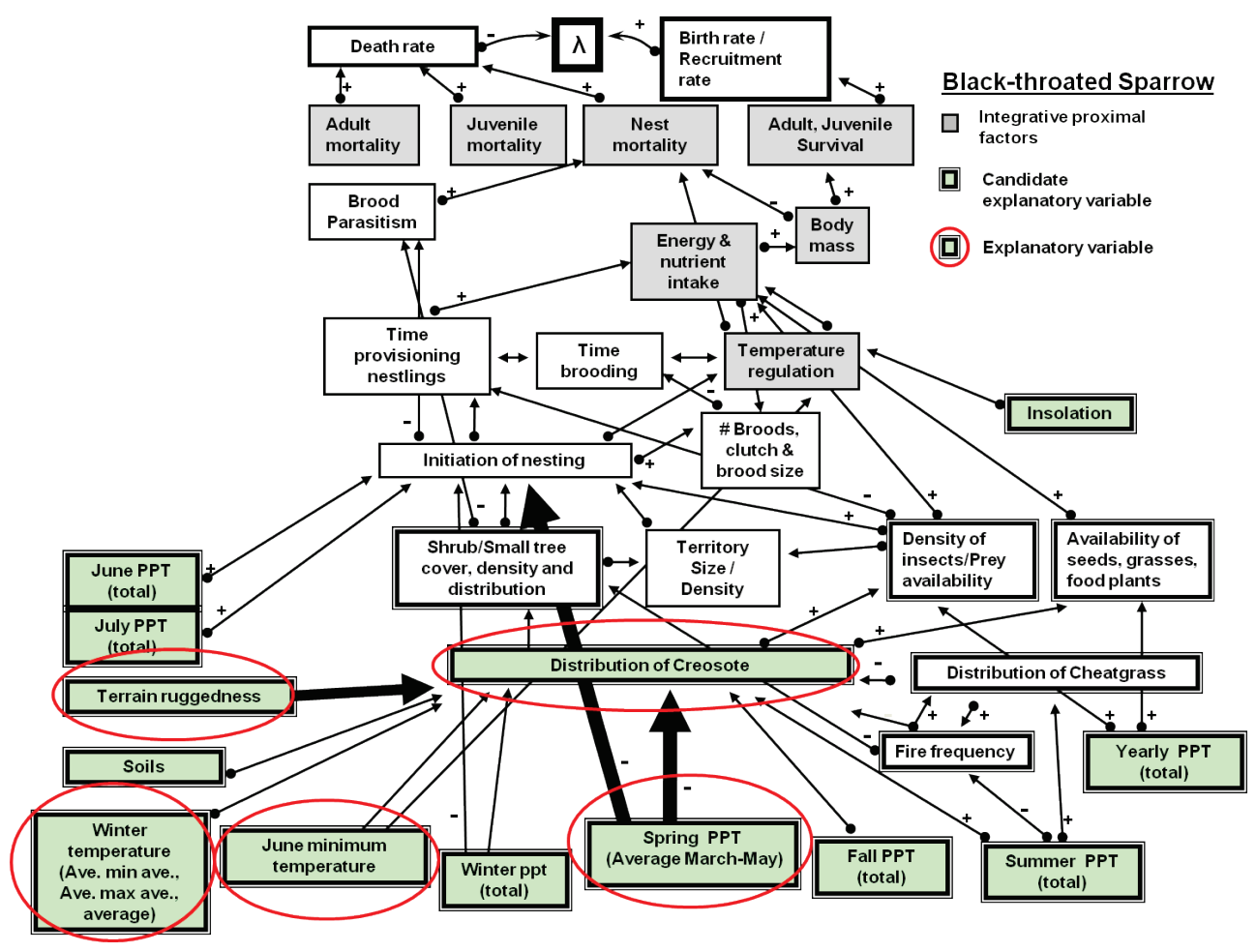

Figure 10.2. Conceptual model of factors affecting black-throated sparrow range and population dynamics, including explanatory variables used to model current range (in green and circled red). The relative strength of different effects is denoted by the width of connecting arrows. 


\section{RANGE PROJECTIONS - 2099}


Figure 10.3. Predicted black-throated sparrow range in 2099, showing levels of agreement among predictions based on 5 different statistically downscaled GCMs plus $a 6^{\text {th }}$ representing an ensemble of 22 GCMs. White denotes areas where all projections agree there will not be sparrow range, whereas blue denotes areas where all agree there will be sparrow range.

Figure 10.4. Areas where $\geq 5$ GCM projections predict there will be blackthroated sparrow range in 2099 compared to range in 2000, showing areas of range loss (red), range gain (green), and range persistence (blue) between 2000 and 2099. 


\section{Rank order of variable influence in the model}

1. Terrain ruggedness (TRI)

2. Mean spring precipitation (PPTAVR_spr)

3. Creosote (Larrea tridentata) range (LATR)

4. Mean winter (December-February) temperatures (TMPAVG_win)

5. Minimum temperature - June (TMPMIN_06)

\section{Relationship}

quadratic

monotonic

monotonic

monotonic

monotonic
Figure 10.5. Relative influence of variables retained in the best model of current range, as measured by the chisquared statistic. Green denotes a positive effect; red denotes a negative effect. Variables with a "2" denote a quadratic term.

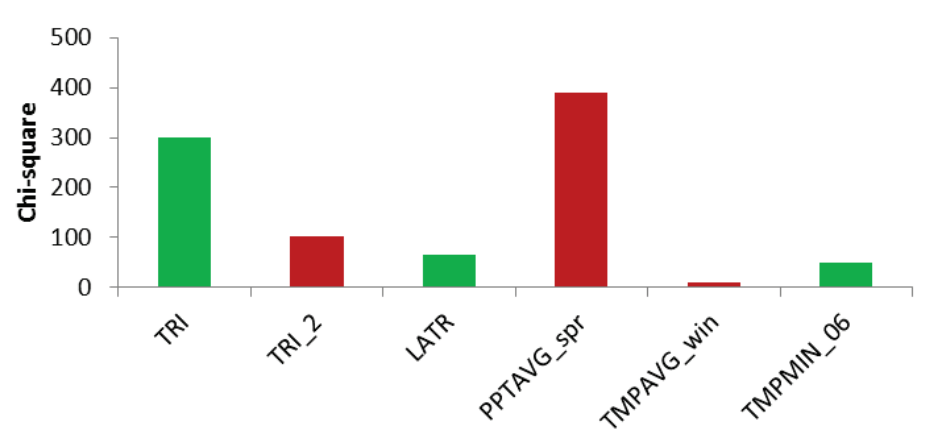

Predictor variable

Figure 10.6. Measures of range change among four decadal intervals for the period 2000 through 2099. The figure on the left shows extent of modeled current or projected future range reckoned in terms of area. The figure on the right shows the change in range extent as a percent of current range. Green bars are results produced by the model that includes the effect of plant species ranges; red bars are results produced by the model that does not include plant range effects. Values were calculated based on areas of agreement of at least 5 of the 6 climate projections.
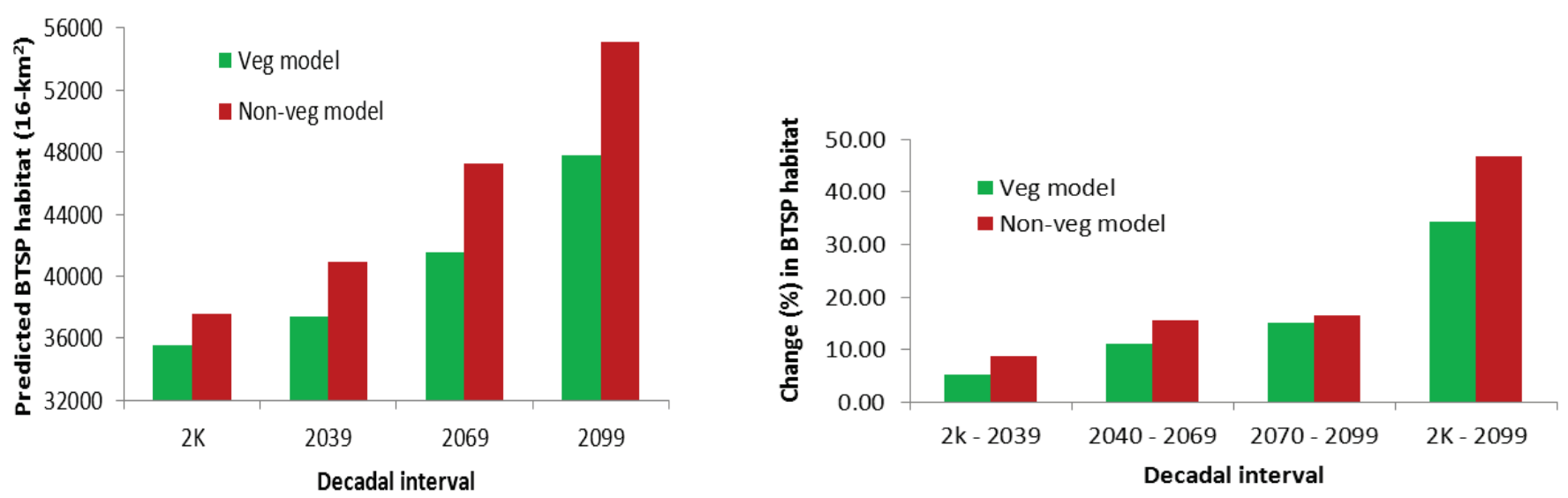


\section{GRAY VIREO}

\section{Vireo vicinior}

The gray vireo inhabits some of the hottest, most arid regions of the southwestern United States. It is a short-distance migrant and withdraws completely from most of its breeding range in winter. It prefers mixed juniper, pinyon, and oak scrub associations, chaparral in hot, arid mountains, and high plains scrubland. It eats a variety of arthropods, including large grasshoppers, cicadas, and caterpillars, which it gleans from the leaves, twigs, branches and trunks of small trees or twigs and branches of shrubby vegetation foliage. Gray vireo nests are often constructed on west- or northfacing tree forks. The nesting pair alternate brooding, which is continuous from hatching of first nestling and diminishes after the $6^{\text {th }}$ day. Eggs are vulnerable to exposure to sun, and both adults have been observed shading nestlings. This species is on the 2007 (most recent) WatchList for United States Birds and the USFWS Federal list of birds of conservation concern due to its rarity.

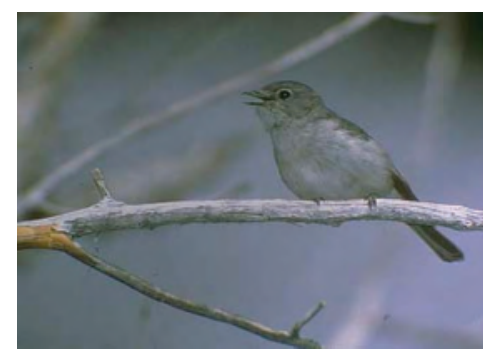

Figure 10.7. Vireo vicinior, photo by Brian E. Small/Utah Division of Wildlife Resources

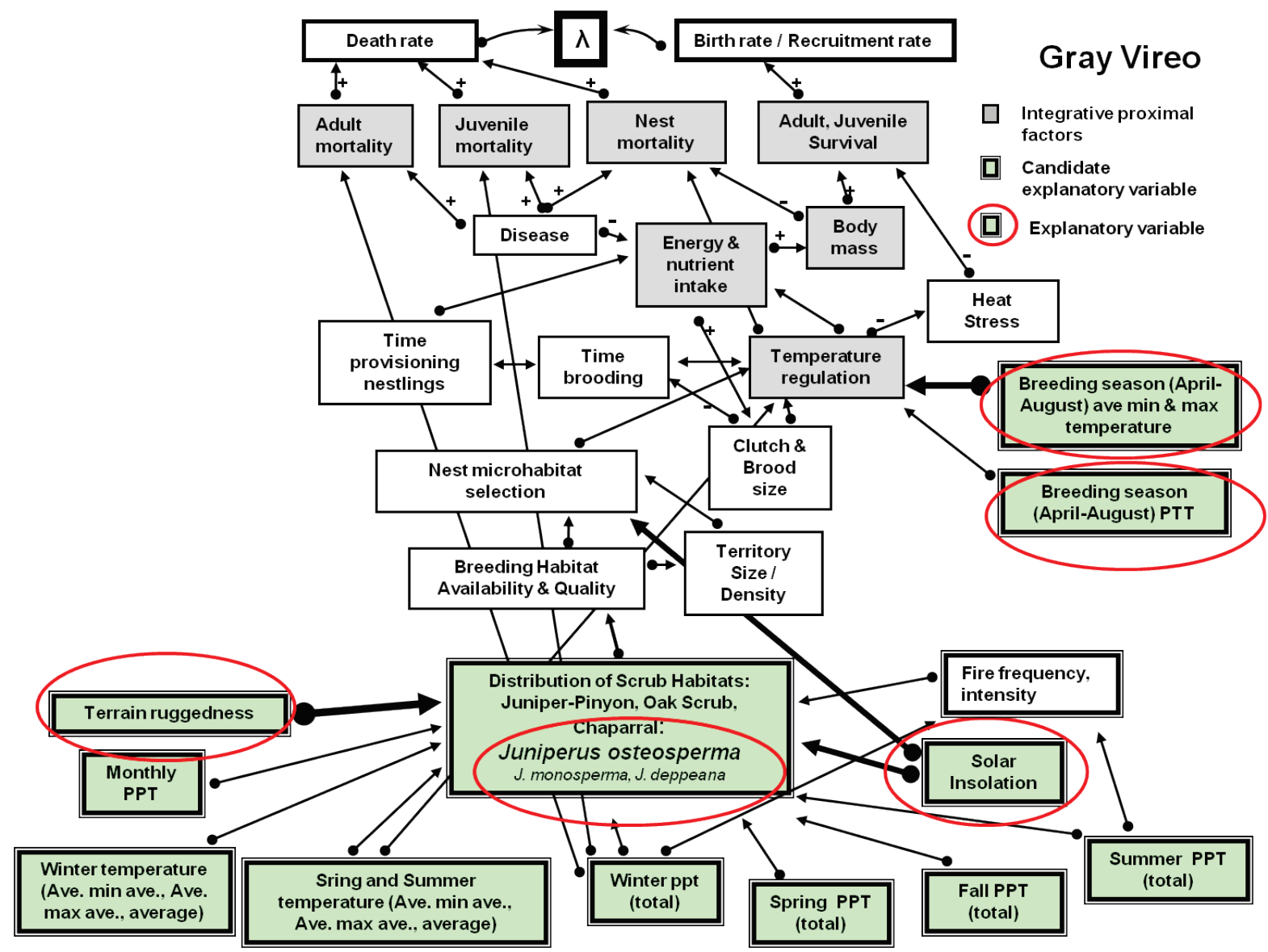

Figure 10.8. Conceptual model of factors affecting gray vireo range and population dynamics, including explanatory variables used to model current range (in green and circled red). The relative strength of different effects is denoted by the width of connecting arrows. 


\section{RANGE PROJECTIONS - 2099}
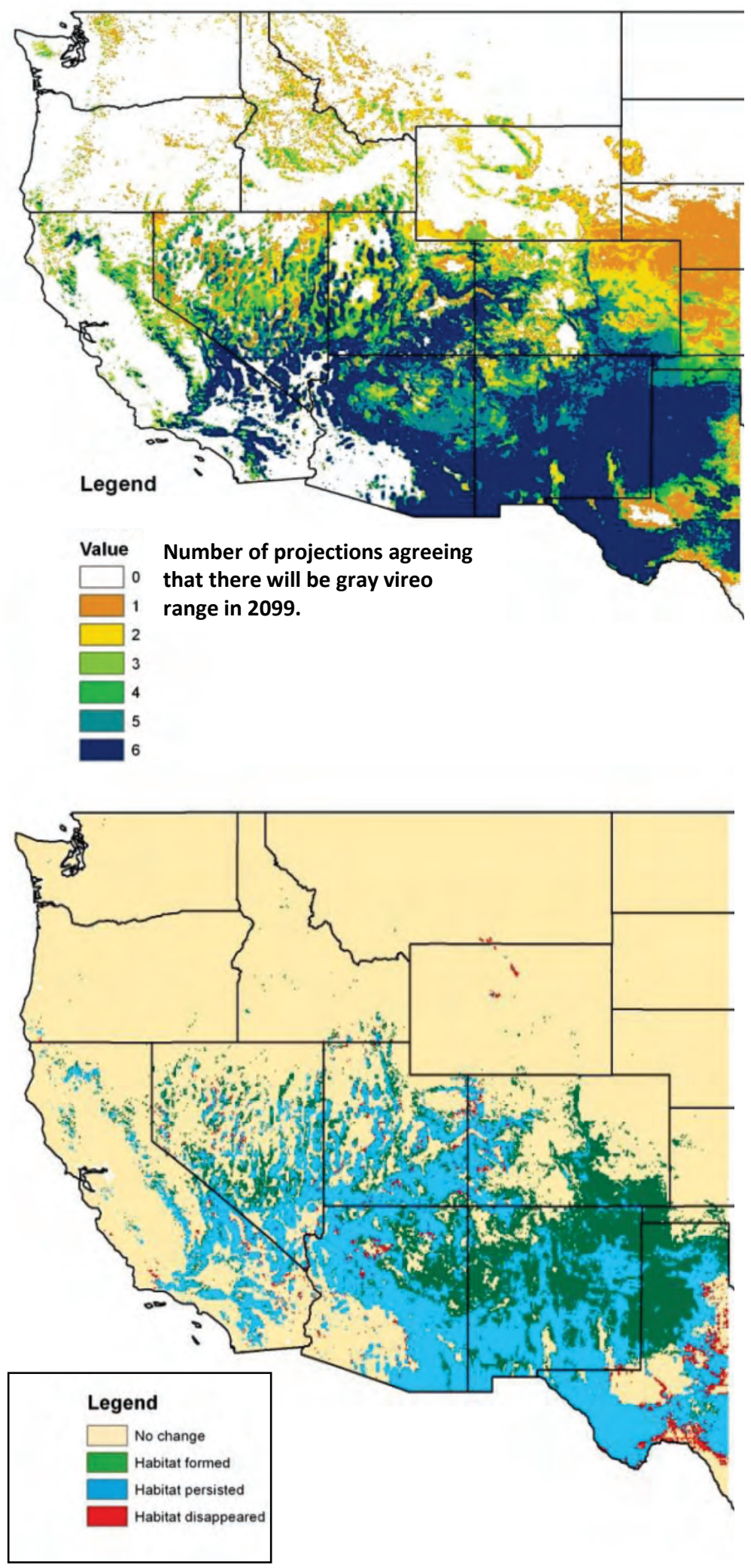

Figure 10.9. Predicted gray vireo range in 2099, showing levels of agreement among predictions based on 5 different statistically downscaled GCMs plus a $6^{\text {th }}$ representing an ensemble of 22 GCMs. White denotes areas where all projections agree there will not be vireo range, whereas blue denotes areas where all agree there will be vireo range.
Figure 10.10. Areas where $\geq 5$ GCM projections predict there will be gray vireo range in 2099 compared to range in 2000, showing areas of range loss (red), range gain (green), and range persistence (blue) between 2000 and 2099. 


\section{Rank order of variable influence in the model}

1. Maximum breeding season (April-August) temperature (TMPmax_aa)

2. Terrain ruggedness (TRI)

3. Juniperous osteosperma range (JUOS_rbf)

4. Solar insolation (Solar_May)

5. Mean breeding season (April-August) precipitation

\section{Relationship}

quadratic

quadratic

monotonic

monotonic

monotonic
Figure 10.11. Relative influence of variables retained in the best model of current range, as measured by the chi-squared statistic. Green denotes a positive effect; red denotes a negative effect. Variables with a "2" denote a quadratic term.
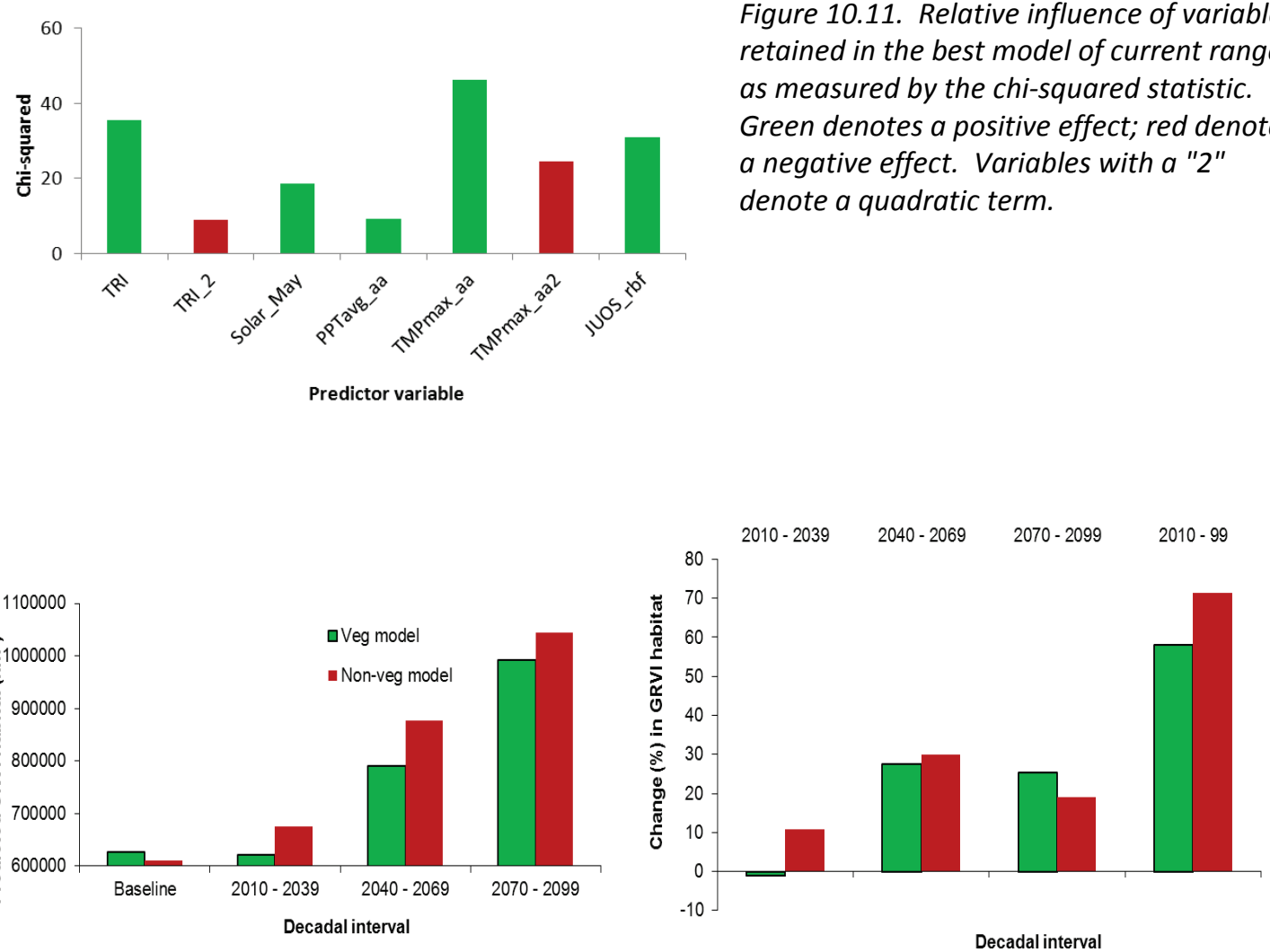

Figure 10.12. Measures of range change among four decadal intervals for the period 2000 through 2099. The figure on the left shows extent of modeled current or projected future range reckoned in terms of area. The figure on the right shows the change in range extent as a percent of current range. Green bars are results produced by the model that includes the effect of plant species ranges; red bars are results produced by the model that does not include plant range effects. Values were calculated based on areas of agreement of at least 5 of the 6 climate projections. 


\section{VIRGINIA'S WARBLER}

\section{Vermivora virginiae}

The Virginia's warbler has a relatively restricted breeding range, inhabiting scrubby habitats below the pine belt in northern part of its range, and scrubby habitats within surrounding conifers in southern part of its range. For breeding habitat, it shows a strong association for steep draws, drainages, or slopes with oak or other shrubby vegetation. In Arizona, this species tends to select locust (Robinia neomexicana)- or oak (Quercus sp.)- dominated sites, which indicate a preference for drier conditions and higher daytime temperatures. In addition, pine-oak-locust habitat with more mesic maple (Acer spp.) had territories established before the same habitat without the maple component, suggesting a preference for moister microhabitats when available. The Virginia's warbler is insectivorous and leafy vegetation is especially important for foraging. In southern Arizona it spends a disproportionate amount of time foraging in oak, even though coniferous foraging habitat is four times more abundant. They build their nests on the ground, and nesting activity begins soon after pairing but may be delayed if snow cover persists, and in periods of poor weather. Nests may also be abandoned in periods of inclement weather. This species is on the 2007 (most recent) WatchList for United States Birds due to its rarity.

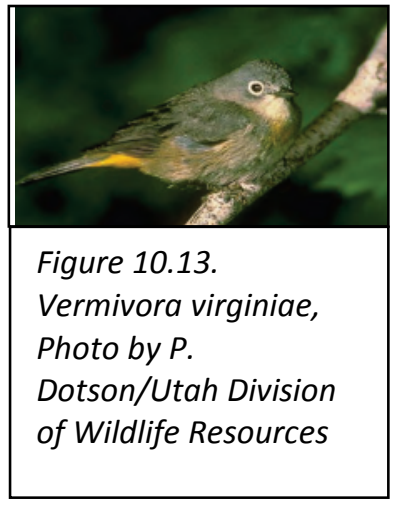

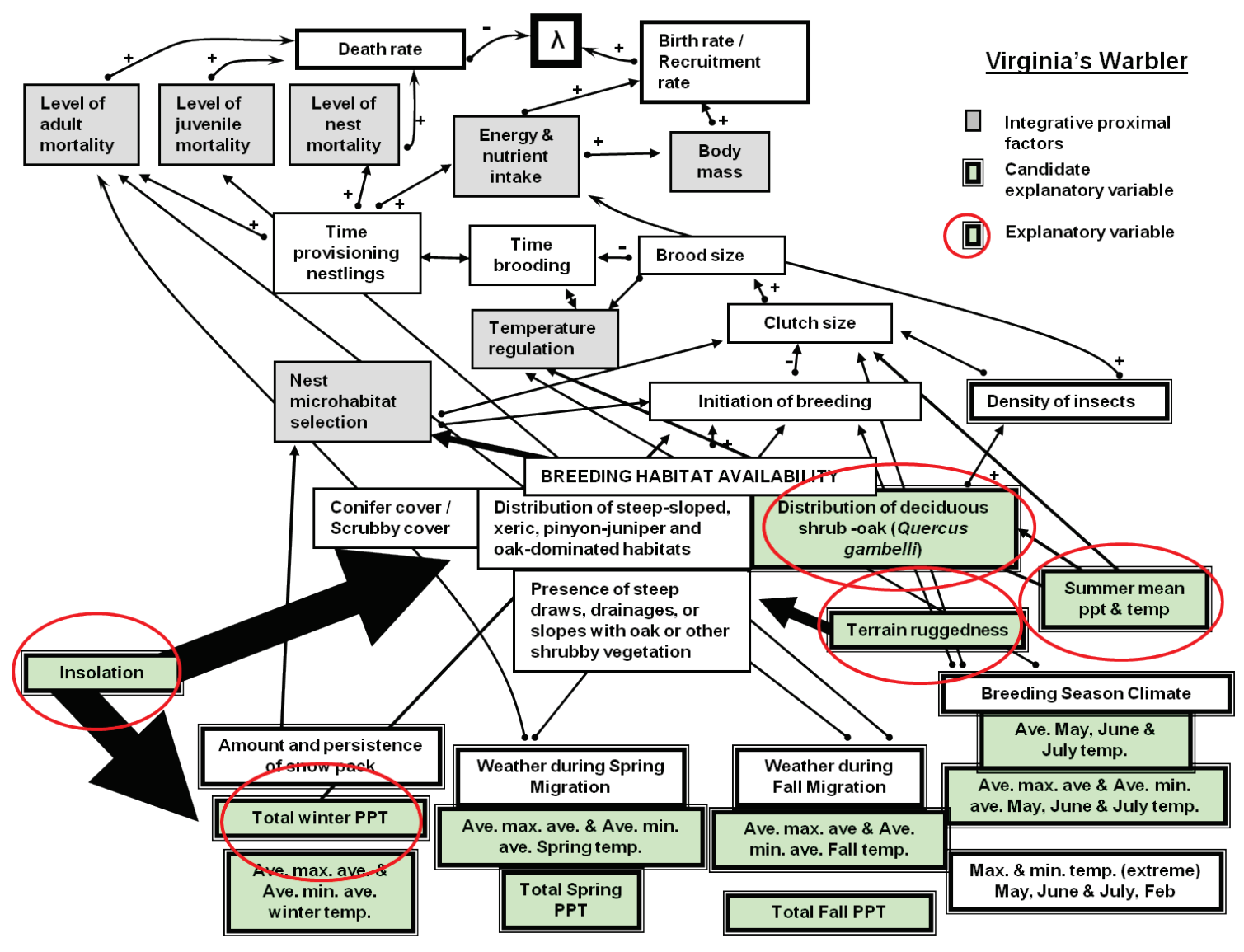

Figure 10.14. Conceptual model of factors affecting Virginia's warbler range and population dynamics, including explanatory variables used to model current range (in green and circled red). The relative strength of different effects is denoted by the width of connecting arrows. 


\section{RANGE PROJECTIONS - 2099}
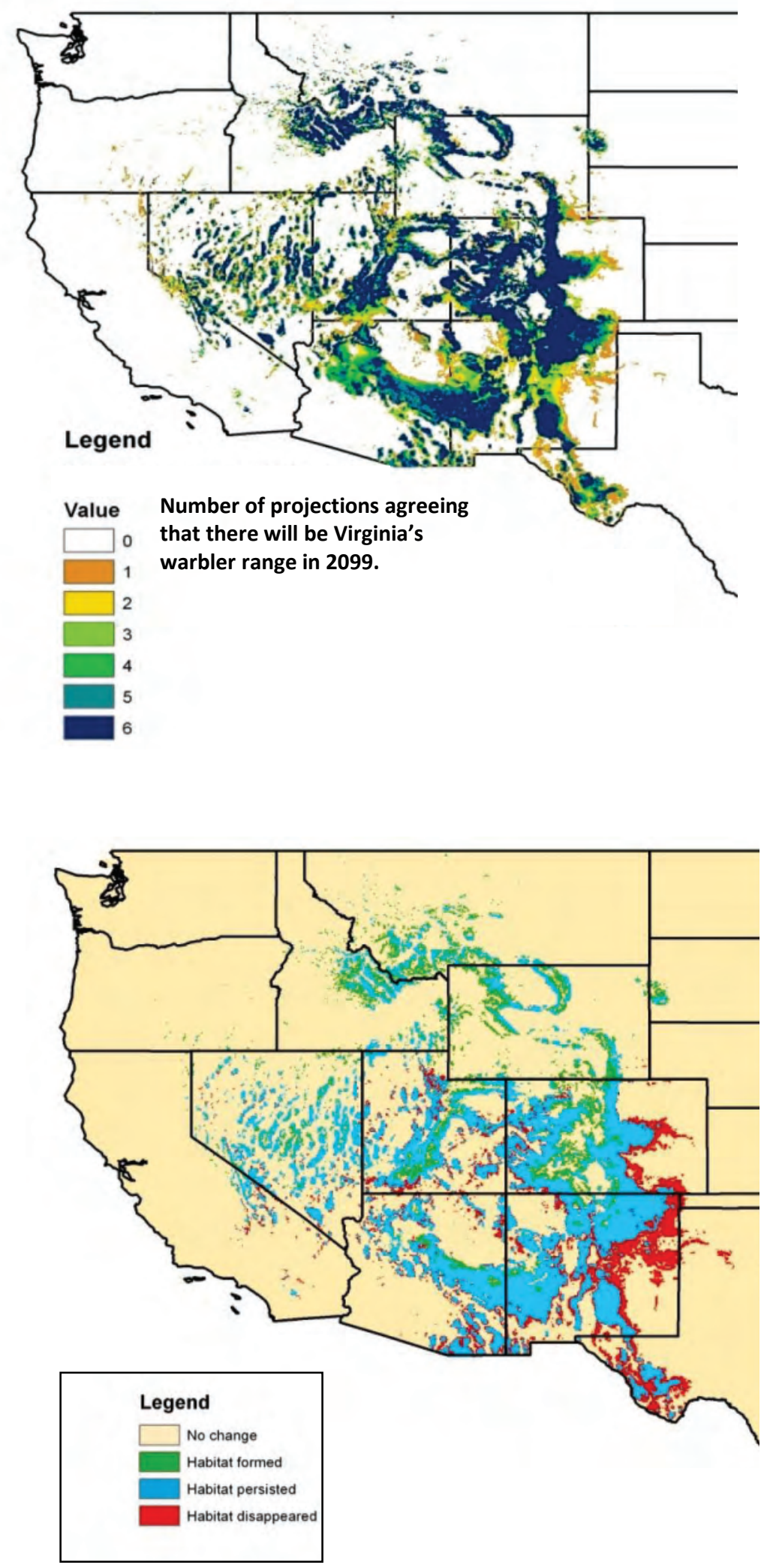

Figure 10.15. Predicted Virginia's warbler range in 2099, showing levels of agreement among predictions based on 5 different statistically downscaled GCMs plus a $6^{\text {th }}$ representing an ensemble of 22 GCMs. White denotes areas where all projections agree there will not be warbler range, whereas blue denotes areas where all agree there will be warbler range.
Figure 10.16. Areas where $\geq 5 \mathrm{GCM}$ projections predict there will be Virginia's warbler range in 2099 compared to range in 2000, showing areas of range loss (red), range gain (green), and range persistence (blue) between 2000 and 2099. 


\section{MODEL RESULTS}

\section{Rank order of variable influence in the model}

1. Terrain ruggedness (TRI)

2. Oak (Quercus gambelii) range (qugabf)

3. Mean winter (Dec. - Feb.) precipitation (pptavg_wk)

4. Mean summer (June - Aug.) temperature (tmpavg_sk)

5. Mean summer (June - Aug.) precipitation (pptavg_sk)

6. Solar insolation (solarmayk)

\section{Relationship}

quadratic monotonic $\quad+$ monotonic quadratic quadratic quadratic

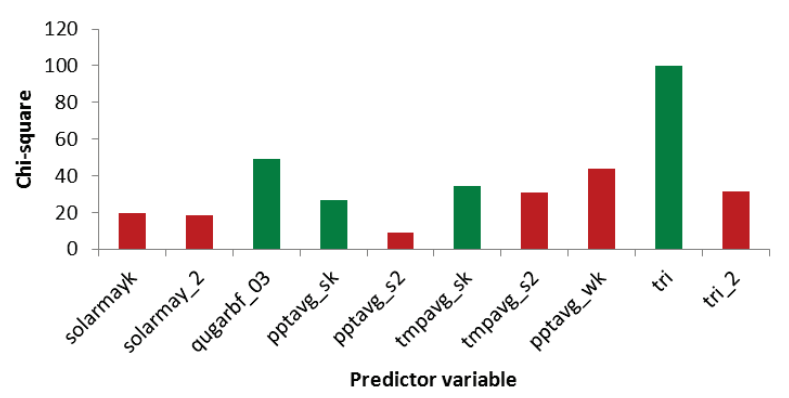

Figure 10.17. Relative influence of variables retained in the best model of current range, as measured by the chisquared statistic. Green denotes a positive effect; red denotes a negative effect. Variables with a "2" denote a quadratic term.
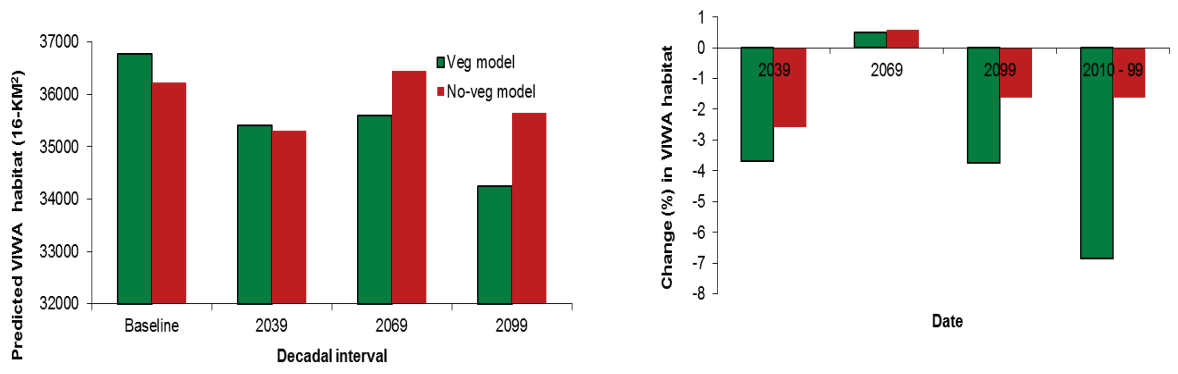

Figure 10.18. Measures of range change among four decadal intervals for the period 2010 through 2099. The figure on the top shows extent of modeled current or projected future range reckoned in terms of area. The figure on the bottom shows the change in range extent as a percent of current range. Green bars are results produced by the model that includes the effect of plant species ranges; red bars are results produced by the model that does not include plant range effects. Values were calculated based on areas of agreement of at least 5 of the 6 climate projections. 


\section{SAGE THRASHER}

\section{Oreoscoptes montanus}

The sage thrasher is considered a sage obligate, and is generally dependent on large patches and expanses of sagebrush steppe for successful breeding. It primarily inhabits areas dominated by big sagebrush (Artemisia tridentate), but has been noted in black greasewood (Sarcobatus vermiculatus) habitat in areas in Utah and Nevada, and bitterbrush (Pursia tridentate) habitat in Washington. Within its range it is more abundant in areas with high sagebrush cover, tall shrubs, woody cover, and bare ground and less abundant in areas with higher percent cover of grasses. In Washington, occurrence was greater on loamy and shallow soils than on sandy soils. Besides the impacts of habitat loss, little is known about factors regulating sage thrasher numbers throughout their range. Temperature and insolation appear to affect nest site selection. Nests are oriented with more easterly exposures than westerly ones, and nest placement patterns are generally consistent with the hypothesis that nests are placed so as to guard against heat loss at night, to avoid direct exposure to the sun during the heat of the day, and to gain heat early in the morning. Temperature and precipitation likely have a greater effect on the distribution of the sage thrasher's habitat. Sagebrush grows in areas with cold winters and summer drought. Recruitment of subspecies of big sagebrush is dependent upon precipitation amounts during specific time periods, depending on the subspecies.

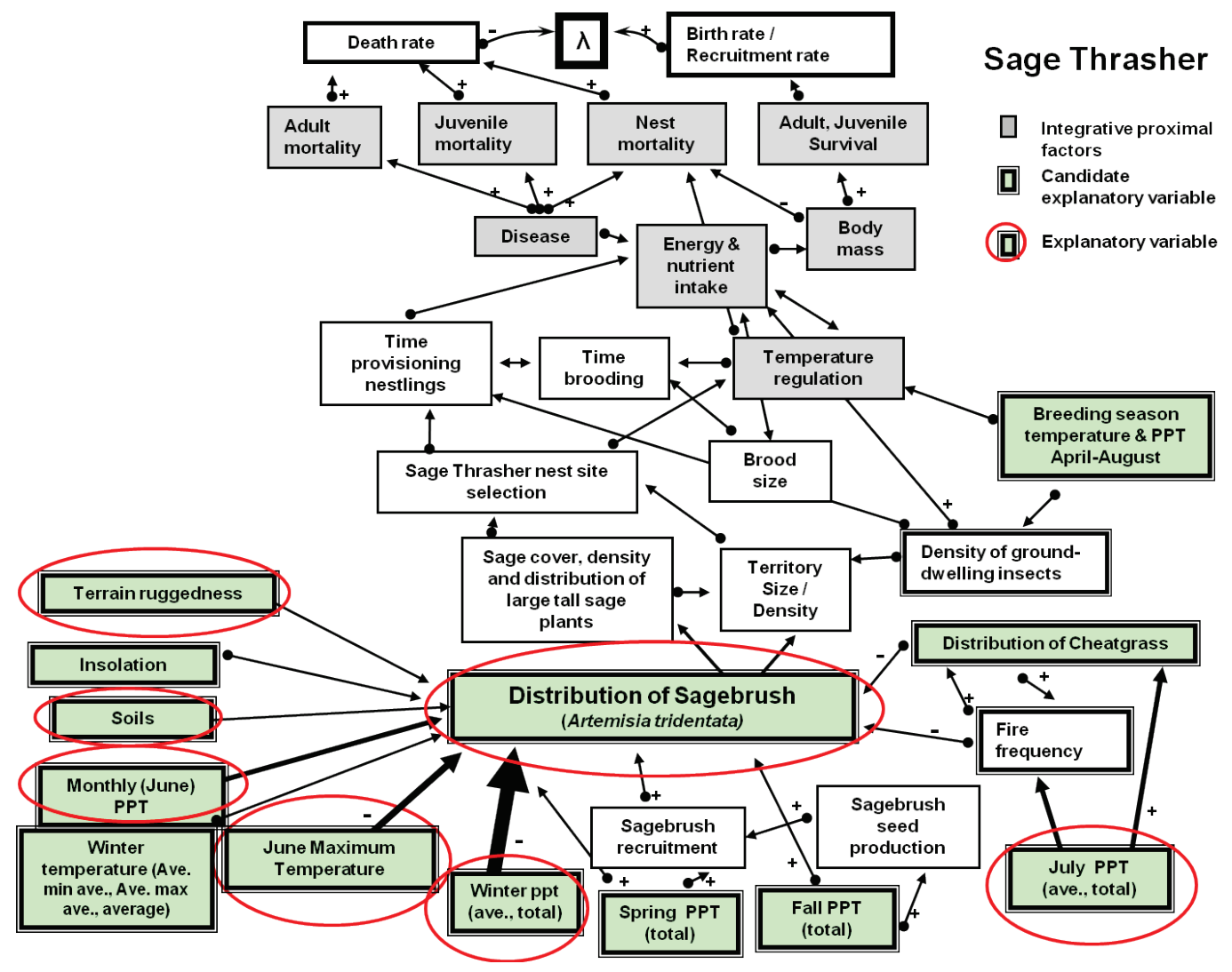

Figure 10.20. Conceptual model of factors affecting Virginia's warbler range and population dynamics, including explanatory variables used to model current range (in green and circled red). The relative strength of different effects is denoted by the width of connecting arrows. 


\section{RANGE PROJECTIONS - 2099}
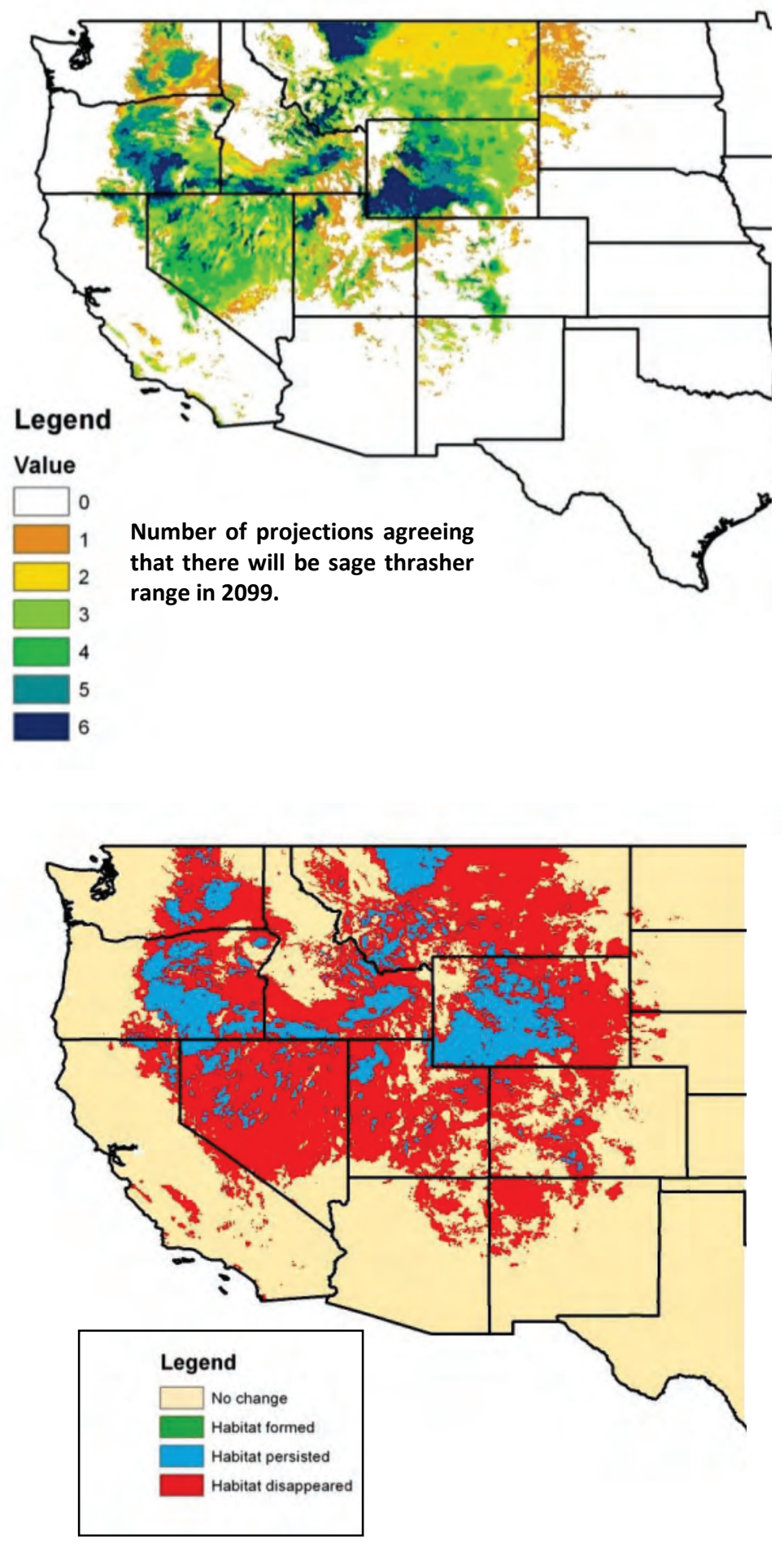

Figure 10.21. Predicted sage thrasher range in 2099, showing levels of agreement among predictions based on 5 different statistically downscaled GCMs plus a $6^{\text {th }}$ representing an ensemble of 22 GCMs. White denotes areas where all projections agree there will not be thrasher range, whereas blue denotes areas where all agree there will be thrasher range.
Figure 10.22. Areas where $\geq 5$ GCM projections predict there will be sage thrasher range in 2099 compared to range in 2000, showing areas of range loss (red), range gain (green), and range persistence (blue) between 2000 and 2099. Note: the predicted range of sagebrush (Artemisia tridentata) was not modeled. 


\author{
Rank order of variable influence in the model \\ 1. Mean winter (Dec. - Feb.) precipitation (PPTAVG_W) \\ 2. Maximum June temperature (TMPMAX_06) \\ 3. Mean July precipitation (PPTAVG_07) \\ 4. Sagebrush (Artemisia tridentata) range (ARTR) \\ 5. Percent sand in soil (PRESAND) \\ 6. Terrain ruggedness (TRI)
}

\author{
Relationship \\ monotonic \\ monotonic \\ monotonic \\ monotonic \\ monotonic \\ quadratic
}

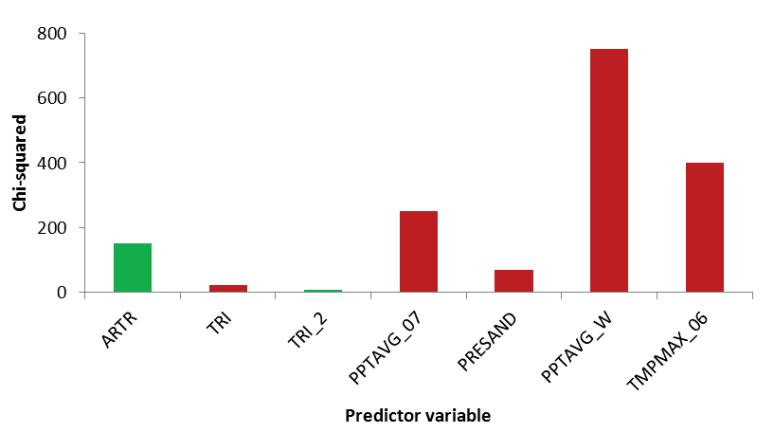

Figure 10.23. Relative influence of variables retained in the best model of current range, as measured by the chi-squared statistic. Green denotes a positive effect; red denotes a negative effect. Variables with a "2" denote a quadratic term.
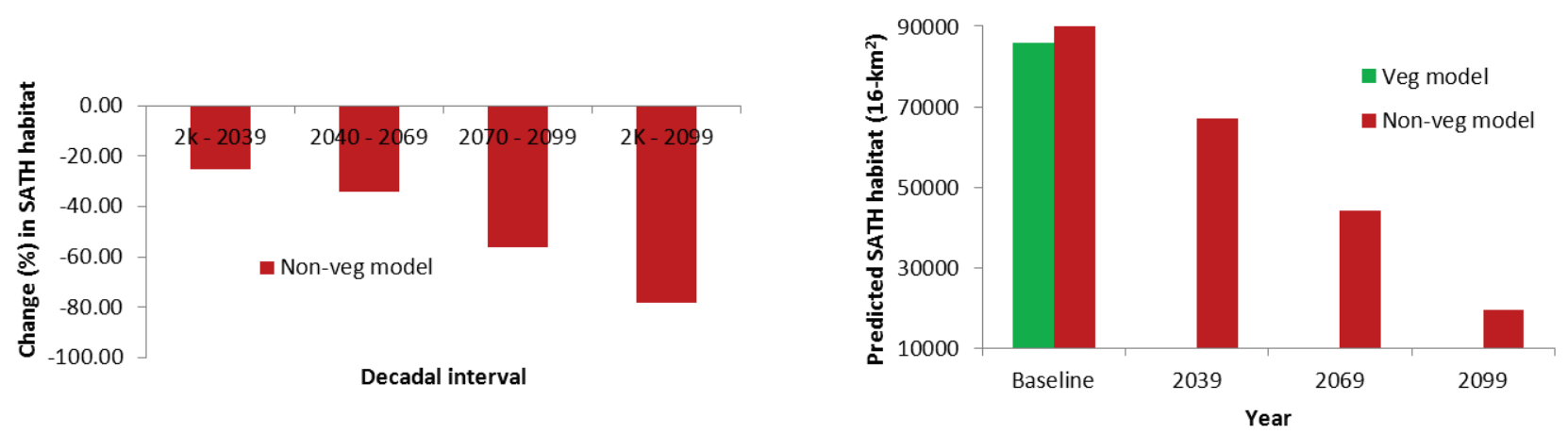

Figure 10.24. Measures of range change among four decadal intervals for the period 2000 through 2099. The figure on the left shows extent of modeled current or projected future range (without plant ranges) reckoned in terms of area. The figure on the right shows the change in range extent as a percent of current range. Green bars are results produced by the model that includes the effect of plant species ranges; red bars are results produced by the model that does not include plant range effects. Plant range effects were not predicted for the sage thrasher. Values were calculated based on areas of agreement of at least 5 of the 6 climate projections. 


\section{PINYON JAY}

\section{Gymnorhinus cynanocephalus}

Pinyon jays coevolved as non-migratory mutualists with pinyon pines. Jays disperse the large wingless seed of pinyon pines over long distances, which can result in relatively rapid colonization. At the same time, the jays obtain energy and nutrients from the seeds. Although closely associated with pinyon pines in most areas, in parts of its range pinyon jays inhabit ponderosa pine (Pinus ponderosa) and Jeffrey pine ( $P$. jeffreyi) forests. During some years, especially when pinyon pine cones are rare or absent, jays harvest and cache large numbers of ponderosa or Jeffrey pine seeds. Pinyon jays prefer to cache seeds at the base of large trees, boulders, or at the base of cliffs, where less snow accumulates and where the snow that does accumulate melts more rapidly. Pinyon jays may assess insolation when nest building, as in northern Arizona where $>50 \%$ of nests are located on the south-facing sides of trees. Females in south-facing nests receive up to $40 \%$ more solar energy compared to females in north-facing nests, which matters, because pinyon jays are among the earliest nesting passerines in the United States.

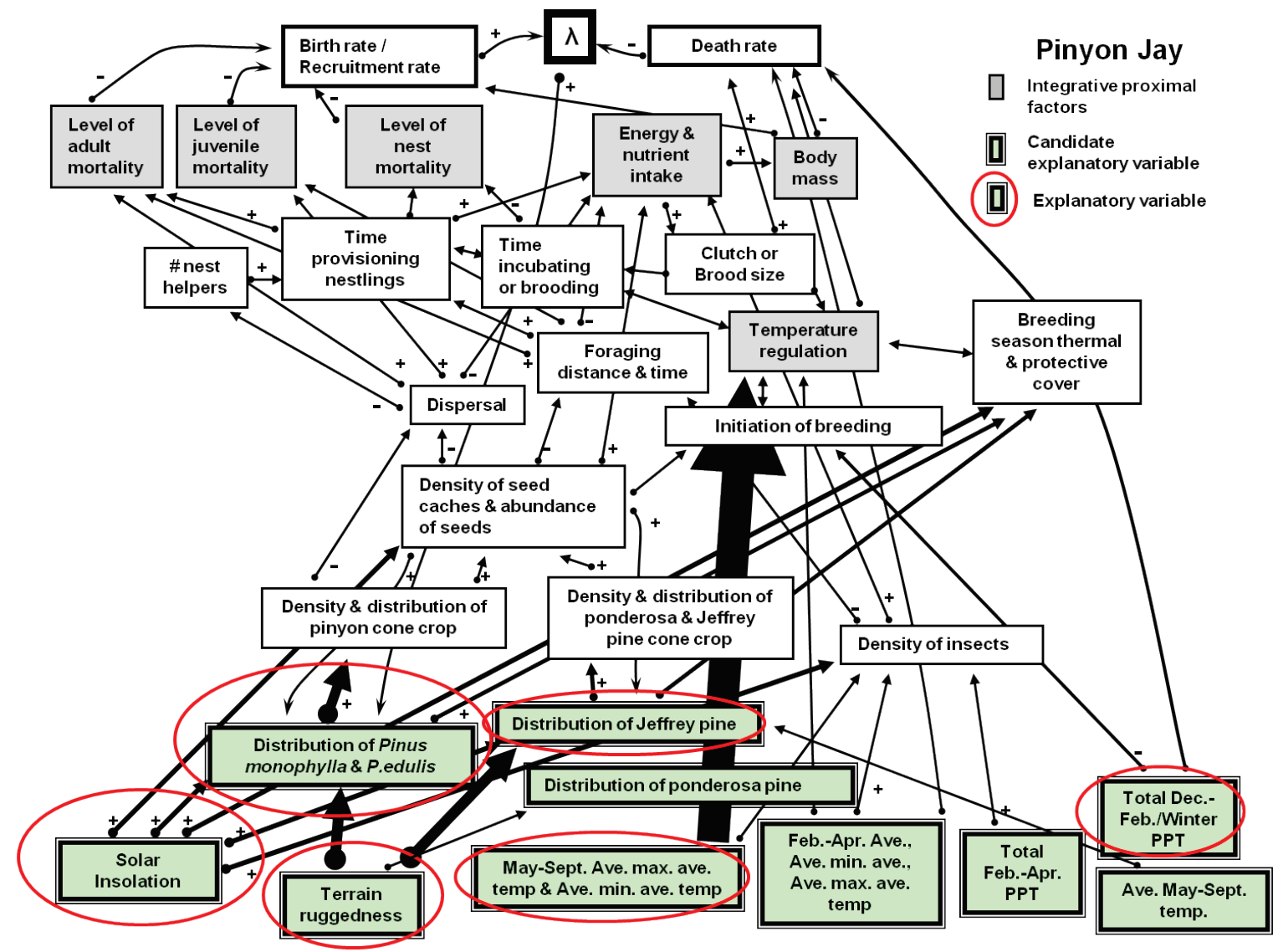

Figure 10.26. Conceptual model of factors affecting pinyon jay range and population dynamics, including explanatory variables used to model current pinyon jay range (in green and circled red). The relative strength of different effects is denoted by the width of connecting arrows. 


\section{RANGE PROJECTIONS - 2099}

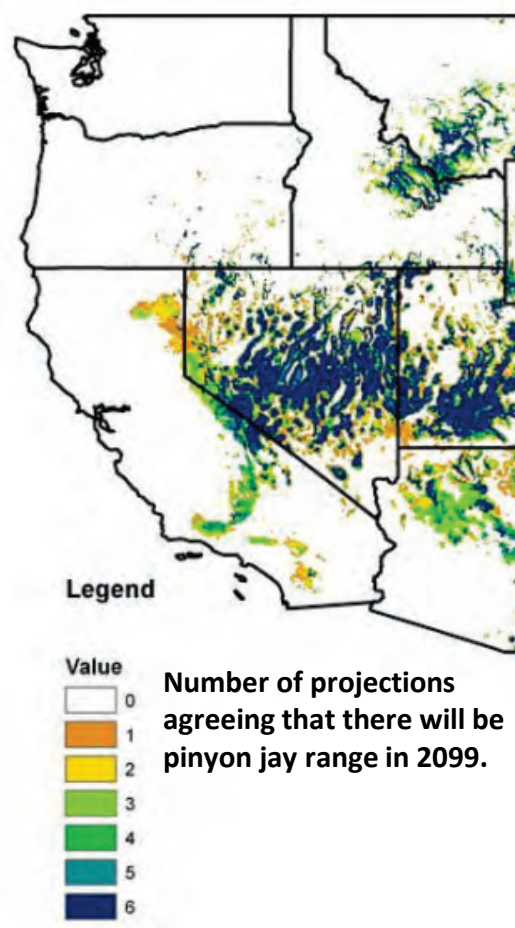

Figure 10.28. Areas where $\geq 5$ GCM projections predict there will be pinyon jay range in 2099 compared to range in 2000, showing areas of range loss (red), range gain (green), and range persistence (blue) between 2000 and 2099.

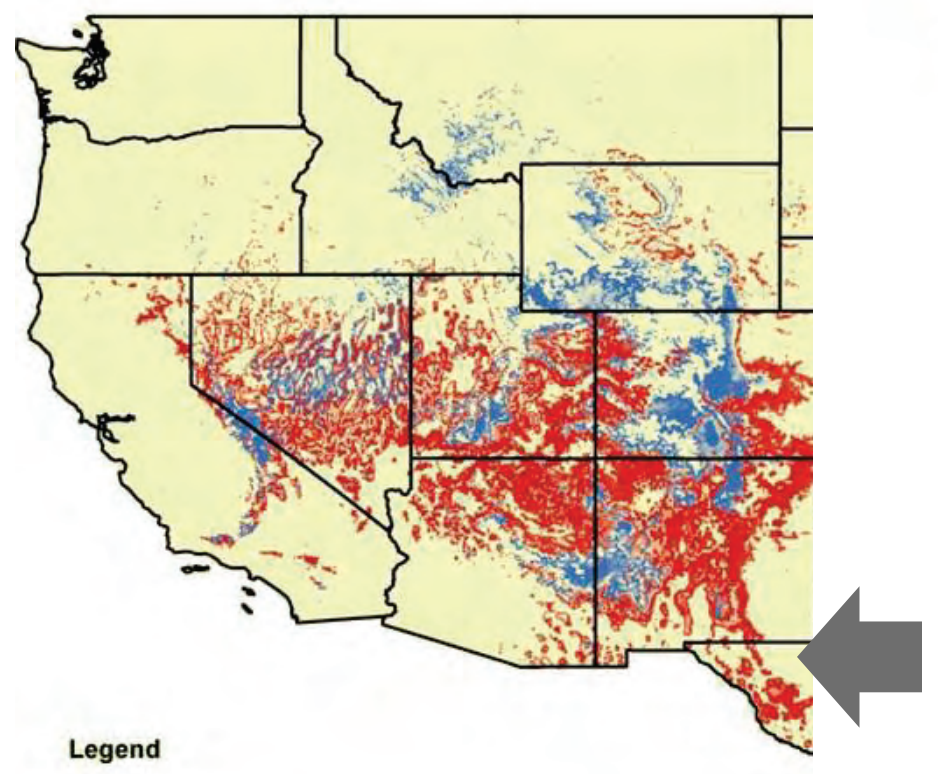

Figure 10.27. Predicted pinyon jay range in 2099, showing levels of agreement among predictions based on 5 different statistically downscaled GCMs plus a $6^{\text {th }}$ representing an ensemble of 22 GCMs. White denotes areas where all projections agree there will not be pinyon jay range, whereas blue denotes areas where all agree there will be pinyon jay range.

Figure 10.29. Areas where $\geq 5$ GCM projections predict there will be pinyon jay range in 2099, showing differences in modeled probabilities of range between 2000 and 2099. Darker blue denotes increased probability of range whereas darker red denotes decreased probability of range.

Value

High : 0.563878

Low : -0.583322

Difference in modeled probabilities between 2000 and 2099. 


\section{Rank order of variable influence in the model}

1. Mean winter (December-February) precipitation

2. Mean maximum summer (May-September) temperatures

3. Pinus edulis range (pied)

4. Pinus monophylla range (pimo)

5. Pinus jeffreyi range (pije)

6. Terrain ruggedness (TRI)

7. May solar insolation

$\begin{array}{ll}\text { Relationship } & \\ \text { monotonic } & - \\ \text { quadratic } & \\ \text { monotonic } & + \\ \text { monotonic } & + \\ \text { monotonic } & + \\ \text { quadratic } & \\ \text { monotonic } & +\end{array}$

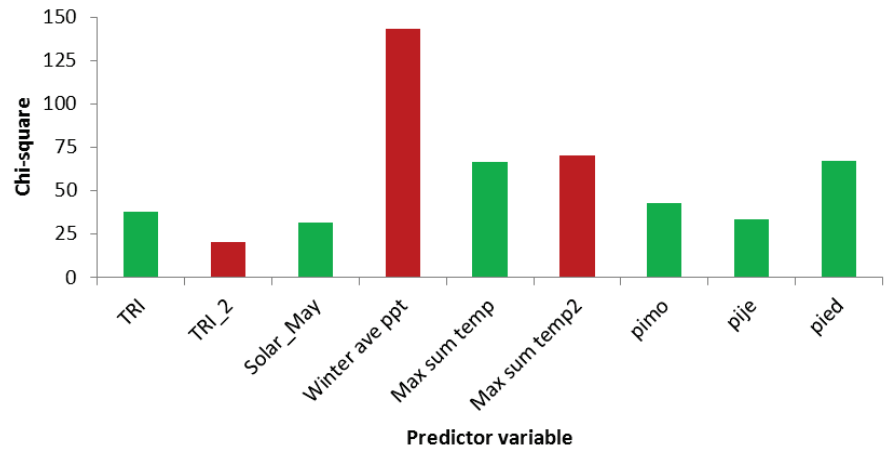

Figure 10.30. Relative influence of variables retained in the best model of current range, as measured by the chisquared statistic. Green denotes a positive effect; red denotes a negative effect. Variables with a " 2 " denote a quadratic term.
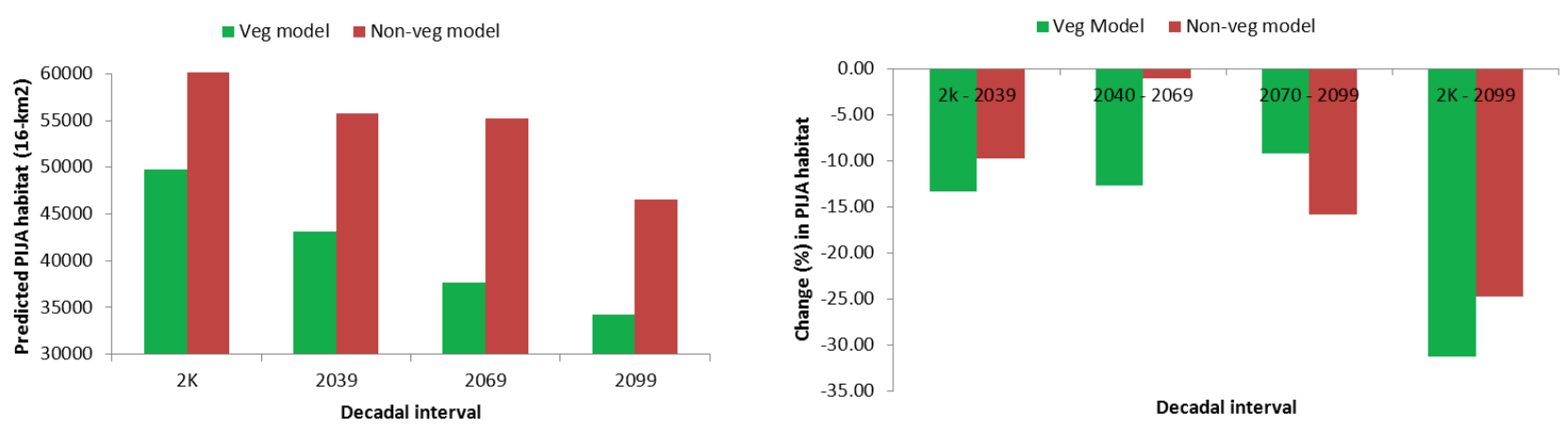

Figure 10.31. Measures of range change among four decadal intervals for the period 2000 through 2099. The figure on the left shows extent of modeled current or projected future range reckoned in terms of area. The figure on the right shows the change in range extent as a percent of current range. Green bars are results produced by the model that includes the effect of plant species ranges; red bars are results produced by the model that does not include plant range effects. Values were calculated based on areas of agreement of at least 5 of the 6 climate projections. 


\section{PYGMY NUTHATCH}

\section{Sitta pygmaea}

The pygmy nuthatch has a strong and almost exclusive preference for longneedled pines including ponderosa, Jeffrey, and similar species. It depends on cavities for nesting and roosting and has clear seasonal cavity preferences, related to thermal insulation and ventilation. Seventy percent of nest cavity openings face southward, others face south and east, away from prevailing winds. Selection of the roost cavity is affected by weather and by characteristics of the cavity (such as type of wood, thickness of bole, size of entrance, and depth of cavity) that afford protection from outside ambient temperatures. Temperature and presence of snow influence both time of roosting and size of roost flock. Flocks roost earlier as temperatures drop and flock size increases when snow covers ground. While roosting they use protected sites, huddling, and hypothermia for energy-saving mechanisms. The pygmy nuthatch feeds almost exclusively in pines and eats weevils, leaf and bark beetles, and pine seeds. Energy assimilated increases with rising ambient temp and barometric pressure, and decreases with higher wind speeds and precipitation. Temperature and wind speed have greatest effect - individuals are less active on colder and windier days, when they are more apt to roost in the shelter of a branch or in a cavity.



Figure 10.32. Sitta pygmaea, photo by nps.gov

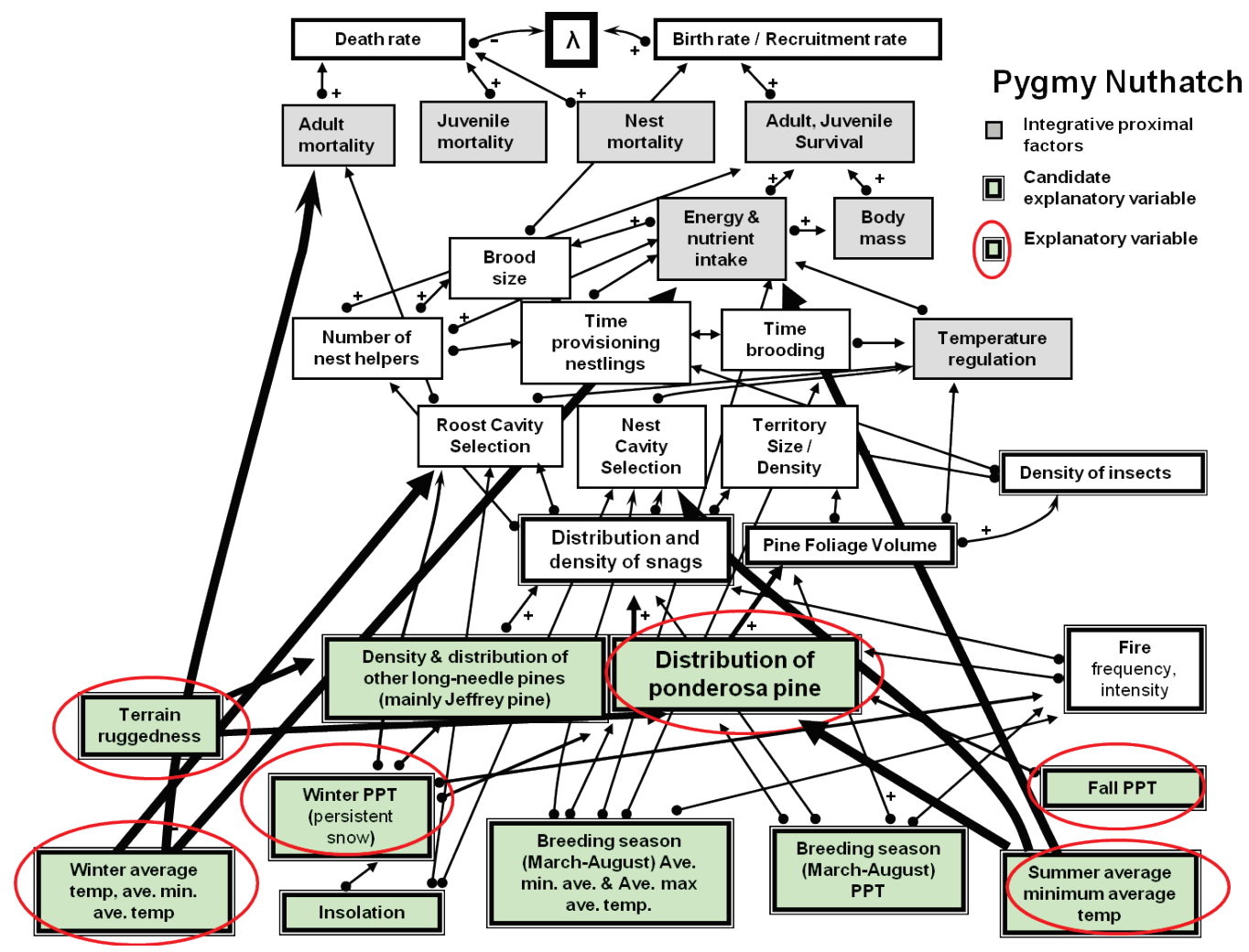

Figure 10.33. Conceptual model of factors affecting pygmy nuthatch range and population dynamics, including explanatory variables used to model current range (in green and circled red). The relative strength of different effects is denoted by the width of connecting arrows. 


\section{RANGE PROJECTIONS - 2099}
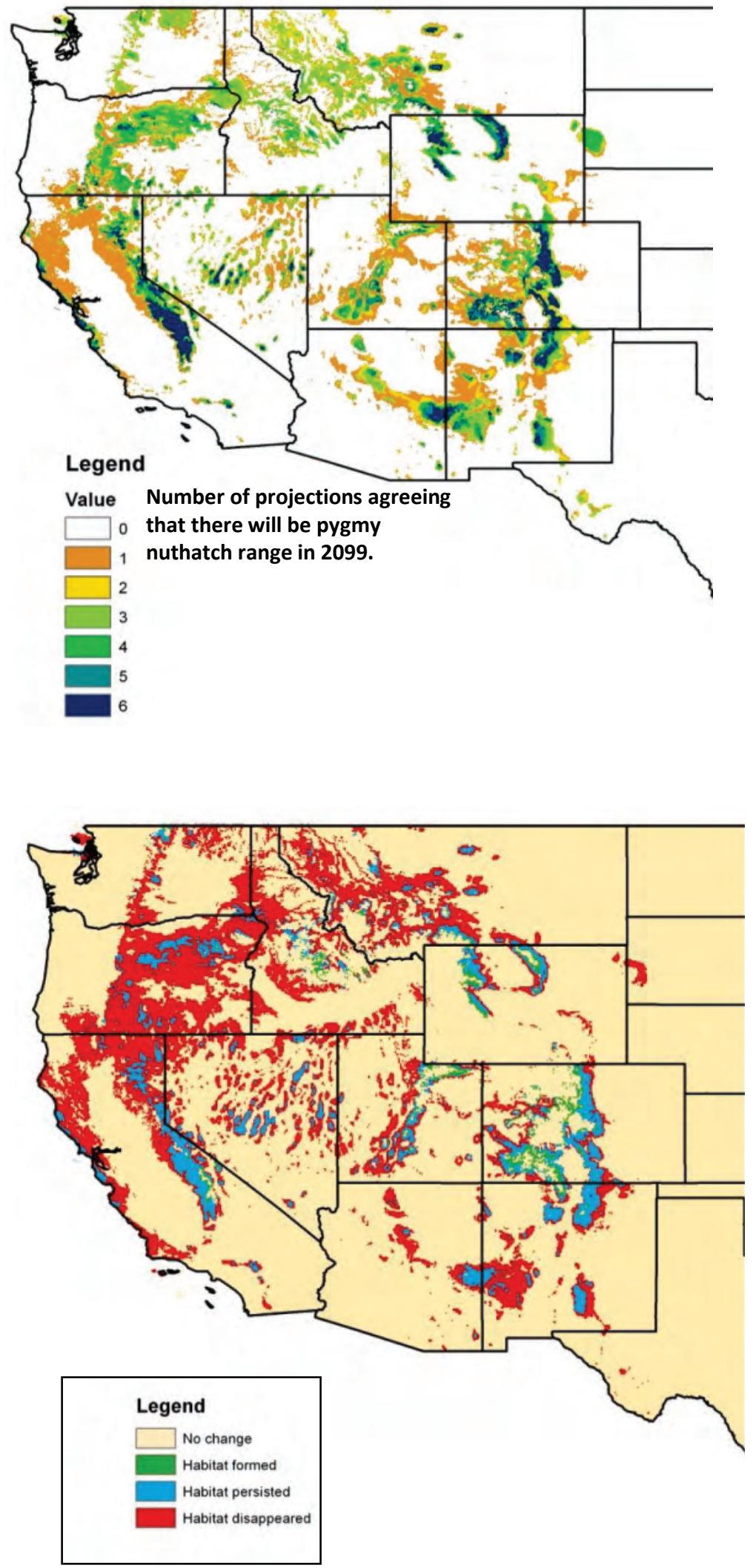

Figure 10.34. Predicted pygmy nuthatch range in 2099, showing levels of agreement among predictions based on 5 different statistically downscaled GCMs plus $a 6^{\text {th }}$ representing an ensemble of 22 GCMs. White denotes areas where all projections agree there will not be nuthatch range, whereas blue denotes areas where all agree there will be nuthatch range.
Figure 10.35. Areas where $\geq 5$ GCM projections predict there will be pygmy nuthatch range in 2099 compared to range in 2000, showing areas of range loss (red), range gain (green), and range persistence (blue) between 2000 and2099. 


\section{Rank order of variable influence in the model}

1. Mean fall (Sept. - Nov.) precipitation (pptavg_f)

2. Mean winter (Dec. - Feb.) temperatures (tmpavg_w)

3. Mean winter (Dec. - Feb.) precipitation (pptavg_w)

4. Pinus ponderosa range (pipo)

5. Minimum summer (June - Aug.) temperature (tmpmin_s)

6. Terrain ruggedness (TRI)

\section{Relationship}

quadratic

quadratic

quadratic

monotonic

quadratic

quadratic

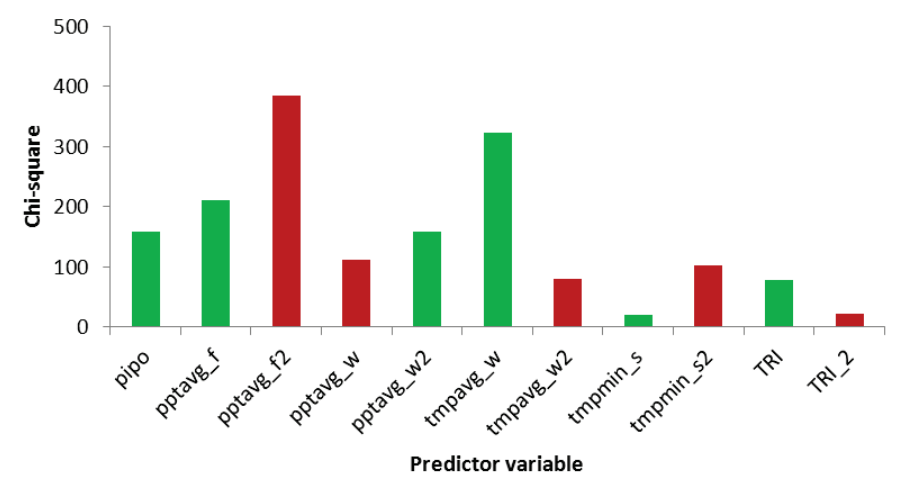

Figure 10.36. Relative influence of variables retained in the best model of current range, as measured by the chisquared statistic. Green denotes a positive effect; red denotes a negative effect. Variables with a "2" denote a quadratic term.
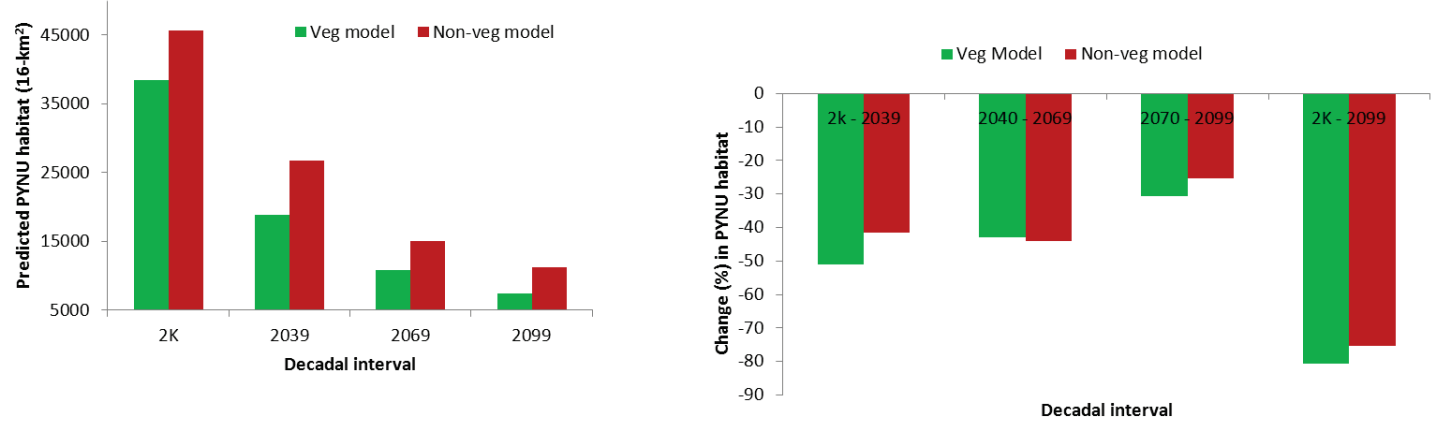

Figure 10.37. Measures of range change among four decadal intervals for the period 2000 through 2099. The figure on the left shows extent of modeled current or projected future range reckoned in terms of area. The figure on the right shows the change in range extent as a percent of current range. Green bars are results produced by the model that includes the effect of plant species ranges; red bars are results produced by the model that does not include plant range effects. Values were calculated based on areas of agreement of at least 5 of the 6 climate projections. 


\section{Williamson's sapsucker}

\section{Sphyrapicus thyroideus}

The Williamson's sapsucker inhabits open coniferous and mixed coniferousdeciduous forests of western North America, and has been considered a sensitive indicator species because of its specific habitat requirements. Like other sapsuckers, it drills conspicuous rings of holes ("sap wells") into tree trunks, specializing on eating coniferous sap and phloem. Breeders switch to a diet of ants during the nestling period. In the Southwest it occupies mixed conifer forests, but may be more common in ponderosa pine (Pinus ponderosa) dominated forests in other areas. Across its range it breeds at middle to high elevations in montane spruce-fir (Picea-Abies), Douglas fir (Pseudotsuga menziesii), lodgepole pine (Pinus contorta) and ponderosa pine forests, as well as mixed deciduous-coniferous forest with quaking aspen (Populus tremuloides). It has a preference for snags as nest sites and in most places aspen snags are preferred over conifer snags. This species is on the 2007 (most recent) WatchList for United States Birds and the USFWS Federal list of birds of conservation concern due to its rarity.

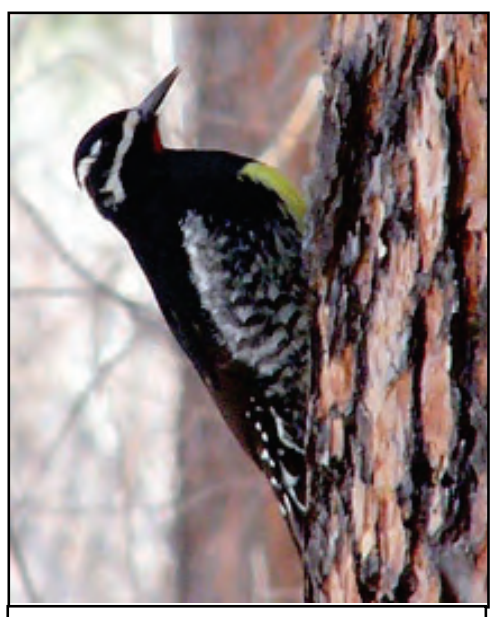

Figure 10.38. Sphyrapicus thyroideus, photo by Sally King/U.S. Fish and Wildlife Service

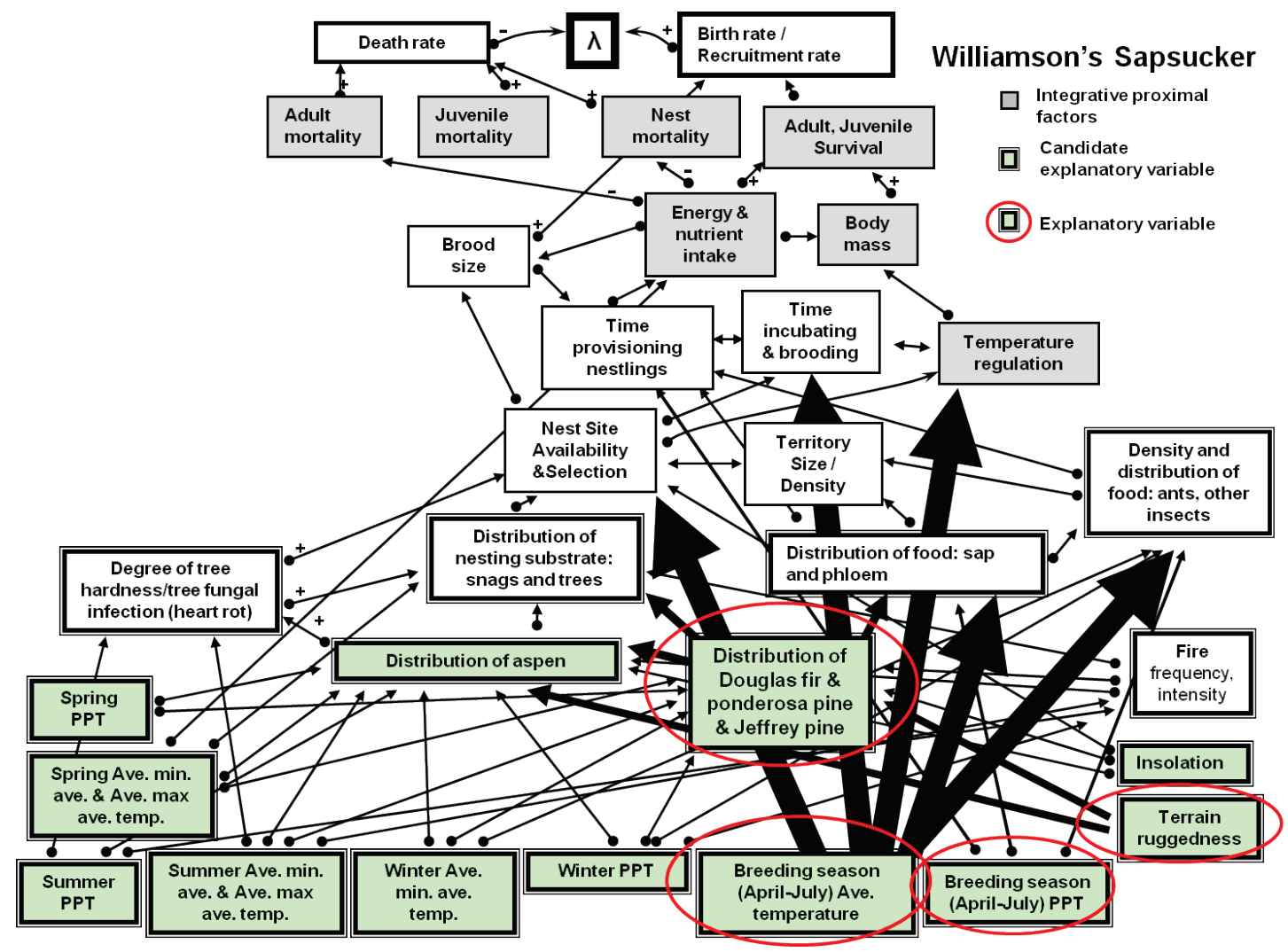

Figure 10.39. Conceptual model of factors affecting Williamson's sapsucker range and population dynamics, including explanatory variables used to model current range (in green and circled red). The relative strength of different effects is denoted by the width of connecting arrows. 


\section{RANGE PROJECTIONS - 2099}
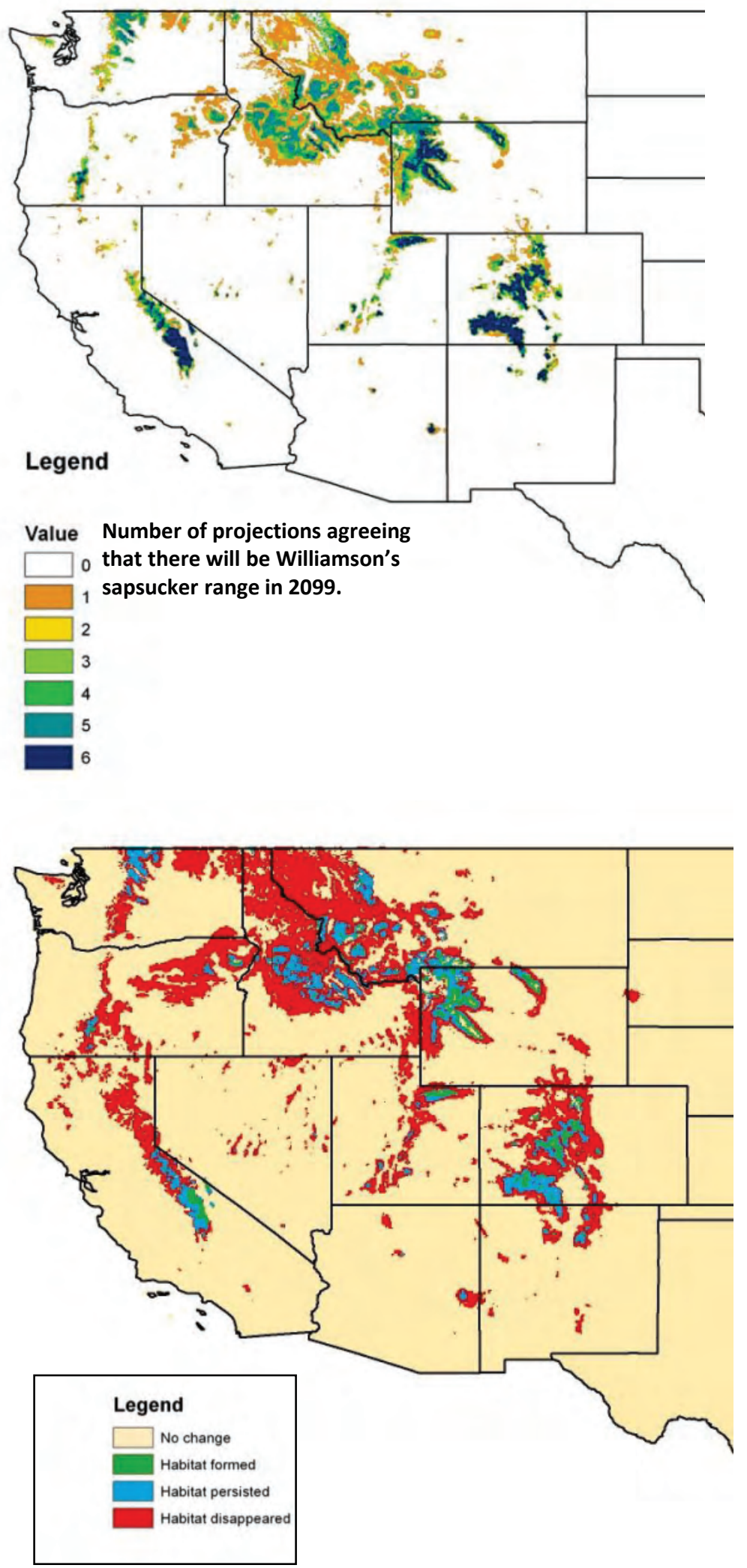

Figure 10.40. Predicted Williamson's sapsucker range in 2099, showing levels of agreement among predictions based on 5 different statistically downscaled GCMs plus a $6^{\text {th }}$ representing an ensemble of 22 GCMs. White denotes areas where all projections agree there will not be sapsucker range, whereas blue denotes areas where all agree there will be sapsucker range.

Figure 10.41. Areas where $\geq 5$ GCM projections predict there will be Williamson's sapsucker range in 2099 compared to range in 2000, showing areas of range loss (red), range gain (green), and range persistence (blue) between 2000 and 2099. 


\begin{tabular}{|lll}
\hline Rank order of variable influence in the model & Relationship \\
1. Pinus jeffreyi range (pije) & monotonic \\
2. Mean breeding season (April-July) temperatures & quadratic \\
3. Pseudotsuga menzeisii range (psmeg) & monotonic \\
4. Pinus ponderosa range (pipo) & monotonic \\
5. Mean breeding season (April-July) precipitation & quadratic \\
6. Terrain ruggedness (TRI) & quadratic \\
\hline
\end{tabular}

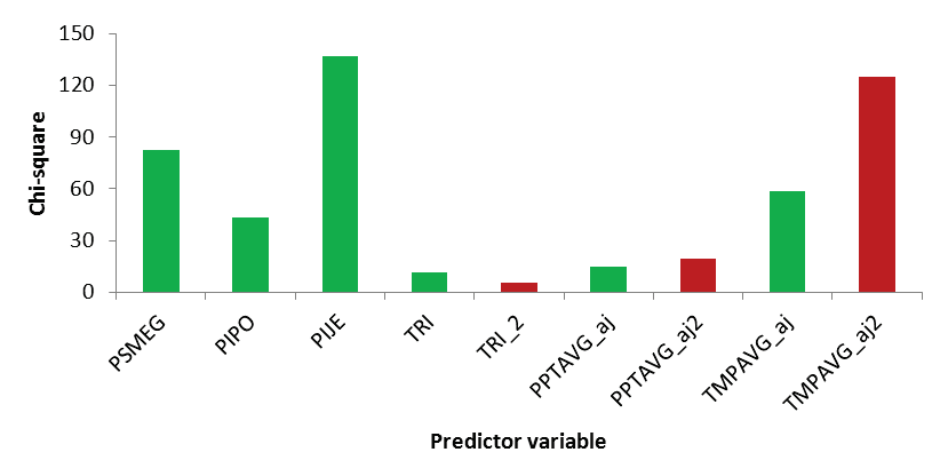

Figure 10.42. Relative influence of variables retained in the best model of current range, as measured by the chisquared statistic. Green denotes a positive effect; red denotes a negative effect. Variables with a "2" denote a quadratic term.
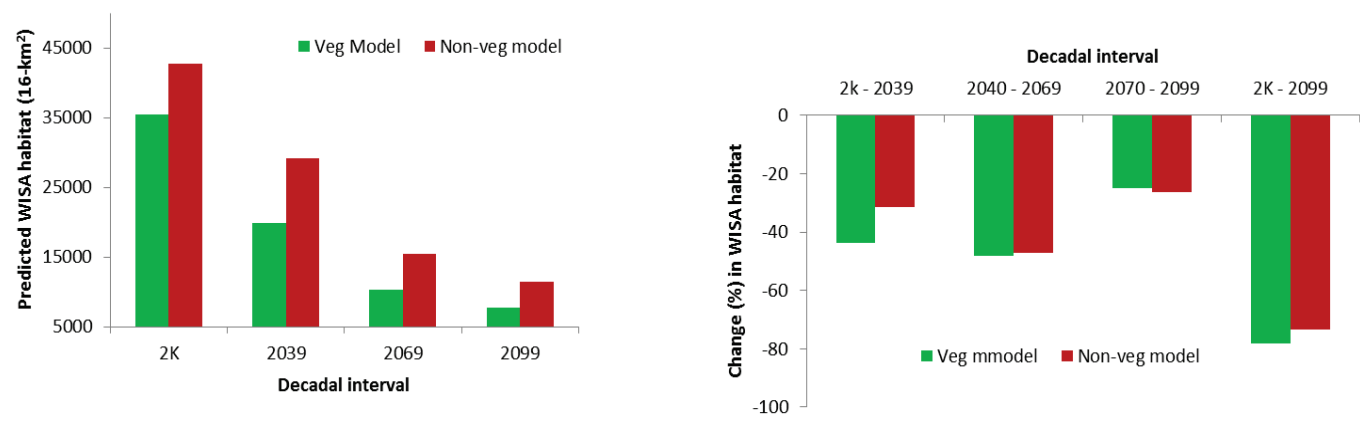

Figure 10.43. Measures of range change among four decadal intervals for the period 2000 through 2099. The figure on the left shows extent of modeled current or projected future range reckoned in terms of area. The figure on the right shows the change in range extent as a percent of current range. Green bars are results produced by the model that includes the effect of plant species ranges; red bars are results produced by the model that does not include plant range effects. Values were calculated based on areas of agreement of at least 5 of the 6 climate projections. 


\section{Insert 11: Reptile Species Accounts}

\section{PLATEAU STRIPED WHIPTAIL}

\section{Aspidoscelis velox}

The plateau striped whiptail lizard species complex inhabits a variety of grassland and scrub and shrub habitats on the Colorado Plateau and in central New Mexico, at elevations ranging from 1,400 to 2,440 m. This is a mediumsized $(70-90 \mathrm{~mm}$ ) all-female species. Unisexual whiptails reproduce by parthenogenesis, in which unfertilized eggs hatch into clones of the mother. Adults live for at least 4-5 years. Adults are typically active between May and mid-September while juveniles are active later into the fall. Female Plateau Striped Whiptails lay three to five eggs in June, and hatchlings emerge between July and September. Whiptail lizards are actively-foraging diurnal insectivores known for running after insect and hatchling lizard prey, and typically maintain body temperatures around 38 degrees Celsius when active. Where present, individuals of Plateau Striped Whiptails are usually abundant. Given their size and unisexual reproductive mode, they may create significant competition for prey where they co-occur with bisexual whiptail and other lizard species.

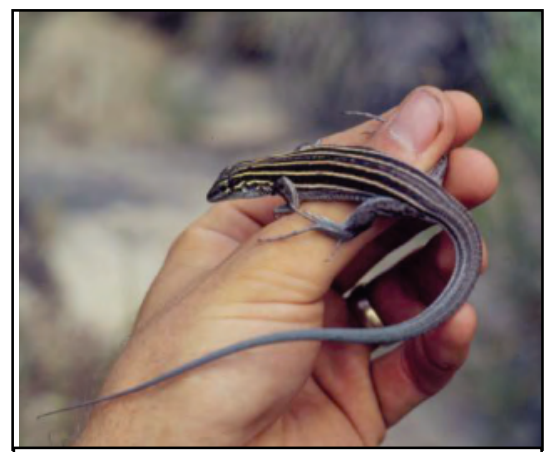

Figure 11.1. Aspidoscelis velox, Arizona, photo by Trevor Persons, Northern Arizona University

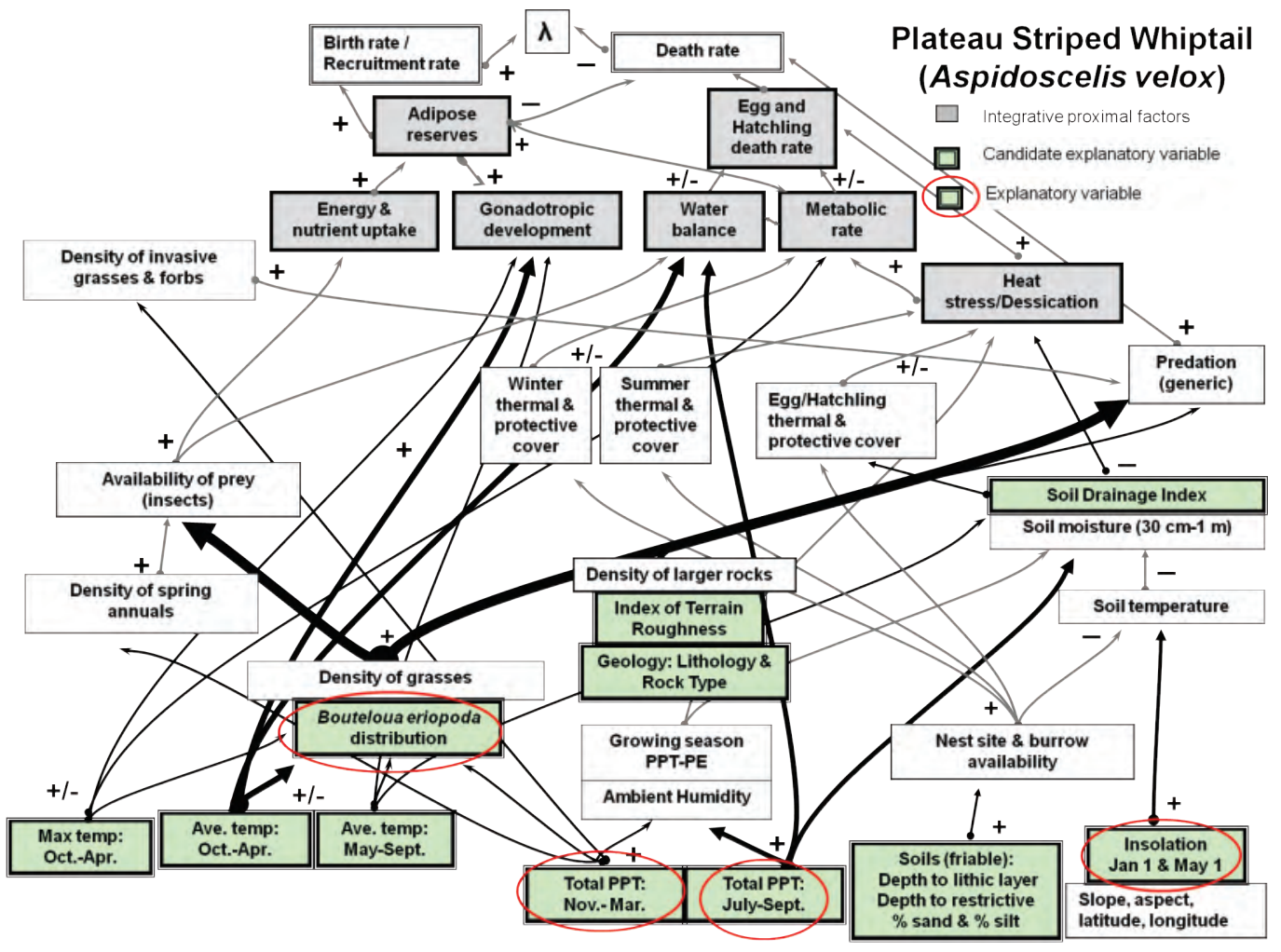

Figure 11.2. Conceptual model of factors affecting suitable habitat for plateau striped whiptail and population dynamics, including explanatory variables used to model current suitable habitat for plateau striped whiptail (in green and circled red). The relative strength of different effects is denoted by the width of connecting arrows. 


\section{Range Projections-2099}

Number of projections agreeing where there will be suitable habitat in 2099.
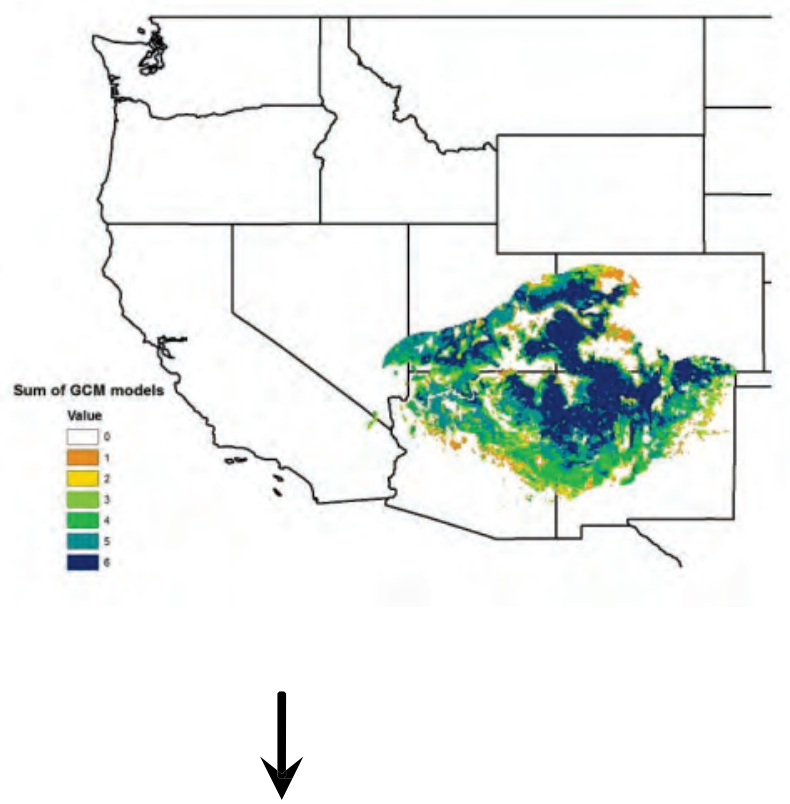

Figure 11.3b. Illustration of Western United States showing modeled areas (including vegetation variables) where projections of greater than or equal to five global circulation models project there will be suitable habitat in 2099, showing areas of habitat loss (red), habitat gain (green), and habitat persistence (blue) between 2010 and 2099.

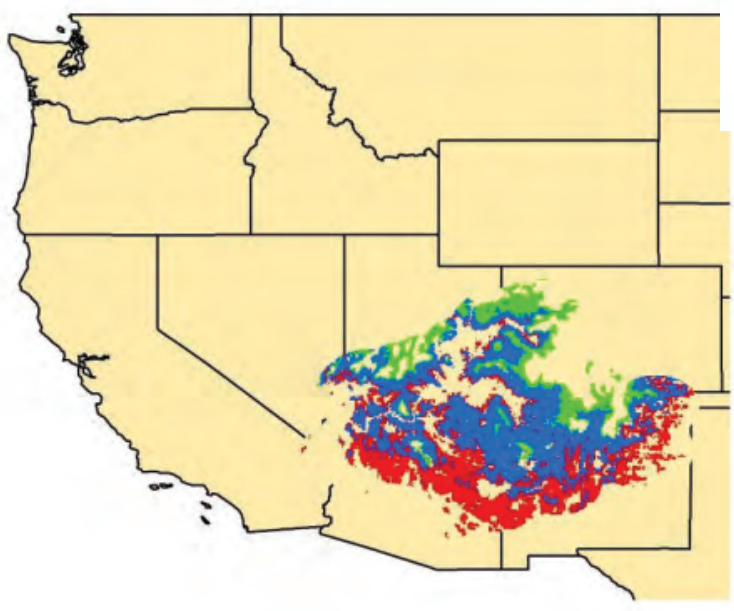

Figure 11.3a. Illustration of Western United States showing projected range in 2099, showing levels of agreement among predictions based on 5 different statistically downscaled global circulation models (GCM) plus a 6th representing an ensemble of 22 GCMs. White denotes areas where all projections agree there will not be suitable habitat, whereas blue denotes areas where all models agree that suitable habitat will exist.

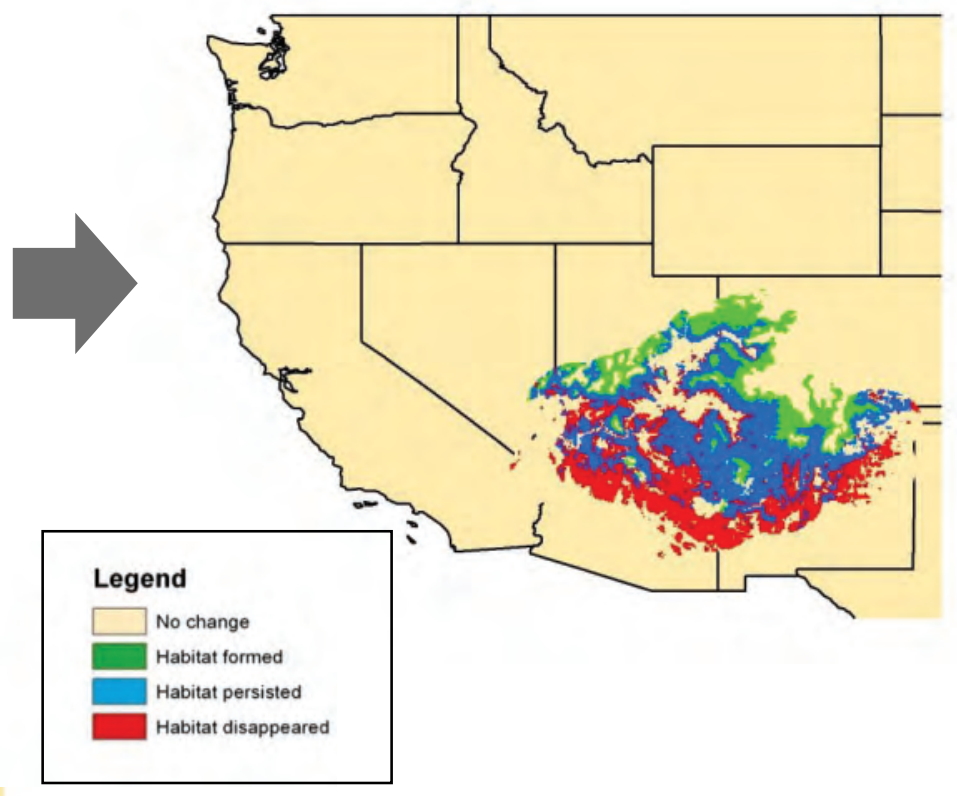

Figure 11.3c. Illustration of Western United States showing modeled areas (excluding vegetation variables) where projections of greater than or equal to five global circulation models project there will be suitable habitat in 2099, showing areas of habitat loss (red), habitat gain (green), and habitat persistence (blue) between 2010 and 2099. 


\section{Model Results}

Area Under the Curve (AUC)
AUC with plant species ranges

0.924

AUC without plant species ranges $\mathbf{0 . 9 2 6}$

\section{Summary of variable importance}

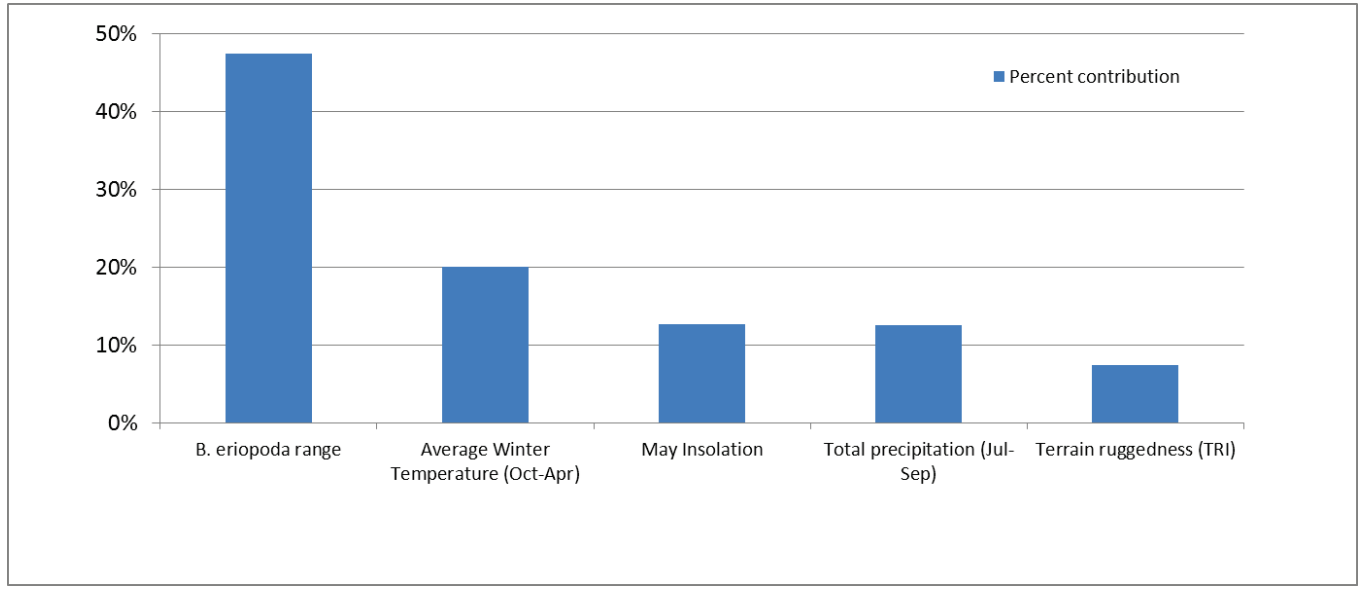

Figure 11.4. Graph showing percent contribution of variables retained in the best model of current range. Variable contributions should be interpreted with caution when the predictor variables are correlated.

\section{Projected change in area of suitable habitat}
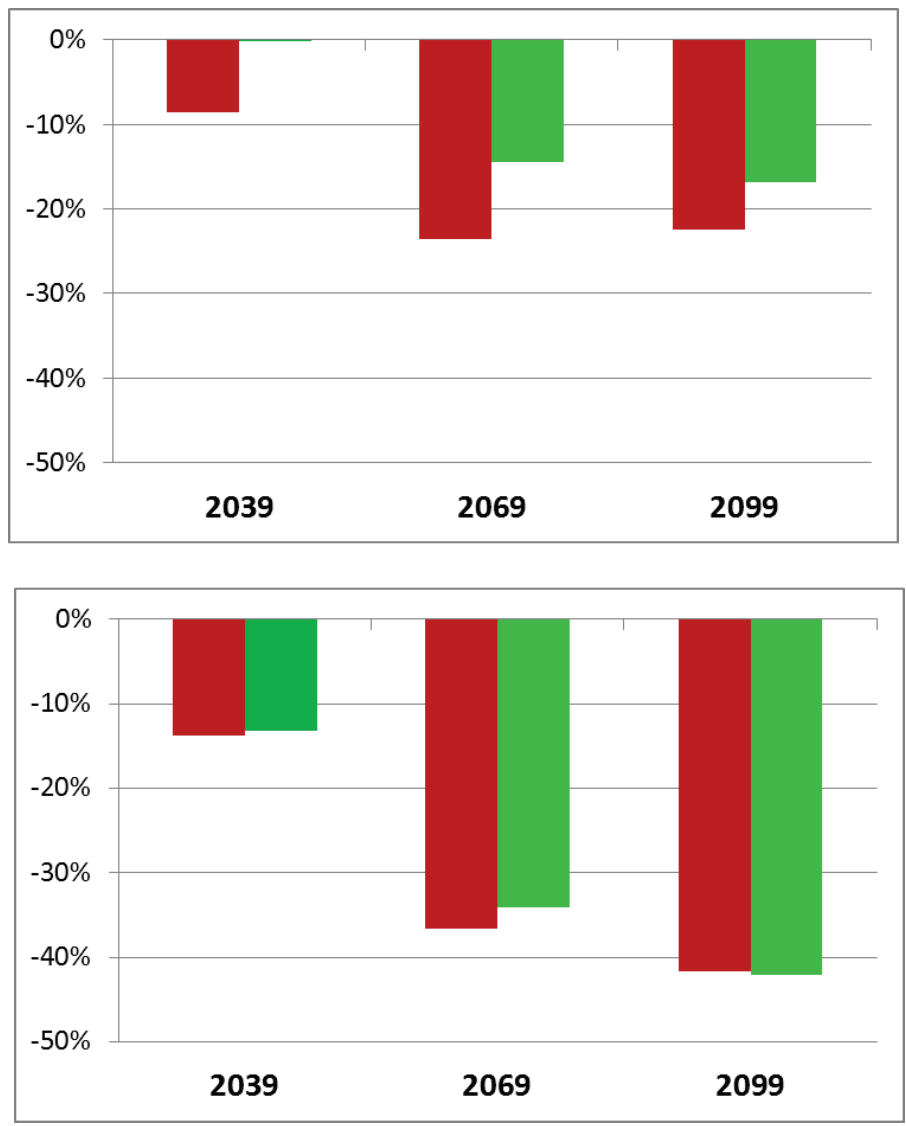

Unlimited dispersal

\section{No dispersal}

Figure 11.5. Measures of projected change in range at end of three different decades as a percent of current modeled range (year 2010). Green bars are results produced by the model that includes the effect of plant species ranges; red bars are results produced by the model that does not include plant range effects. Values were calculated based on areas of agreement of at least five of the six climate projections. 


\section{ARIZONA BLACK RATTLESNAKE}

\section{Crotalus cerberus}

The Arizona black rattlesnake is a high-elevation medium-sized $(<1,000$ $\mathrm{mm}$ ) rattlesnake found primarily in Arizona and extreme western New Mexico. Adults are dark brown or black in background color, with white- or yellow-edged barker hexagonal blotches. Juveniles are born with a grey background and dark blotches. Arizona black rattlesnakes are typically found in pine-oak woodlands or chaparral habitats. At high elevations, they appear to rely on south, west, or east-facing blocky volcanic outcrops surrounded by talus, to survive freezing winter temperatures. In lower deserts, the species appears restricted to cool, moist drainages, and may favor hibernation locations with northern or western aspects. Adults eat small mammals, birds, and lizards, while juveniles eat lizards. The species is long-lived and very social, with all ages hibernating in large groups, and pregnant females gestating and giving birth in smaller groups. This sociality is possibly due to limited suitable hibernation and rookery sites, or

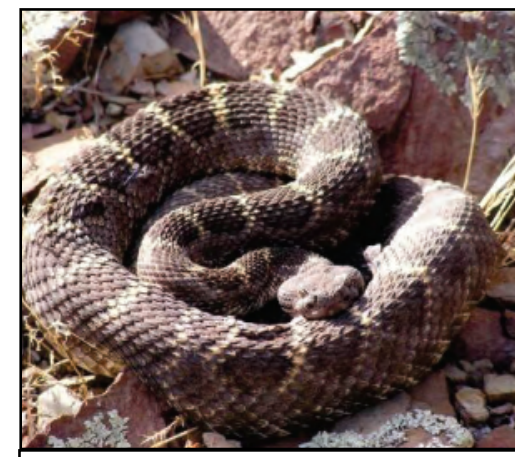

Figure 11.6. Crotalus Cerberus, photo by Erika Nowak, U.S.G.S., and Northern Arizona University relatedness.

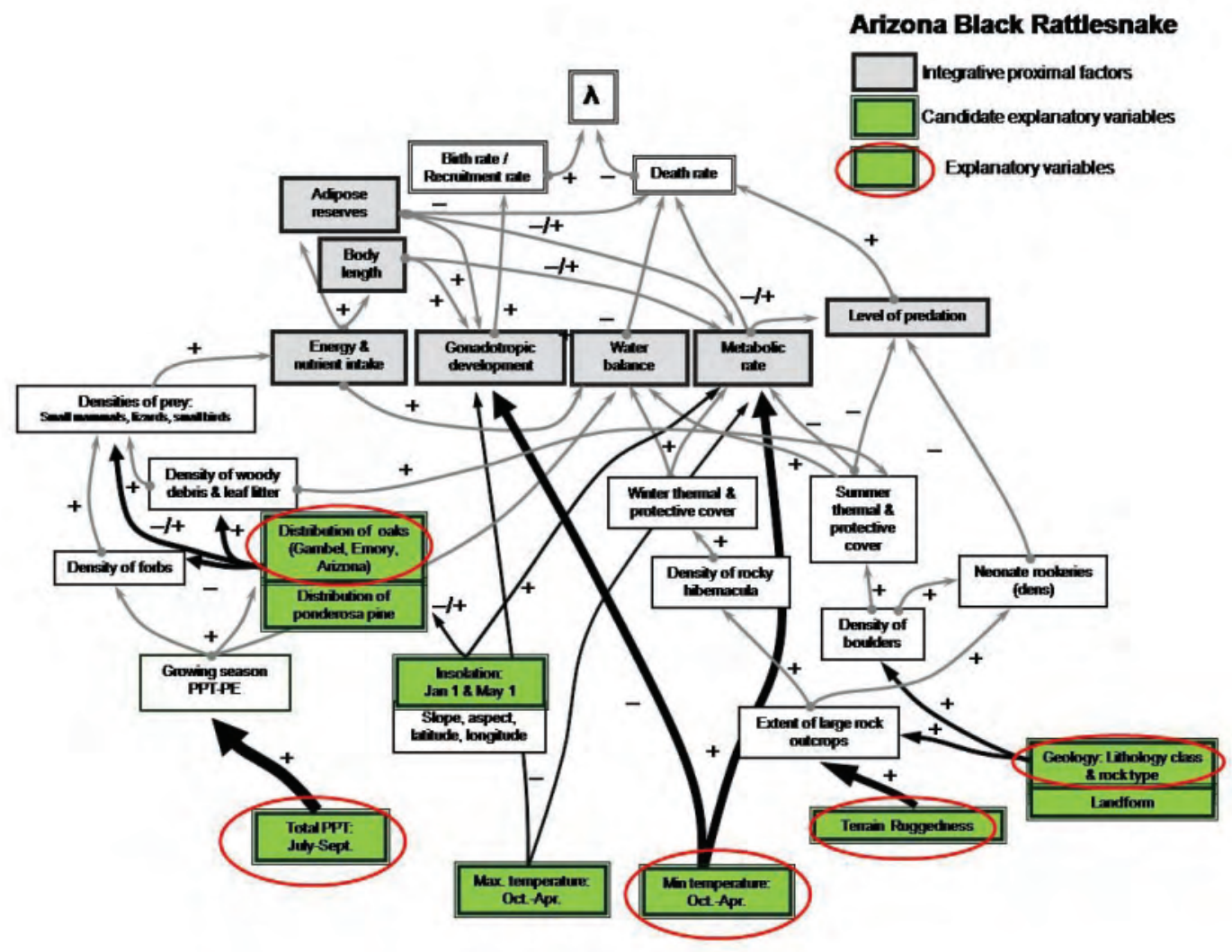

Figure 11.7. Conceptual model of factors affecting suitable habitat for Arizona black rattlesnake and population dynamics, including explanatory variables used to model current suitable habitat for Arizona black rattlesnake (in green and circled red). The relative strength of different effects is denoted by the width of connecting arrows. 


\section{PROJECTIONS - 2099}

Number of projections agreeing where there will be suitable habitat in 2099.
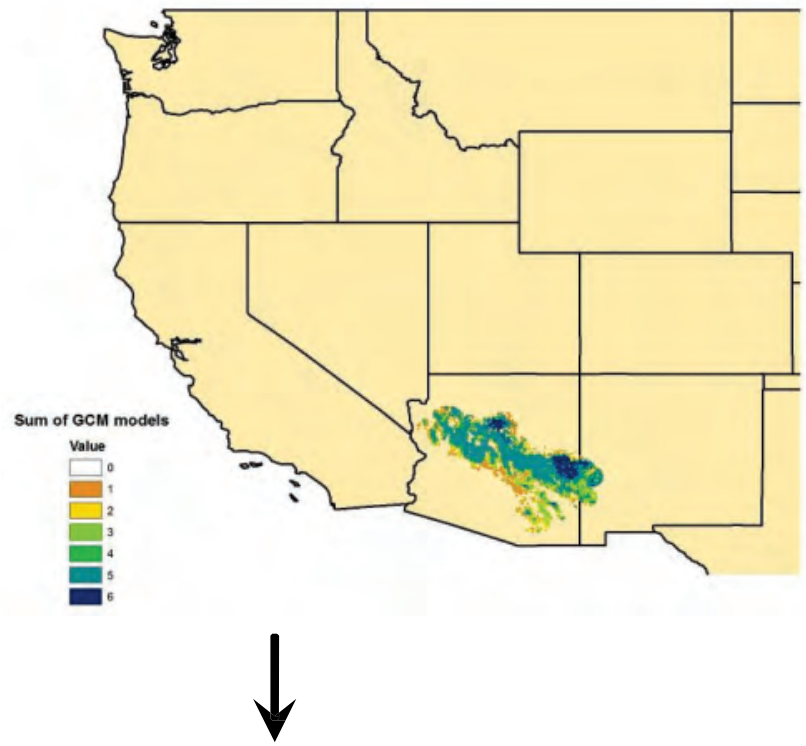

Figure 11.8b. Illustration of Western United States showing modeled areas (including vegetation variables) where projections of greater than or equal to five global circulation models predict there will be suitable habitat in 2099, showing areas of habitat loss (red), habitat gain (green), and habitat persistence (blue) between 2010 and 2099.

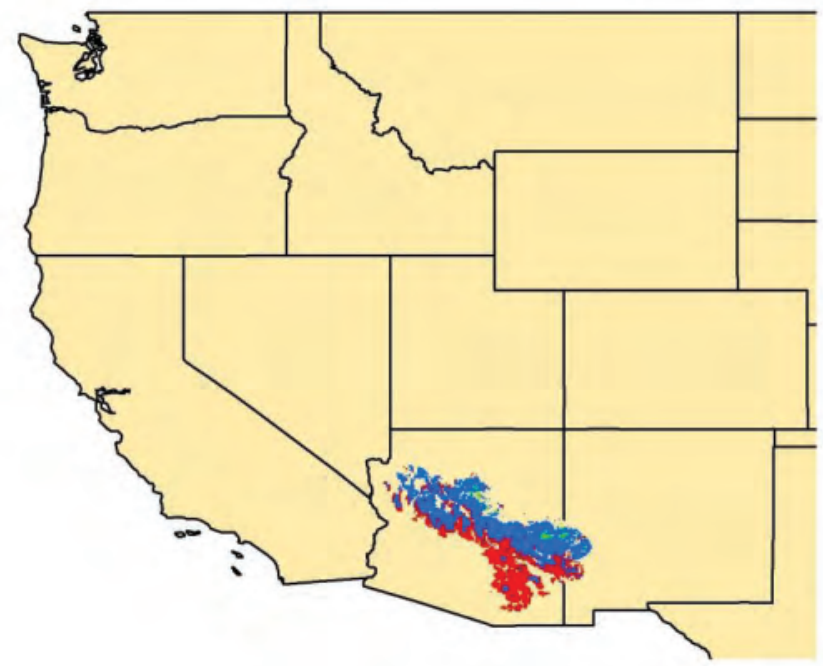

Figure 11.8a. Illustration of Western United States showing predicted range in 2099, showing levels of agreement among predictions based on 5 different statistically downscaled global circulation models (GCM) plus a 6th representing an ensemble of 22 GCMs. White denotes areas where all projections agree there will not be suitable habitat, whereas blue denotes areas where all models agree that suitable habitat will exist.

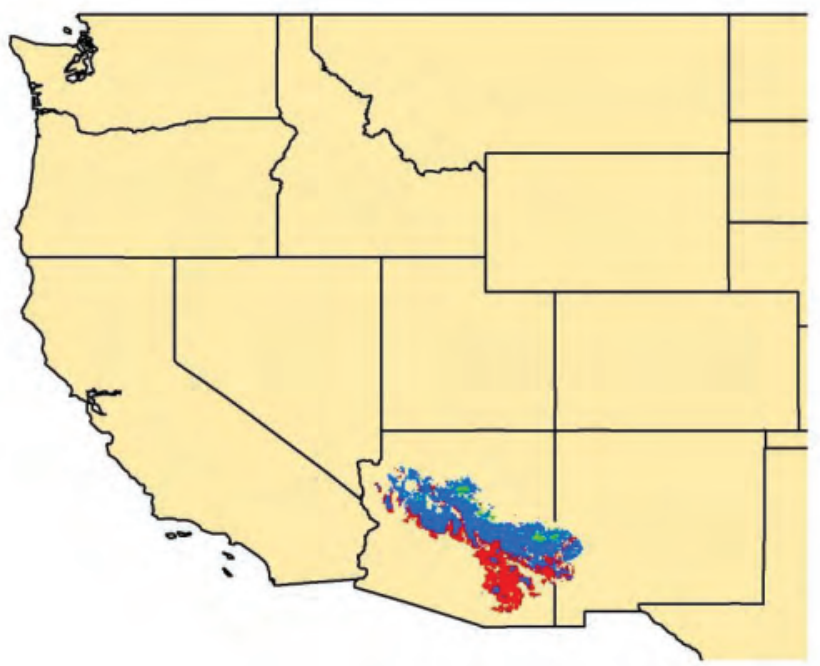

Legend

No change

Habitat formed

Habitat persisted

Habitat disappeared
Figure 11.8c. Illustration of Western United States showing modeled areas (excluding vegetation variables) where projections of greater than or equal to five global circulation models predict there will be suitable habitat in 2099, showing areas of habitat loss (red), habitat gain (green), and habitat persistence (blue) between 2010 and 2099. 


\section{Summary of variable importance}

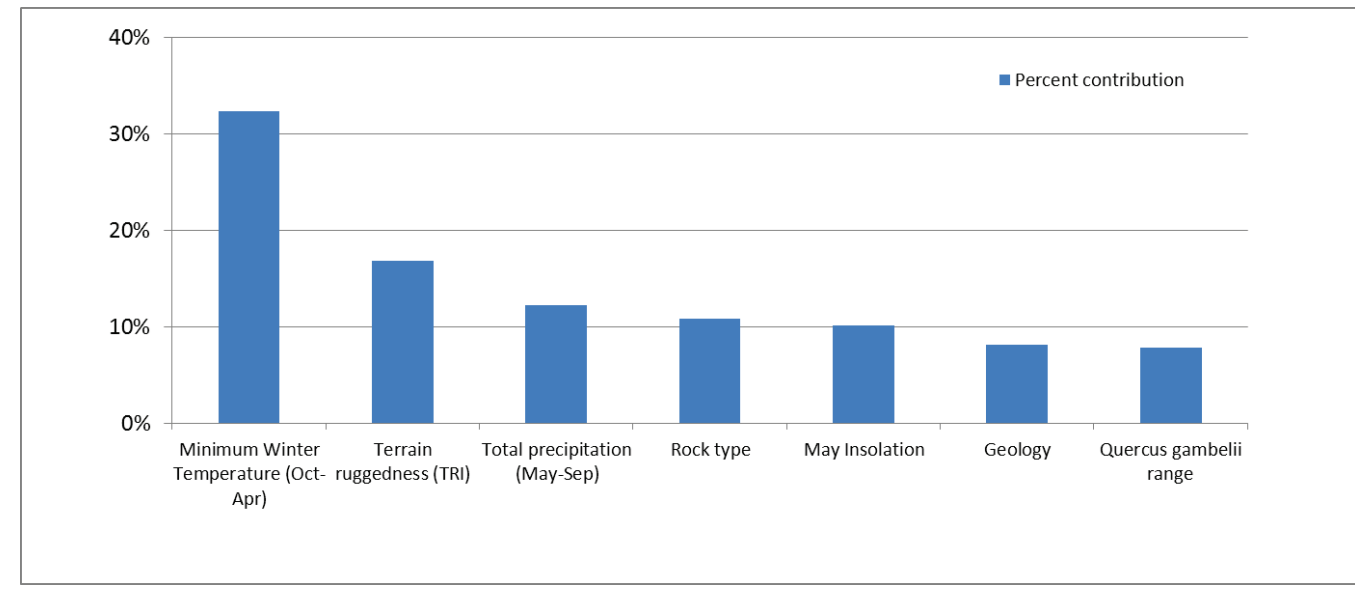

Figure 11.9. Graph showing percent contribution of variables retained in the best model of current range. Variable contributions should be interpreted with caution when the predictor variables are correlated.

\section{Projected change in area of suitable habitat}

Unlimited dispersal

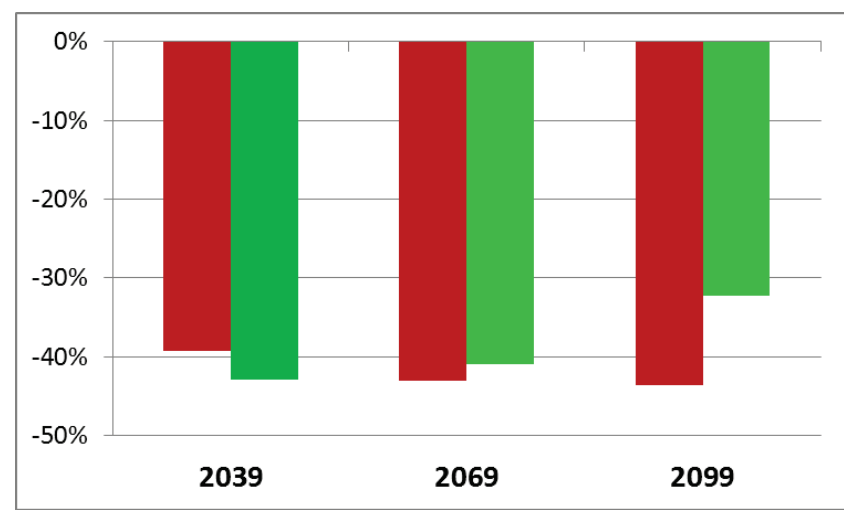

No dispersal

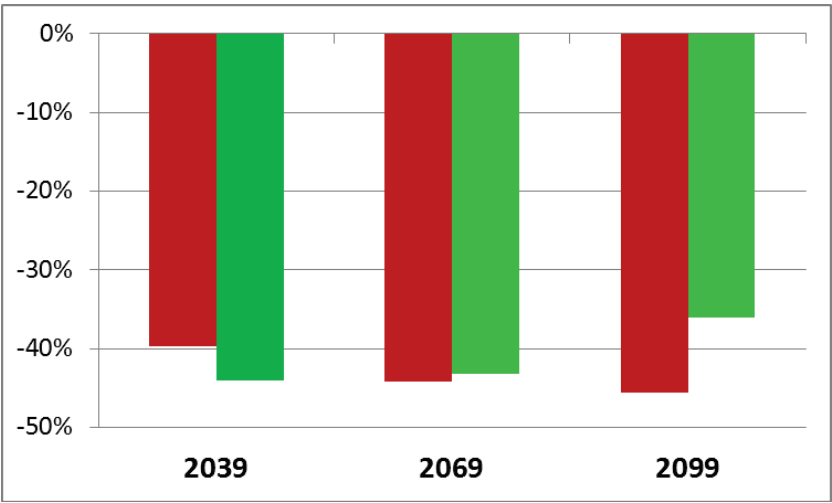

Figure 11.10. Measures of projected change in range at end of three different decades as a percent of current modeled range (year 2010). Green bars are results produced by the model that include the effect of plant species ranges; red bars are results produced by the model that does not include plant range effects. Values were calculated based on areas of agreement of at least five of the six climate projections. 


\section{DESERT TORTOISE}

\section{Gopherus agassizii}

The desert tortoise is found across the Mojave and Sonoran deserts of the US and Mexico. Recent work suggests that the Sonoran Desert population is genetically distinct; this species (G. morafkai) occurs in upland Sonoran Desert scrub and grassland associations with rocky outcrops and alluvial fans, at elevations up to $1,420 \mathrm{~m}$. Individuals use burrows that they excavate under outcrops, boulders, or caliche caves for retreat and hibernation sites. Tortoises feed on perennial and winter annual plants; favored forage plants include grasses, mallows, and desert vine. Individuals are particularly active during mid-March to May and late July to late September following rainfall-induced increases in plant productivity. To survive during dry periods, tortoises cease feeding, and rely on water stored in their bladders and very low metabolic rates. Female Sonoran tortoises lay 1-12 eggs in a single clutch in late June and July. Hatchlings emerge in early fall following monsoon rains, and are particularly susceptible to desiccation and starvation during dry years. This very long-lived species is facing many conservation threats, including habitat loss, overgrazing, invasive plants, disease, and subsidized predators (such as, dogs and ravens [Corvus corax]).

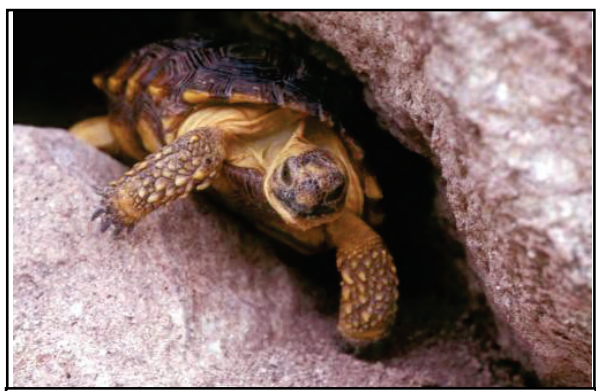

Figure 11.11. Gopherus agassizii, photo by Cecil Schwalbe/University of Arizona SNRE and U.S.G.S. Sonoran Desert Research Station



Figure 11.12. Conceptual model of factors affecting suitable habitat for Sonoran desert (Morafka's) tortoise, and population dynamics, including explanatory variables used to model current suitable habitat for Sonoran desert tortoise (in green and circled red). The relative strength of different effects is denoted by the width of connecting arrows. 


\section{PROJECTIONS - 2099}

Number of projections agreeing where there will be suitable habitat in 2099.

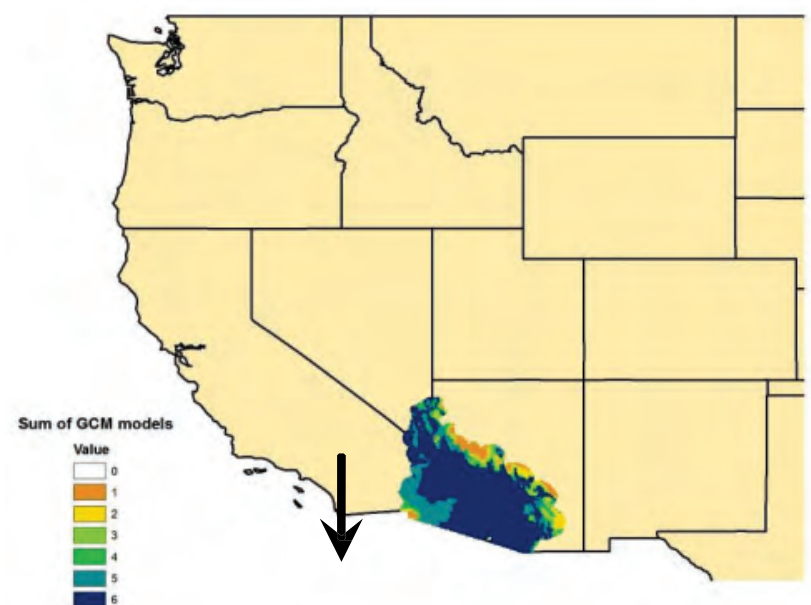

Figure 11.13b. Illustration of Western United States showing modeled areas (including vegetation variables) where projections of greater than or equal to five global circulation models predict there will be suitable habitat in 2099, showing areas of habitat loss (red), habitat gain (green), and habitat persistence (blue) between 2010 and 2099.

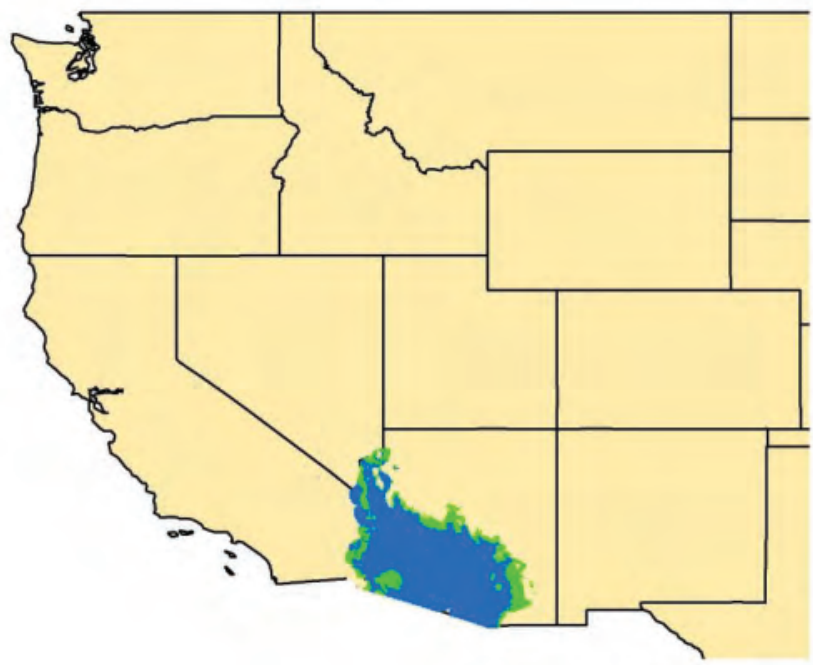

Figure 11.13a. Illustration of Western United States showing predicted range in 2099, showing levels of agreement among predictions based on 5 different statistically downscaled global circulation models (GCM) plus a 6th representing an ensemble of 22 GCMs. White denotes areas where all projections agree there will not be suitable habitat, whereas blue denotes areas where all models agree that suitable habitat will exist.

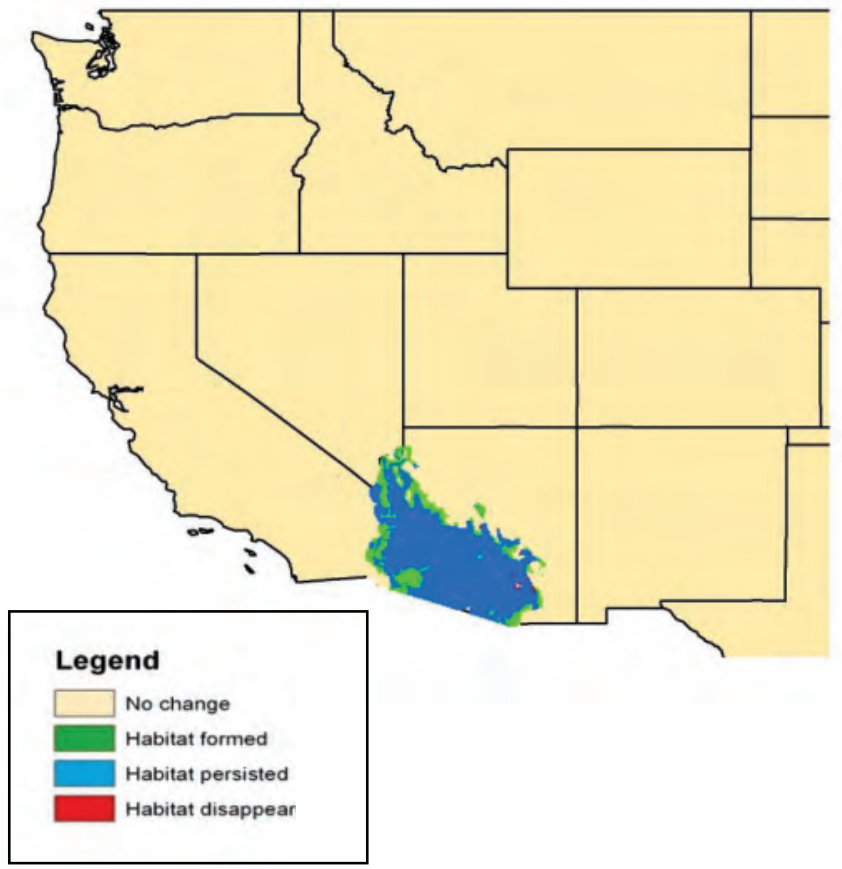

Figure 11.13c . Illustration of Western United States showing modeled areas (excluding vegetation variables) where projections of greater than or equal to five global circulation models predict there will be suitable habitat in 2099, showing areas of habitat loss (red), habitat gain (green), and habitat persistence (blue) between 2010 and 2099. 


\section{Summary of variable importance}

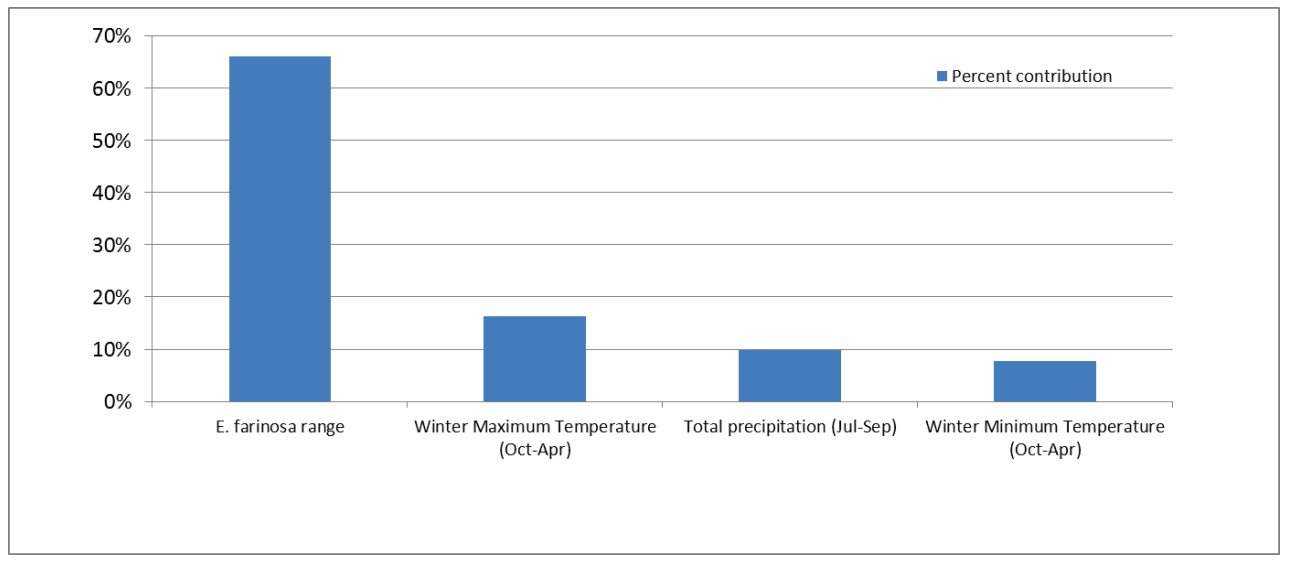

Figure 11.14. Graph showing percent contribution of variables retained in the best model of current range. Variable contributions should be interpreted with caution when the predictor variables are correlated.

\section{Projected change in area of suitable habitat}

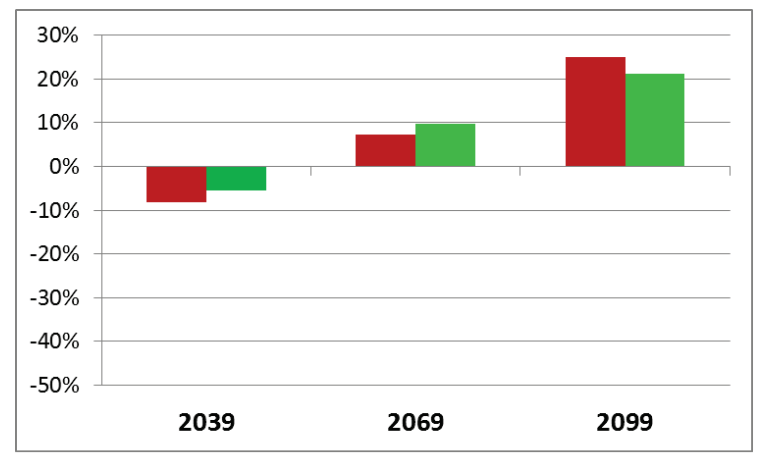

Unlimited dispersal

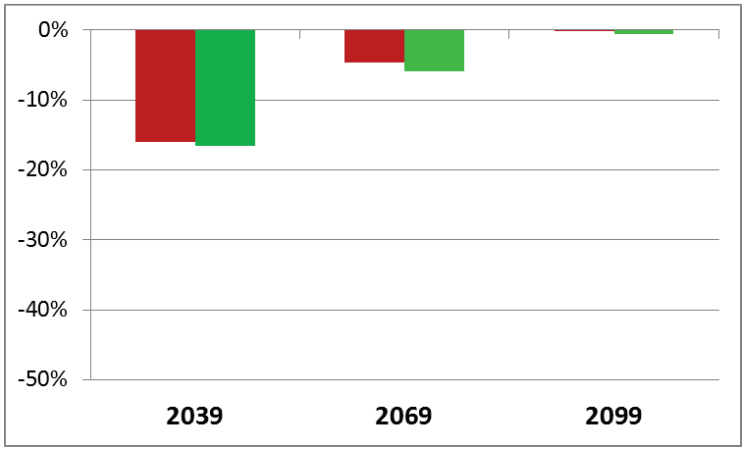

\section{No dispersal}

Figure 11.15. Measures of projected change in range at end of three different decades as a percent of current modeled range (year 2010). Green bars are results produced by the model that include the effect of plant species ranges; red bars are results produced by the model that does not include plant range effects. Values were calculated based on areas of agreement of at least five of the six climate projections. 


\section{LESSER EARLESS LIZARD}

\section{Holbrookia maculata}

The lesser earless species complex is found across short-grass prairie and open habitats of the southern Colorado Plateau, New Mexico, Texas, northern Mexico, and on the western edge of the Great Plains, at elevations ranging from 500 to $2,200 \mathrm{~m}$. The taxonomy of this wide-ranging species has been debated; in our modeling, we did not include museum records in the current range of $H$. elegans. While vegetative habitat types vary, generally this small lizard is found in areas with sandy or loose gravel-covered soils suitable for burrowing, in flats or grasslands. These small, short-lived diurnal lizards are primarily insectivorous, but adults also may eat hatchling lizards. Mating occurs from May to July, and females typically lay one or two clutches of four to six eggs each per year, with hatchlings emerging between July and early fall. The species is of conservation concern because of extensive habitat loss that has occurred across its former range; in many areas this has been a result of habitat conversion following overgrazing by cattle and sheep.

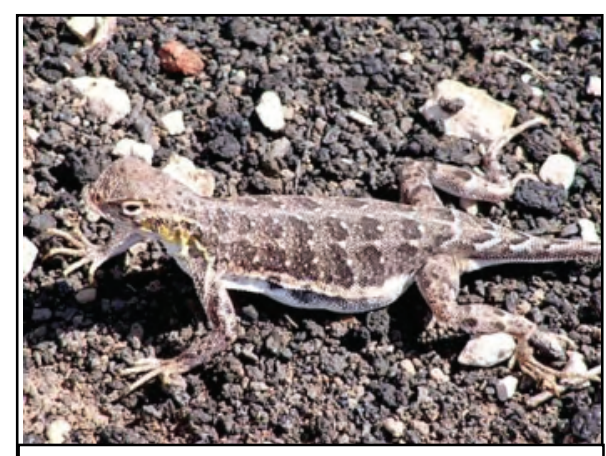

Figure 11.16. Holbrookia maculate, photo by Erika Nowak, U.S.G.S. and Northern Arizona University

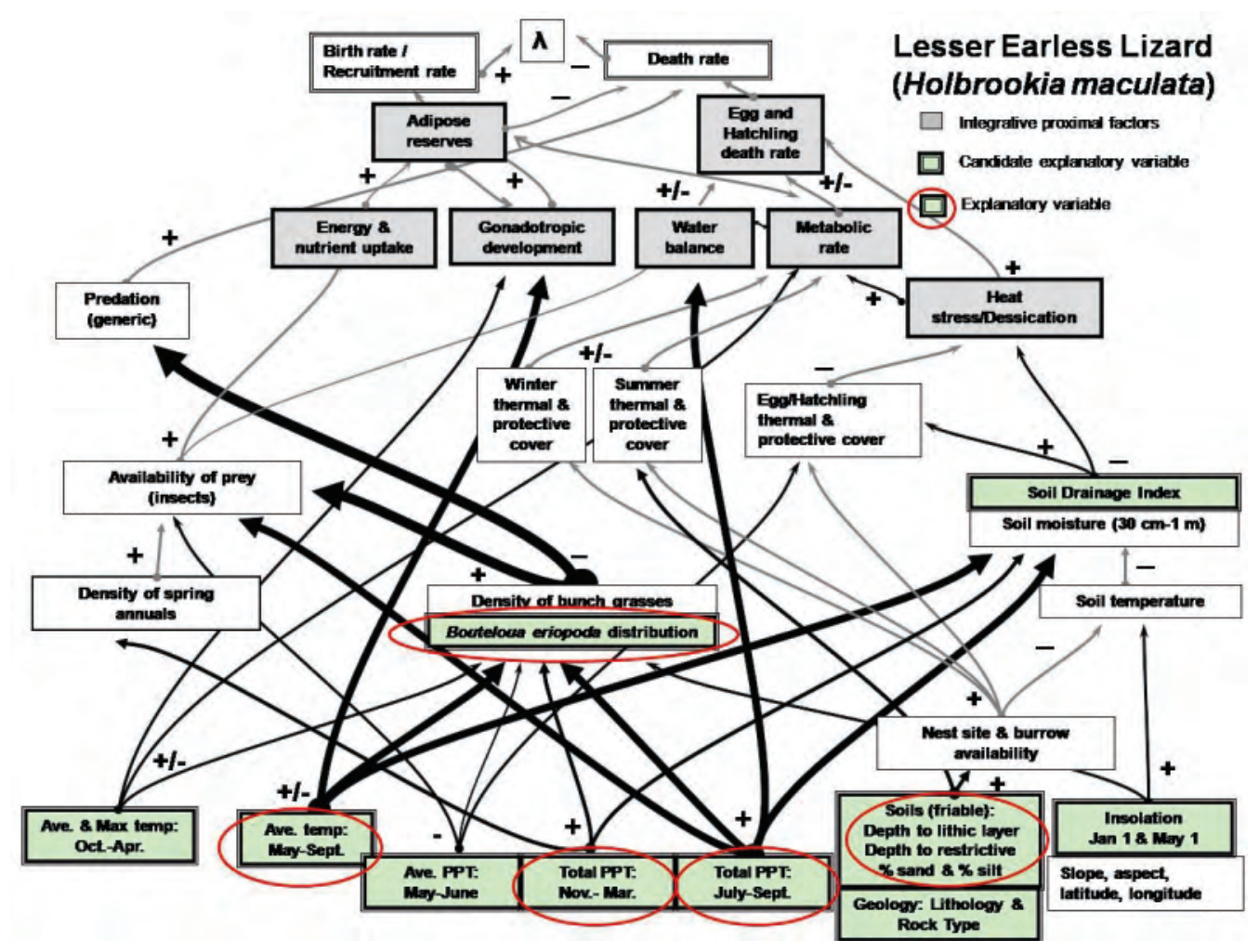

Figure 11.17. Conceptual model of factors affecting suitable habitat for common lesser earless lizard and population dynamics, including explanatory variables used to model current suitable habitat for lesser earless lizard (in green and circled red). The relative strength of different effects is denoted by the width of connecting arrows. 


\section{PROJECTIONS - 2099}

Number of projections agreeing where there will be suitable habitat in 2099.

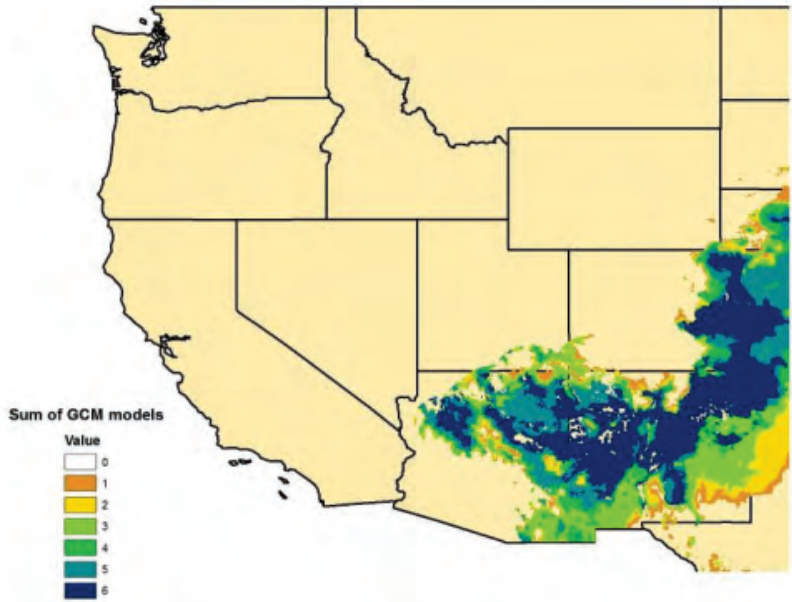

$y$

Figure 11.18b. Illustration of Western United States showing modeled areas (including vegetation variables) where projections of greater than or equal to five global circulation models predict there will be suitable habitat in 2099, showing areas of habitat loss (red), habitat gain (green), and habitat persistence (blue) between 2010 and 2099.

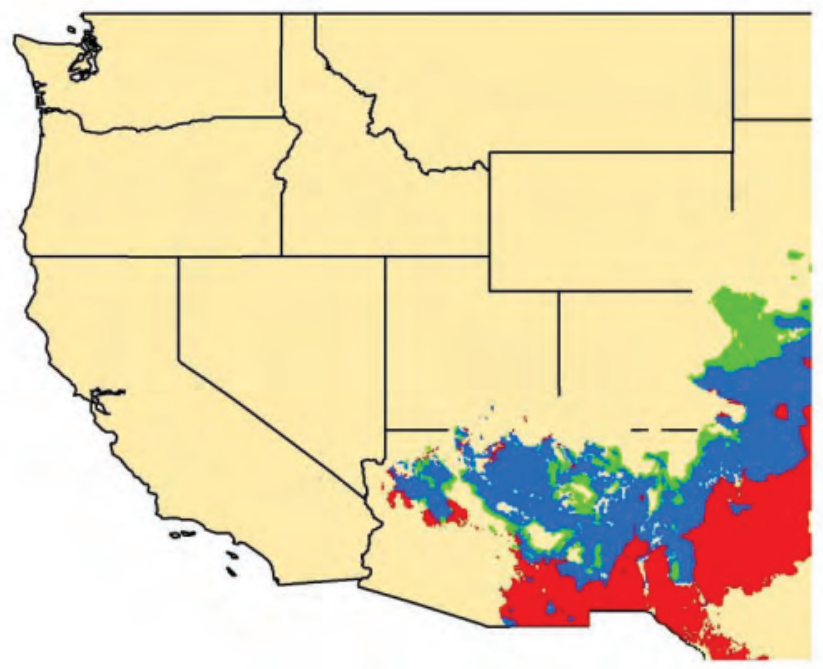

Figure 11.18a. Illustration of Western United States showing predicted range in 2099, showing levels of agreement among predictions based on 5 different statistically downscaled global circulation models (GCM) plus a 6th representing an ensemble of 22 GCMs. White denotes areas where all projections agree there will not be suitable habitat, whereas blue denotes areas where all models agree that suitable habitat will exist.

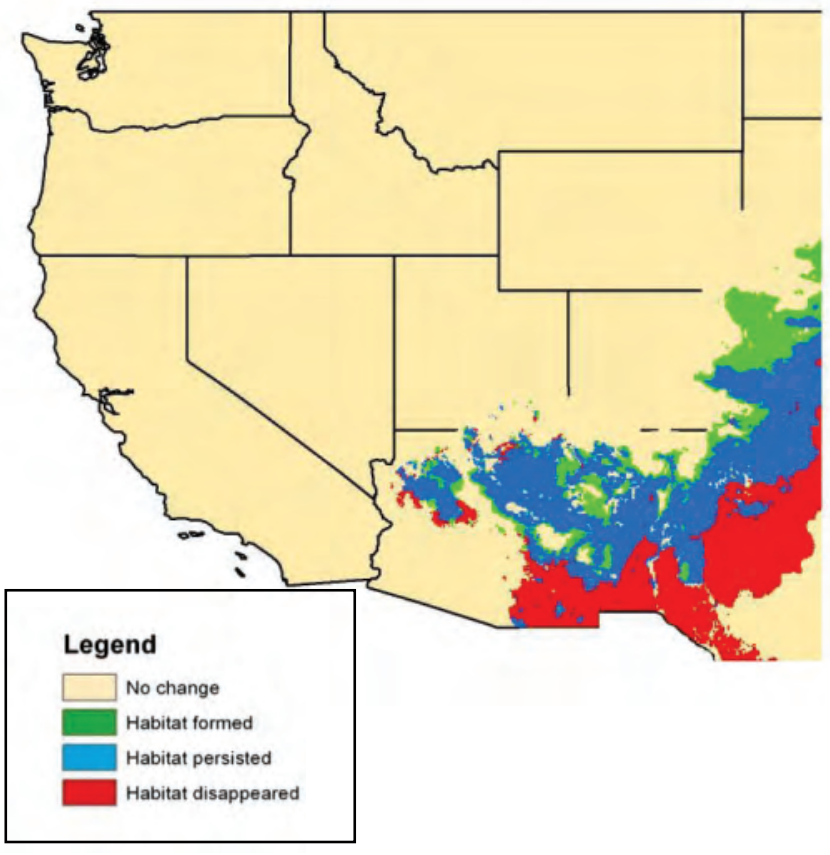

Figure 11.18c. Illustration of Western United States showing modeled areas (excluding vegetation variables) where projections of greater than or equal to five global circulation models predict there will be suitable habitat in 2099, showing areas of habitat loss (red), habitat gain (green), and habitat persistence (blue) between 2010 and 2099. 


\section{MODEL RESULTS}

Area Under the Curve (AUC)

\section{Summary of variable importance}

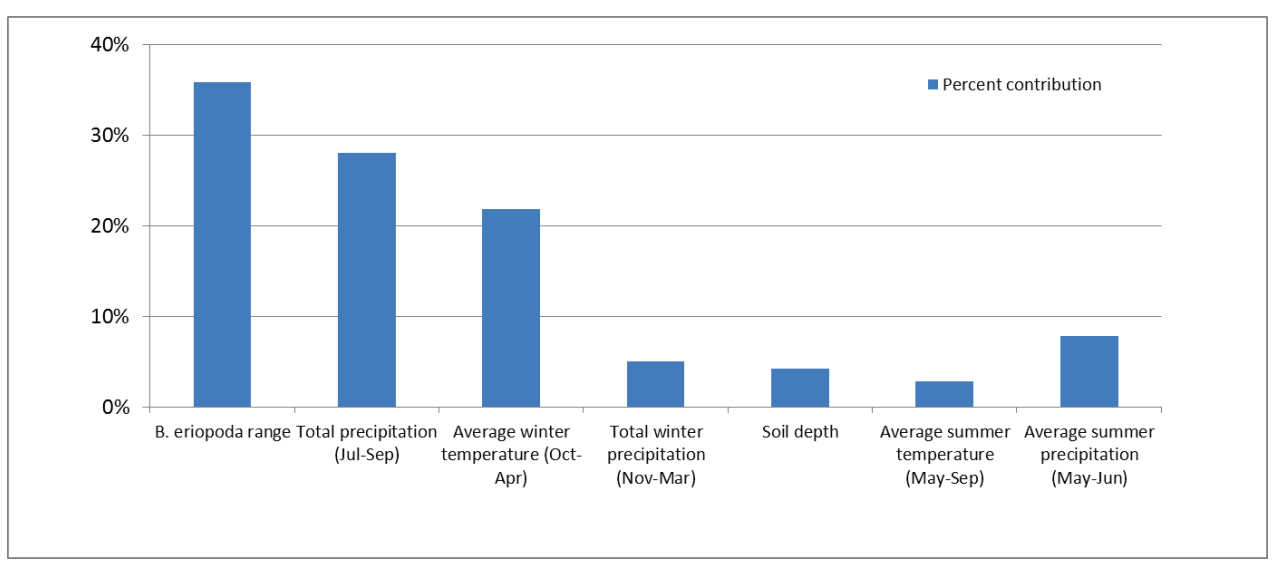

Figure 11.19. Graph showing percent contribution of variables retained in the best model of current range. Variable contributions should be interpreted with caution when the predictor variables are correlated.

\section{Projected change in area of suitable habitat}

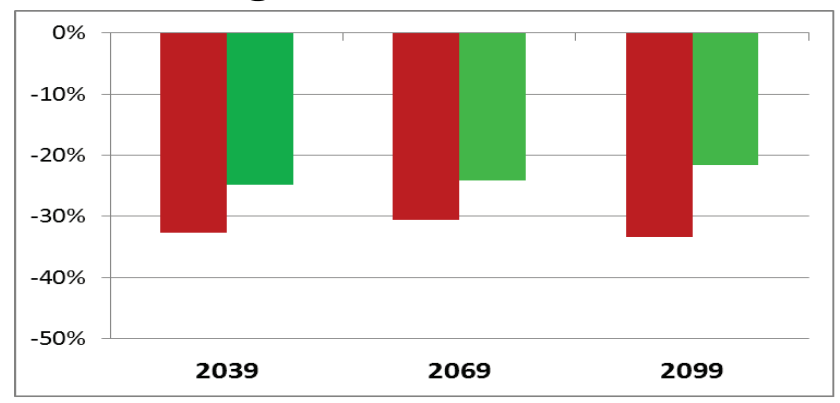

\section{Unlimited dispersal}

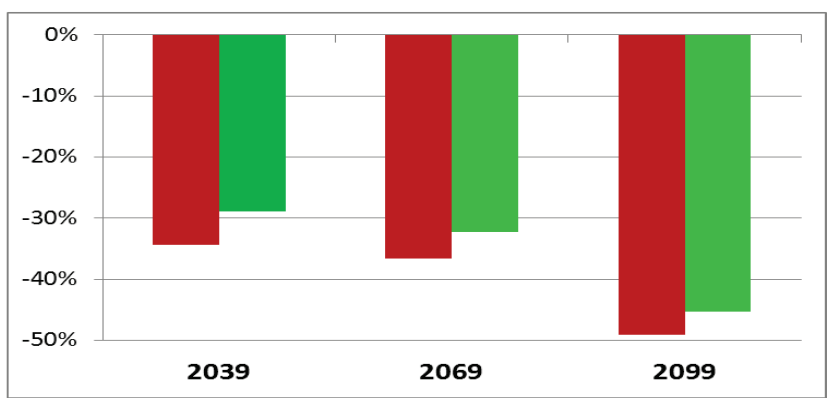

No dispersal

Figure 11.20. Measures of projected change in range at end of three different decades as a percent of current modeled range (year 2010). Green bars are results produced by the model that include the effect of plant species ranges; red bars are results produced by the model that does not include plant range effects. Values were calculated based on areas of agreement of at least five of the six climate projections. 


\section{COMMON CHUCKWALLA}

\section{Sauromalus ater}

The Common Chuckwalla is primarily found across the Mojave and Sonoran deserts of the United States and Mexico, at elevations ranging from sea level to $1,370 \mathrm{~m}$. This large $(125-180 \mathrm{~mm})$ lizard is dorsoventrally flattened and has wrinkles on its belly and neck. Chuckwallas are strongly associated with rock outcrops, lava flows, and boulder piles, and are well-known for their defensive behavior of inflating their bodies to wedge themselves in crevices. They are herbivorous, eating the leaves, flowers, and shoots of annual and perennial plants in the Mojave desert, and primarily perennial plants in the Sonoran desert. Preferred species of forage plants near Phoenix, Arizona, included mallows, desert lavender, America threefold, goldeneye, wolfberry, foothills palo verde, and ocotillo. Chuckwallas usually maintain active body

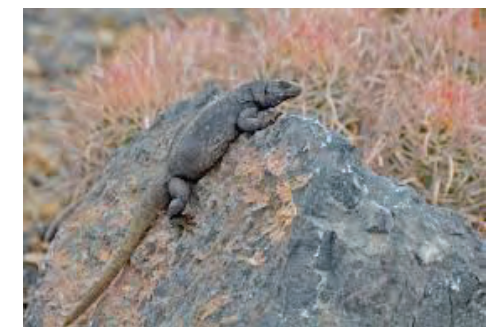

Figure 11.21. Sauromalus ater, photo by Fish and Wildlife Service/fws.gov temperatures between 35 and 40 degrees Celsius, yet wild individuals apparently obtain all of their water for metabolic needs from eating plants. Chuckwallas are long-lived and females may not breed every year. A clutch of 5-16 eggs is laid in mid to late summer, and hatchlings emerge in the fall, winter, or even the following spring. Although this species is common in many areas, in some locations excessive collecting and habitat destruction threaten population.

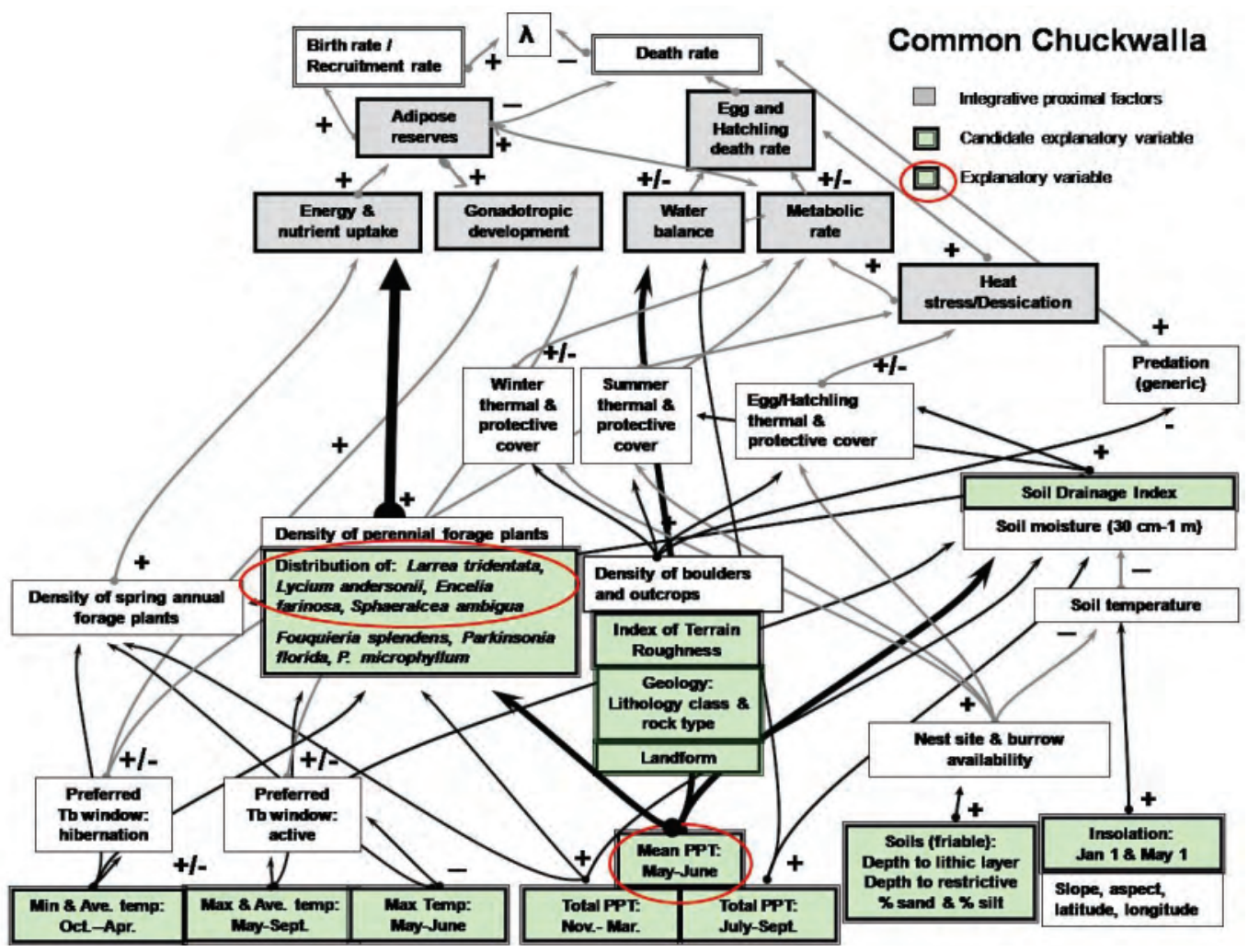

Figure 11.22. Conceptual model of factors affecting suitable habitat for common chuckwalla and population dynamics, including explanatory variables used to model current suitable habitat for common chuckwalla (in green and circled red). The relative strength of different effects is denoted by the width of connecting arrows. 


\section{PROJECTIONS - 2099}

Number of projections agreeing where there will be suitable habitat in 2099.
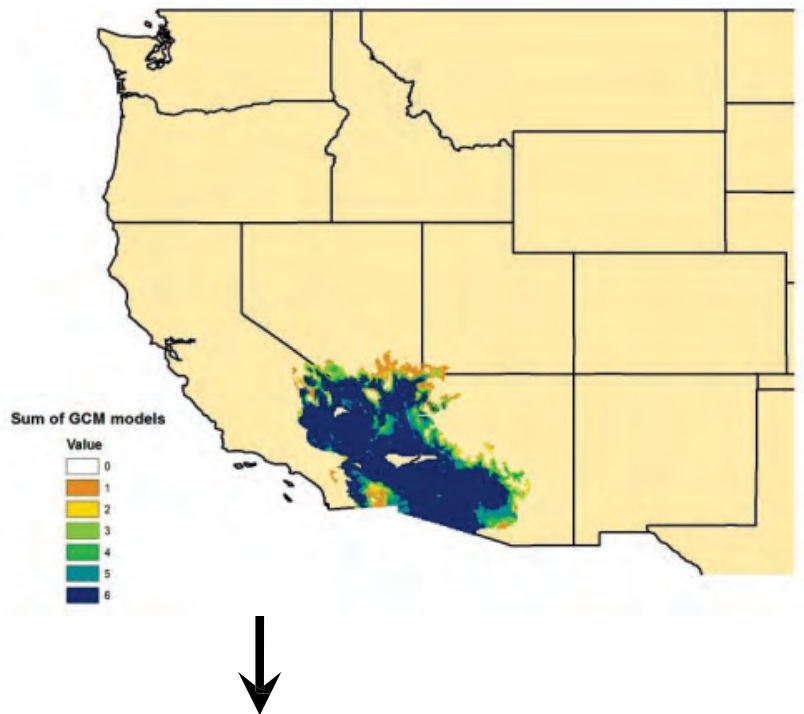

Figure 11.23b. Illustration of Western United States showing modeled areas (including vegetation variables) where projections of greater than or equal to five global circulation models predict there will be suitable habitat in 2099, showing areas of habitat loss (red), habitat gain (green), and habitat persistence (blue) between 2010 and 2099.

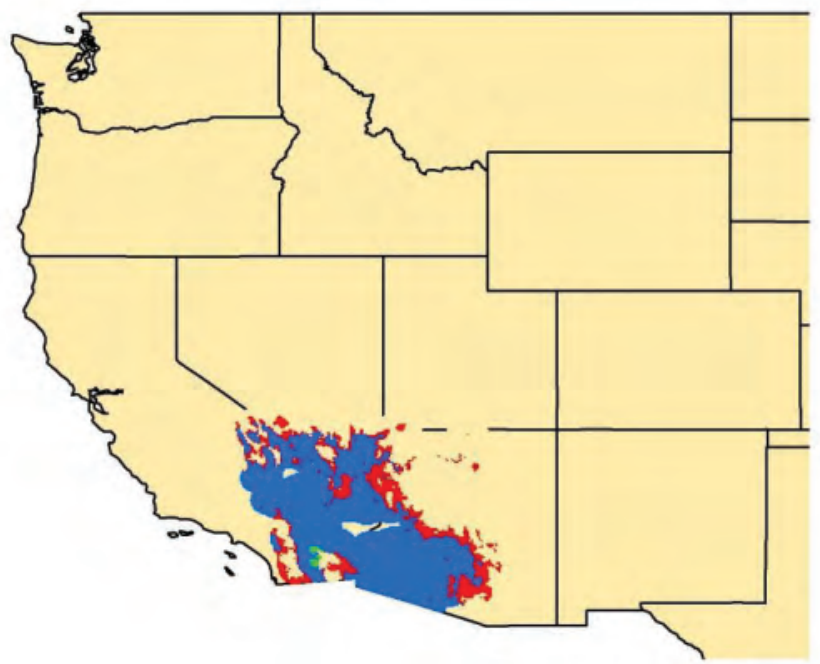

Figure 11.23a. Illustration of Western United States showing predicted range in 2099, showing levels of agreement among predictions based on 5 different statistically downscaled global circulation models (GCM) plus a 6th representing an ensemble of 22 GCMs. White denotes areas where all projections agree there will not be suitable habitat, whereas blue denotes areas where all models agree that suitable habitat will exist.

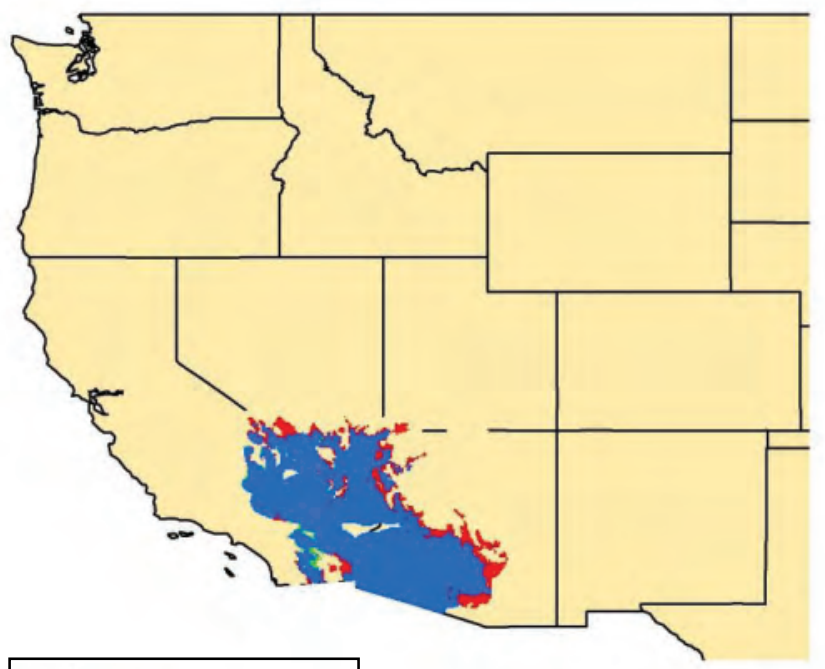

Legend

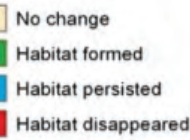

Figure 11.23c. Illustration of Western United States showing modeled areas (excluding vegetation variables) where projections of greater than or equal to five global circulation models predict there will be suitable habitat in 2099, showing areas of habitat loss (red), habitat gain (green), and habitat persistence (blue) between 2010 and 2099. 


\section{MODEL RESULTS}

\section{Summary of variable importance}

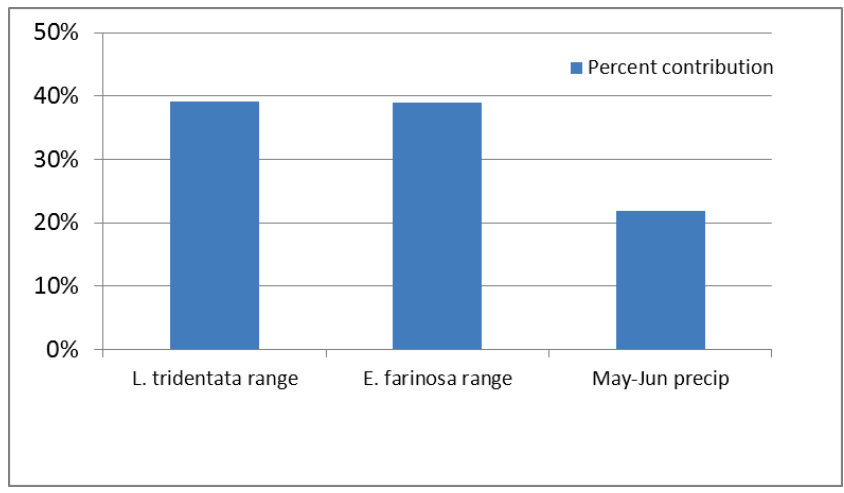

Figure 11.24. Graph showing percent contribution of variables retained in the best model of current range. Variable contributions should be interpreted with caution when the predictor variables are correlated.

\section{Projected change in area of suitable habitat}

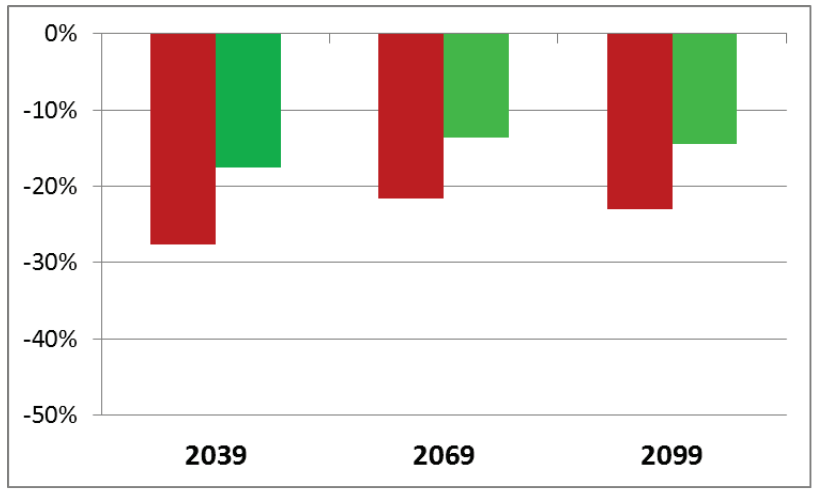

Unlimited dispersal

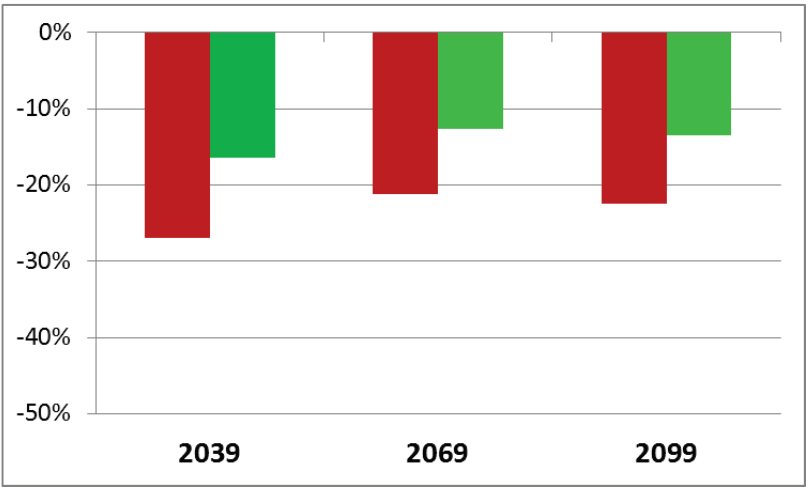

\section{No dispersal}

Figure 11.25. Measures of projected change in range at end of three different decades as a percent of current modeled range (year 2010). Green bars are results produced by the model that includes the effect of plant species ranges; red bars are results produced by the model that does not include plant range effects. Values were calculated based on areas of agreement of at least five of the six climate projections. 


\section{References Cited}

Araújo, M.B., Thuiller, W., and Pearson, R.G., 2006, Climate warming and the decline of amphibians and reptiles in Europe: Journal of Biogeography, v. 33, p. 1712-1728.

ArcGIS $^{\circledR}$ Server 10. (http://cpbc.bio.nau.edu/CPBC_ArcGIS/rest/services[accessed 9/12/2013]).

Arundel, S., 2005, Using special models to establish climate limiters of plant species?:

Ecological Modelling v. 182, p. 159-181.

Austin, M.P., 2002, Spatial prediction of species distribution-An interface between ecological theory and statistical modelling: Ecological Modelling, v. 157, p. 101-118.

Austin, M.P., and Van Neil, K.P., 2011, Improving species distribution models for climate change studies: Variable selection and scale: Journal of Biogeography, v. 38, p. 1-8.

Avian Knowledge Network (AKN) (http://www.avianknowledge.net)[accessed 9/12/2013]

Balda, R.P., 2002, Pinyon Jay (Gymnorhinus cyanocephalus), in Pool, A., ed., 2002, The Birds of North America Online: Ithaca N.Y., Cornell Lab of Ornithology; accessed August 29, 2013, at http://bna.birds.cornell.edu/bna/species/605, doi:10.2173/bna.605.

Barbet-Massin, M., Thuiller, W., and Jiguet, F., 2010, How much do we overestimate local extinction rates when restricting the range of occurrence data in climate suitability models?: Ecography, v. 33, p. 878-886.

Barlow, J.C., Leckie, S.N., and Baril, C.T., 1999, Gray Vireo (Vireo vicinior). in Pool, A., ed., 1999, The Birds of North America Online: Ithaca N.Y., Cornell Lab of Ornithology; accessed August 29, 2013 at http://bna.birds.cornell.edu/bna/species/447. doi:10.2173/bna.447

Barnett, T.P., Pierce, E.W., Hidalgo, H.G., Bonfils, C., Santer, B.D., Das, R., Bala, G., Wood, A.W., Nozawa, T., Mirin, A.A., Cayan, D.R., and Dettinger, M.D., 2008, Human-induced changes in the hydrology of the western United States: Science, v. 319, p. 1080-1083.

Barry, R.G., and Chorley, R.J., 1976, Atmosphere, weather and climate (3d ed.): Methuen Publishing Ltd, London, U.K., 432 p.

Barry, S., and Elith, J., 2006, Error and uncertainty in habitat models, Journal of Applied Ecology, v. 43, p. 413-423.

Berry, K. H., Morafka, D.J., and Murphy, R.W., 2002, Defining the desert tortoise(s)—Our first priority for a coherent conservation strategy: Chelonian Conservation and Biology, v. 4, p. 249-262.

Berteaux, D., Humphries, M.M., Krebs, C.J., Lima, M., McAdam, A.G., Pettorelli, N., Reale, D., Saitoh, T., Tkadlec, E., Weladji, R.B., Stenseth, N.C, 2006, Constraints to projecting the effects of climate change on mammals: Climate Research, v. 32, p. 151-158.

Brady, N C., and Weil, R.R., 2002, The Nature and properties of soils (13th ed.): Prentice Hall, Upper Saddle River, N.J., 960 p.

Boykin, K.G., Thompson, B.C., Deitner, R.A., Schrupp, D., Bradford, D., O’Brien, L., Drost, C., Propeck-Gray, S., Rieth, W., Thomas, K., Kepner, W., Lowry, J., Cross, C., Jones, B., Hamer, T., Mettenbrink, C., Oakes, K.J., Prior-Magee, J., Schulz, K., Wynne, King, J.J.C., Puttere, Schrader, J.S., Schwenke, Z. 2007, Predicted animal habitat distributions and species richness, in Prior-Magee, J.S., and others (eds.), Southwest regional gap analysis final report: Moscow, Idaho, U.S. Geological Survey, Gap Analysis Program, p. 39-78.

Burnham, K.P., and Anderson, D.R., 2002, Model selection and multimodel inference-A practical information, Theoretic approach, (2d ed.): Springer-Verlag, New York, 488 p. California Avian Data Center (http://data.prbo.org/cadc2/index.php?page=climate-changedistribution. [accessed 9/12/2013]). 
Centre National de Recherches Meteorologiques (CNRM) (http://wwwpcmdi.llnl.gov/ipcc/model_documentation/CNRM-CM3.htm [accessed 9/12/2013]).

Christensen, N.S., and Lettenmaier, D.P., 2007, A multimodel ensemble approach to assessment of climate change impacts on the hydrology and water resources of the Colorado River basin: Hydrology and Earth Systems Science, v. 11, p. 1417-1434.

Commonwealth Scientific and Industrial Research Organization (CSIRO). Models. (http://www.csiro.au/[accessed 9/12/2013]).

Cole, K.L., Ironside, K., Arundel, S., Duffy, P., and Shaw, J., 2008, Modeling future plant distributions on the Colorado Plateau-An example using Pinus edulis, in, van Riper, III, C., and Sogge, M.K., eds., The Colorado Plateau III-Cultural, biological, and physical research: University of Arizona Press, Tucson, Arizona, p. 319-330.

Collar, N.J., Wege, D.C., and Long, A.J., 1997, Patterns and causes of endangerment in the New World avifauna: Ornithological Monographs, v. 48 p. 237-260.

Consortium of California Herbaria, (http://ucjeps.berkeley.edu/consortium/) [accessed 9/12/2013].

Czech, B., and Krausman, P.R., 1997, Distribution and causation of species endangerment in the United States: Science, v. 277, p. 1116.

Daszak, P., Cunnigham, A.A., and Hyatt, A.D., 2003, Infectious disease and amphibian population declines: Diversity and Distribution, v. 9, p. 141-150.

De Leo, G., Dobson, A., and Goodman, A., 2002, Wildlife perspectives on the evolution of virulence, in Dieckmann, U., Metz, J.A.J., Sabelis, M.W., and Sigmund, K. (eds.), Adaptive dynamics of infectious diseases - In pursuit of virulence management: Cambridge University Press, Cambridge, U.K., p. 26-38.

Diffenbaugh, N.S., Giorgi, F., and Pal, J.S., 2008, Climate change hotspots in the United States: Geophysical Research Letters, v. 35, p. L16709.

Dobbs, R.C., Martin, T.E., and Conway, C.J., 1997, Williamson's sapsucker, in Poole, A. (ed.), The Birds of North America Online: Cornell Lab of Ornithology, Ithaca, N.Y., accessed August 29, 2013, at http://bna.birds.cornell.edu/bna/species/285

Dubayah, R., and Rich, P.M., 1995, Topographic solar radiation models for GIS: International Journal of Geographical Information Systems, v. 9, p. 405-419.

Dudík, M., Phillips, S.J., and Schapire, R.E., 2007, Maximum entropy density estimation with generalized regularization and an application to species distribution modeling: Journal of Machine Learning Research, v. 8, p. 1217-1260.

Egan, J.P., 1975, Signal detection theory and ROC analysis: Series in Cognition and Perception, Academic Press, New York, p. 277.

Elith, J., Graham, C.H., Anderson, R.P., Dudík, M., Ferrier, S., Guisan, A., Hijmans, R.J., Huettmann, F., Leathwick, J.R., Lehmann, A., Li, J., Lohmann, L.G., Loiselle, B.A., Manion, G., Moritz, C., Nakamura, M., Nakazawa, Y., Overton, J.M., Peterson, A.T., Phillips, S.J., Richardson, K., Scachetti-Pereira, R., Schapire, R.E., Soberon, J., Williams, S., Wisz, M.S., and Zimmermann, N.,E., 2006, Novel methods improve prediction of species' distributions from occurrence data: Ecography, v. 29, p.129-151.

Elith, J., Kearney, M., and Phillips, S., 2010, The art of modeling range-shifting species: Methods in Ecology and Evolution, v. 1, p. 330-342.

Elith, J., and Leathwick, J.R., 2009, Species distribution models-Ecological explanation and prediction across space and time: Annual Review of Ecology Evolution and Systematics, v. 40, p. 677-697. 
Elith, J., Phillips, S.J., Hastie, T., Dudík, M., Chee, Y.E., and Yates, C.J., 2011, A statistical explanation of MaxEnt for ecologists: Diversity and Distributions, v. 17, p. 43-57.

Environmental Systems Research Institute (ESRI), 1992, Cell-based modeling with GRID, (2d ed.): Environmental Systems Research Institute, Redlands, California, 267 p.

Ernst, C.H., and Lovich, J.E., 2009, Desert tortoise, Gopherus agassizii, in Turtles of the United States and Canada, (2d ed.): Johns Hopkins University Press, Baltimore, Md., p. 540-570

Fawcett, R., 2003. ROC Graphs: Notes and Practical Considerations for Data Mining Research. Technical Report HPL-2003-4. HP Laboratories, Palo Alto, California

Fielding, A.H., and Bell, J. F., 1997, A review of methods for the assessment of prediction errors in conservation presence/absence models: Environmental Conservation, v. 24, p. 38-49.

Foley, J., Clifford, D., Castle, K., Cryan, P., and Ostfeld, R.S., 2011, Investigating and managing the rapid emergence of white-nose syndrome, a novel, fatal, infectious disease of hibernating bats: Conservation Biology, v. 25, p. 223-231.

Freeman, E.A., and Moisen, G.G., 2008, A comparison of the performance of threshold criteria for binary classification in terms of predicted prevalence and kappa: Ecological Modeling, v. 217, p. 48-58.

Friend, M., McLean, R.G., and Dein, J., 2001, Disease emergence in birds-Challenges for the twenty-first century: The Auk, v. 118, p. 290-303.

Garfin, G.M., Eischeid, J.K., Lenart, M.T., Cole, K.L., Ironside, K., and Cobb, N., 2010, Downscaling climate projections in topographically diverse landscapes of the Colorado Plateau in the arid southwestern United States, in van Riper, III, C., Wakeling, B.F., and Sisk T.D., (eds.), The Colorado Plateau IV-Shaping conservation through science and management: University of Arizona Press, Tucson, Ariz., p. 22-43.

Global Biodiversity Information Facility (GBIF; Accessed through GBIF Data Portal, http://data.gbif.org) [accessed 9/12/2013].

Geographic Coordinate System, World Geodetic System, U.S. Department of Defense. 1972.

GEOLocate ver. 3.21, (http://www.museum.tulane.edu/geolocate/[accessed 9/13/2013]).

Global Biodiversity Information Facility (http://www.gbif.org/), [accessed 9/12/2013].

Guisan, A., andThuiller, W., 2005, Predicting species distribution—offering more than simple habitat models: Ecology Letters, v. 8, p. 993-1009.

Guisan, A., and Zimmermann, N.E., 2000, Predictive habitat distribution models in ecology. Ecological Modelling, v. 135, p. 147-186

Gutiérrez, R.J., Cody, M., Courtney, S., and Franklin, A.B., 2007, The invasion of barred owls and its potential effect on the spotted owl-A conservation conundrum: Biological Invasions, v. 9, p. 181-196.

Forest Inventory and Analysis (FIA) databases (http://apps.fs.fed.us/fiadbdownloads/datamart.html), [accessed 9/30/2013].

Hastie, T., Tibshirani, R., and Friedman, J.H., 2009, The elements of statistical learning-Data mining, inference, and prediction: Springer Verlag, New York, 763 p.

Hayes, M. P., and Jennings, M.R., 1986, Decline of rand frog species in western North America-Are bullfrogs (Lithobates catesbeiana) responsible?: Journal of Herpetology, v. 20, p. 490-509.

HerpNET data portal (http://www.herpnet.org) [accessed 9/12/2013].

Hilborn, R., and Mangel, M., 1997, The ecological detective-Confronting models with data:

Princeton University Press, Princeton, N.J., p. 330. 
Hosmer, D.W., and Lemeshow, S., 1989, Applied logistic regression, (1st ed.): John Wiley \& Sons, New York, p. 392.

Huntley, B., Green, R.E., Collingham, Y.C., Hill, J.K., Willis, S.G., Bartlein, P.J., Cramer, W., Hagemeijer, J.M., and Thomas, C.J., 2004, The performance of models relating species geographical distributions to climate is independent of trophic level: Ecology Letters, v. 7, p. 417-426.

Ibáñez, I., Clark, J S., Dietze, M.C., Feeley, K., Hersh, M., LaDeau, S., McBride, A., Welch, N.E., and Wolosin, M.S., 2006, Predicting biodiversity change-Outside the climate envelope, beyond the species-area curve: Ecology, v. 87, p. 1896-1906.

Jackson, S.T., Betancourt, J.L., Booth, R.K., and Gray, S.T., 2009, Ecology and the ratchet of events - Climate variability, niche dimensions, and species distributions: Proceedings of the National Academy of Sciences, v. 106, p.19685-19692

Johnson, M.J., Van Riper, III, C., and Pearson, K.M. 2002, Black-throated sparrow, in Poole, A., ed., The Birds of North America Online: Cornell Lab of Ornithology, Ithaca, N.Y., accessed August 29, 2013, at: http://bna.birds.cornell.edu/bna/species/637.

Kadmon, R., Farber, O., and Danin, A., 2003, A systematic analysis of factors affecting the performance of climatic envelope models: Ecological Applications, v., 13, p. 853-867.

Kats, L.B., and Ferrer, R.P., 2003, Alien predators and amphibian declines-A review of two decades of science and transition to conservation: Diversity and Distributions, v. 9, p. 99-110.

Keating, K.A., and Cherry, S., 2004, Use and interpretation of logistic regression in habitat selection studies: Journal of Wildlife Management, v. 68, p. 774-789.

Kelly, E.G., Forsman, E.D., and Anthony, R.G., 2003, Are barred owls displacing spotted owls?: The Condor, v. 105, p. 45-53.

Kingery, H.E., and Ghalambor, C.K., 2001, Pygmy nuthatch (Sitta pygmaea), in Poole, A., ed., The Birds of North America Online: Cornell Lab of Ornithology, Ithaca, N.Y., accessed August 29, 2013, at: http://bna.birds.cornell.edu/bna/species/567.doi:10.2173/bna.567.

Kissling, W.D., Field, R., Korntheuer, H., Heyder, U., and Böhning-Gaese, K., 2010, Woody plants and the prediction of climate-change impacts on bird diversity: Philosophical Transactions of the Royal Society B, v. 365, p. 2035-2045.

Lawler, J.J., Shafer, S.L., White, D., Kareiva, P., Maurer, E.P., Blaustein, A.R., and. Bartlein, P.J., 2009, Projected climate-induced faunal change in the Western Hemisphere: Ecology, v. 90, p. 588-597.

Lawrence Livermore National Laboratory, Program for Climate Model Diagnosis and Intercomparison, accessed September 11, 2013, at http://www-pcmdi.llnl.gov.

Legendre, P., 1993, Spatial autocorrelation: trouble or new paradigm?: Ecology, v. 74, p. 16591673.

Legendre, P., Dale, M.R.T., Fortin, M.-J., Gurevitch, J., Hohn, M., and Myers, D., 2002, The consequences of spatial structure for the design and analysis of ecological field experiments: Ecography, v. 25, p. 601-615.

Liu, C.R., Berry, P.M., Dawson, T.P., and Pearson, R.G., 2005, Selecting thresholds of occurrence in the prediction of species distributions: Ecography, v. 28, p. 385-393.

Lobo, J.M., Jiménez Valverde, A., and Real, R., 2008, AUC: a misleading measure of the performance of predictive distribution models: Global Ecology and Biogeography, v. 17, p. 145-151.

Longley, P.A., Goodchild, M.F., Maguire, D.J., and Rhind, D.W., 2005, Geographic information systems and science, (2d ed.): John Wiley and Sons, Hoboken, N.J., p. 517. 
Luoto, M., and Heikkinen, R.K., 2008, Disregarding topographical heterogeneity biases species turnover assessments based on bioclimatic models: Global Change Biology, v. 14, p. 483-494.

MacKenzie, D.I., Nichols, J.D., Lachman, G.B., Droege, S., Andrew Royle, J., and Langtimm, C.A., 2002, Estimating site occupancy rates when detection probabilities are less than one: Ecology, v. 83, p. 2248-2255.

Marzluff, J.M., and Balda, R.P., 2010, The Pinyon Jay-Behavioral ecology of a colonial and cooperative Corvid: T \& AD Poyser, London, U.K., p. 344

Maurer, E.P., Brekke, L., Pruitt, T., and Duffy, P.B., 2007, Fine-resolution climate projections enhance regional climate change impact studies: Eos, Transactions American Geophysical Union, v. 88, no. 47, p. 504.

Maxent software for species habitat modeling. 3.3.3k version. http://www.cs.princeton.edu/ schapire/maxent/ [accessed 9/12/2013].

McMahon, S.M., Harrison, S.P., Armbruster, W.S., Bartlein, P.J., Beale, C.M., Edwards, M.E., Kattge, J., Midgley, G., Morin, X., and Prentice, I.C., 2011, Improving assessment and modelling of climate change impacts on global terrestrial biodiversity: Trends in Ecology and Evolution, v. 26, no. 5, p. 248-259.

Mearns, L.O., Gutowski, W., Jones, R., Leung, L.-Y., McGinnis, S., Nunes, A.M.B., and Qian, Y., 2009, A regional climate change assessment program for North America: Eos, Transactions American Geophysical Union, v. 90, no. 36, p. 311-312.

Millennium Ecosystem Assessment, 2005, Ecosystems and human well-being-Biodiversity synthesis: World Resources Institute, Washington D.C., 86 p.

Muñoz, J., and Felicísimo, A.M., 2004, Comparison of statistical methods used in predictive modelling: Journal of Vegetation Science. v. 15, p. 285-292.

Nature Serve online encyclopedia (http://www.natureserve.org/explorer/) [accessed 9/12/2013].

NHDPlus database (geo-spatial, hydrologic framework dataset) http://www.horizonsystems.com/nhdplus/ [accessed 9/12/2013].

North American Bird Conservation Initiative, U.S. Committee, 2010. The State of the Birds 2010 Report on Climate Change, United States of America. U.S. Department of the Interior: Washington, D.C.

Olson, C.R., and Martin, T.E., 1999, Virginia's warbler (Oreothlypis virginiae), in Poole, A., ed., The Birds of North America Online: Cornell Lab of Ornithology, Ithaca, N.Y., accessed August 29, 2013, at: http://bna.birds.cornell.edu/bna/species/477, doi:10.2173/bna.477.

Paremsan, C., 2006, Ecological and evolutionary responses to recent climate change: Annual Review of Ecology, Evolution, and Systematics, v. 37, p. 637-669.

Pearson, R.G., Thuiller, W., Araújo, M.B., Martinez-Mayer, E., Brotons, L., McClean, C., Miles, L., Seguardo, P., Dawson, T.P., and Less, D.C., 2006, Model-based uncertainty in species range prediction: Journal of Biogeography, v. 33, p. 1704-1711.

Pearson, R.G., Raxworthy, C.J., Nakamura, M., and Peterson, A.T., 2007, Predicting species distributions from small numbers of occurrence records: a test case using cryptic geckos in Madagascar: Journal of Biogeography, v. 34, p. 102-117.

Peduzzi, P., Concato, J., Kemper, E., Holford, T.R., and Feinstein, A.R., 1996, A simulation study of the number of events per variable in logistic regression analysis: Journal of Clinical Epidemiology, v. 49, p. 1373-1379.

Persons, T.B., and Nowak, E.M., 2006a, Inventory of amphibians and reptiles at Death Valley National Park: U.S. Geological Survey Open-File Report 2006-1233, 36 p. 
Persons, T.B., and Nowak, E,M., 2006b, Inventory of amphibians and reptiles in southern Colorado Plateau National Parks-Final Report: U.S. Geological Survey, Southwest Biological Science Center, Flagstaff, Arizona, 73 p.

Persons, T.B., Nowak, E.M., and Hillard, S., 2006, Inventory of amphibians and reptiles at Manzanar National Historic Site, California: U.S. Geological Survey Open-File Report 20061232, $31 \mathrm{p}$.

Persons, T.B., and Nowak, E.M., 2007, Inventory of amphibians and reptiles at Mojave National Preserve: U.S. Geological Survey Open-File Report 2007-1109.

Phillips, S.J., Anderson, R.P., and Schapire, R.E., 2006, Maximum entropy modeling of species geographic distributions: Ecological Modelling, v. 190, p. 231-259.

Phillips, S.J., and Dudík, M., 2008, Modeling of species distributions with Maxent-New extensions and a comprehensive evaluation: Ecography, v. 31, p. 161-175.

Phillips, S.J., Dudík, M., Elith, J., Graham, C.H., Lehmann, A., Leathwick, J., and Ferrier, S., 2009, Sample selection bias and presence-only distribution models-Implications for background and pseudo-absence data: Ecological Applications, v. 19, p. 181-197.

PRISM Climate Group, Oregon State University, http://prism.oregonstate.edu [accessed 9/12/2013].

ReGAP project (http://earth.gis.usu.edu/swgap/trainingsites.html) [accessed 9/12/2013].

Reisner, M., 1986, Cadillac desert-The American West and its disappearing water: Penguin Books, New York, 608 p.

Reynolds, T.D., Rich, T.D., and Stephens, D.A., 1999, Sage Thrasher, in Poole, A., ed., The Birds of North America Online: Cornell Lab of Ornithology, Ithaca, N.Y., accessed August 29, 2013, at: http://bna.birds.cornell.edu/bna/species/463.

Rios, N.E., and Bart, H.L., 2010, GEOLocate (version 3.22), [Computer software]: Tulane University Museum of Natural History, Belle Chasse, Lousiana.

Rowland, E.L., Davison, J.E., and Graumlich, L.J., 2011, Approaches to evaluating climate impacts on species-A guide to initiating the adaptive planning process: Environmental Management, v. 47, p. 322-337.

Saltelli, A., Ratto, M., Andres, T., Campolongo, F., Cariboni, J., Gatelli, D., Saisana, M., and Tarantola, S., 2008, Global Sensitivity Analysis: The Primer, Chichester, England: John Wiley \& Sons.

Schofer, J.X., 2007, Movements, thermal biology, habitat use, and natural history of Crotalus cerberus in Northern Arizona, Master’s Thesis, Northern Arizona University, Flagstaff, Arizona.

Schweiger, O., Settele, J., Kudrna, O., Klotz, S., and Kühn, I., 2008, Climate change can cause spatial mismatch of trophically interacting species: Ecology, v. 89, p. 3472-3479.

Seager, R., Ting, M., Held, I., Kushnir, Y., Lu, J., Vecchi, G., Huang, H., Harnik, N., Leetma, A., Lau, N., Li, C., Velez, J., and Naik, N., 2007, Model projections of an imminent transition to a more arid climate in southwestern North America: Science, v. 316, p. 1181-1184.

Shafroth, P.B., Stromberg, J.C., and Patton, D.T., 2002, Riparian vegetation response to altered disturbance and stress regimes: Ecological Applications, v. 12, p. 107-123.

Sinclair, S.J., White, W.D., and Newell, G.R., 2010, How useful are species distribution models for managing biodiversity under future climates?: Ecology and Society, v. 15, no. 1, article 8, accessed August 30, 2013, at http://www.ecologyandsociety.org/vol15/iss1/art8/. 
Solomon, S., Qin, D., Manning, M., Chen, Z., Marquis, M., Averyt, K,B., Tignor, M., and Miller H.L., (eds.), 2007, Contribution of working group I to the Fourth Assessment Report of the Intergovernmental Panel on Climate Change, in Intergovernmental Panel on Climate Change, Climate change-The physical science basis, 2007: Cambridge University Press, Cambridge, United Kingdom and New York.

Southwest Environmental Information Network (SEINet http://swbiodiversity.org/seinet/projects/index.php).[accessed 9/12/2013].

Southwest Plant Atlas, Northern Arizona University. http://www4.nau.edu/swplantatlas/endemic.html [accessed 9/12/2013]

Stanton, J.C., Pearson, R.G., Horning, N., Ersts, P., and Akçakaya, H.R., 2012, Combining static and dynamic variables in species distribution models under climate change: Methods in Ecology and Evolution, v. 3, p. 349-357.

Stiling, P., 1996, Ecology-Theory and applications (2d ed.): Prentice Hall, Upper Saddle River, N.J., 539 p.

Story, M., and Congalton, R.G., 1986, Accuracy assessment-A user's perspective:

Photogrammatry Engineering and Remote Sensing: v. 52, p. 397-399.

Thuiller, W., Brotons, L., Araújo, M.B., and Lavorel, S., 2004, Effects of restricting environmental range of data to project current and future species distributions: Ecography, v. 27, p. 165-172.

Thuiller, W., Albert, C., Araújo, M.B., Berry, P.M., Cabeza, M., Guisan, A., Hickler, T., Midgley, G.F., Paterson, J., Schurr, F.M., Sykes, M.T., and Zimmermann, N.E, 2008, Predicting global change impacts on plant species distributions-Future challenges: Perspectives in Plant Ecology, Evolution and Systematics, v. 9, p. 137-152.

Tracy, C.R., Averill-Murray, R., Boarman, W.I., Delehanty, D., Heaton, J., McCoy, E., Morafka, D., Nussear, K., Hagerty, B., and Medica, P., 2004, Desert tortoise recovery plan assessment: DTRPAC Report prepared for the U.S. Fish and Wildlife Service, 254 p., accessed August 30, 2013, at http://www.fws.gov/southwest/es/arizona/Documents/SpeciesDocs/DesertTortoise/DTRPACre port.pdf.

Tuft, Edward, 2013, Maps and Data Displays (http://www.edwardtufte.com/tufte/ [accessed 9/12/2013]).

U.S.D.A. Web Soil Survey, 2013, (http://websoilsurvey.sc.egov.usda.gov [accessed 09/30/2013]).

U.S. Forest Service FIA Data Mart: http://apps.fs.fed.us/fiadb-downloads/datamart.html . [accessed 9/11/2013].

U.S. Fish and Wildlife Service, 2008, Birds of Conservation Concern 2008: United States Department of Interior, Fish and Wildlife Service, Division of Migratory Bird Management, Arlington, Virginia, 85 p. [Online version available at http://www.fws.gov/migratorybirds/>].

U.S. Fish and Wildlife Service, 2010, Rising to the urgent challenge-Strategic plan for responding to accelerating climate change: U.S. Fish and Wildlife Service, Washington D.C., $32 \mathrm{p}$.

U.S. Fish and Wildlife Service, 2011, 2011 revised recovery plan for the Mojave population of the desert tortoise (Gopherus agassizii): U.S. Fish and Wildlife Service, Washington D.C., 227 p., accessed August 30, 2013, at http://www.fws.gov/nevada/desert_tortoise/documents/recovery_plan/RRP\%20for\%20the\%20 Mojave\%20Desert\%20Tortoise\%20-\%20May\%202011.pdf. 
U.S. Geological Survey, GEOSS, http://rmgsc.cr.usgs.gov/ecosystems/usa.shtml [accessed 9/12/2013].

U.S. Geological Survey GAP Analysis Program. Moscow, Idaho. 1999. (http://earth.gis.usu.edu/swgap/data/metadata/landform_albers.htm).[accessed 9/12/2013].

U.S. Geological Survey National Gap Analysis Program, 2004, Southwest Regional Gap Analysis Project Field Sample Database. Version 1.1. RS/GIS Laboratory, College of Natural Resources, Utah State University. http://earth.gis.usu.edu/swgap/trainingsites.html

U.S. Government. Data Catalog, (http://catalog.data.gov/dataset [accessed September 16, 2013])

VanDerWal, J., Shoo, L.P., Graham, C., and Williams, S.E., 2009, Selecting pseudo-absence data for presence-only distribution modeling-How far should you stray from what you know?: Ecological Modelling, v. 220, p. 589-594.

Van Devender, T.R., 2002, The Sonoran Desert Tortoise-Natural history, biology, and conservation: University of Arizona Press and the Arizona-Sonora Desert Museum, Tucson, Arizona, 389 p.

van Riper, C., III, van Riper, S.G., Goff, M.L., and Laird, M., 1986, The epizootiology and ecological significance of malaria in Hawaiian land birds: Ecological Monographs, v. 56, no. 4, p. 327-344.

Veloz, S.D., Williams, J.W., Blois, J.A., He, F., Otto-Bliesner, B., and Liu, Z., 2012, No-analog climates and shifting realized niches during the late Quaternary-Implications for $21^{\text {st }}$-Century predictions of species distribution models: Global Change Biology, v. 18, p. 1698-1713.

Virkkala, R., Marmion, M., Heikkinen, R.K., Thuiller, W., and Luoto, M., 2010, Predicting range shifts of northern birds: Influence of modelling technique and topography: Acta Oecologica, v. 36, p. 269-281.

Warren, D.L., Glor, R.E., and Turelli, M., 2010, ENMTools: a toolbox for comparative studies of environmental niche models. Ecography 33:607-611.

Warren, D.L., and Seifert, S.N., 2011, Ecological niche modeling in Maxent-The importance of model complexity and the performance of model selection criteria: Ecological Applications, v. 21, p. 335-342.

Webb, R.H., and Leake, S.A., 2006, Ground-water surface-water interactions and long-term change in riverine riparian vegetation in the southwestern United States: Journal of Hydrology, v. 320. P. 302-323.

Wicz, M.S., Hijmans, R.J., Li, J., Peterson, A.T., Graham, C.H., Guisan, A., and NCEAS Predicting Species Distributions Working Group, 2008, Effects of sample size on performance of species distribution models: Diversity and Distributions, v. 14, p. 763-773. 
This page left intentionally blank 